NBSIR 80-2004

\title{
The Measurement of the Smoke Leakage of Door Assemblies During Standard Fire Exposures
}

Leonard Y. Cooper

Center for Fire Research National Engineering Laboratory National Bureau of Standards U.S. Department of Commerce Washington, D.C. 20234

June 1980

Final Report
100
Prepared for: 

a

\section{THE MEASUREMENT OF THE SMOKE \\ LEAKAGE OF DOOR ASSEMBLIES \\ DURING STANDARD FIRE EXPOSURES}

Leonard Y. Cooper

Center for Fire Research

National Engineering Laboratory

National Bureau of Standards

U.S. Department of Commerce

Washington, D.C. 20234

June 1980

Final Report

Prepared for:

The Occupational Safety and Health Administration (OSHA) U.S. Department of Labor

Washington, D.C. 20210

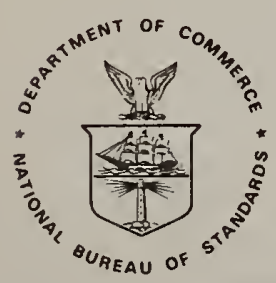

U.S. DEPARTMENT OF COMMERCE, Philip M. Klutznick, Secretary Luther H. Hodges, Jr., Deputy Secretary Jordan J. Baruch, Assistant Secretary for Productivity, Technology, and Innovation NATIONAL BUREAU OF STANDARDS, Ernest Ambler, Director 



\section{PREFACE}

This report on smoke leakage of door assemblies is one product of an ongoing joint research program of the Occupational Safety and Health Administration (OSHA) of the Department of Labor and the National Bureau of Standards (NBS), Center for Fire Research. The program is entitled: Key Elements of Emergency Escape Requirements for Employees in Workspaces Under OSHA Jurisdiction. Other ongoing areas of research presently included in this program are: Estimating safe available egress times for workspaces subsequent to the ignition of hazardous fires; the relation of building design and human factors to emergency evacuation of workspaces; and studies of building smoke control by means of open stairwellsprinkler systems. 
1. INTRODUCTION

1.1 The Ability of Building Occupants to Achieve Safe Egress or Refuge . . . . . . . . . . . . . . . . . . . . . . . . . 1

1.2 The Effect of Compartmentation on the Phenomenon of Smoke Migration . . . . . . . . . . . . . . . . . . . . . . . . . 2

1.3 The Utility of High Temperature Smoke Leakage Measurements . . . . . . . . 3

1.4 An Overview of This Investigation . . . . . . . . . . . . . . . . . . . . . 4

2. APPLYING THE HIGH TEMPERATURE TEST METHOD

2.1 The Proposed ISO Test Method for Measuring the Smoke Leakage of Door Assemblies During Standard Fire Exposures . . . . . . . . . . . . . . . . . . . . . . . . . 4

2. 2 The Original Objective of This Investigation . . . . . . . . . . . . . . . 5

2.3 An Overview of the Results of Applying the Test Method . . . . . . . . . . 6 2.3.1 The First Test . . . . . . . . . . . . . . . . . . . . . . 6

2.3.1.1 Description of the Test . . . . . . . . . . . . . 6

2.3.1.2 Results . . . . . . . . . . . . . . . . . . 7

2.3.1.3 Reflecting on the Results . . . . . . . . . . . . . . . 7

2.3.1.4 Conclusions of the First Test................ . . 8

2.3.2 The Second Test . . . . . . . . . . . . . . . . . . . . 8

2.3.2.1 Description of the Test . . . . . . . . . . . . . 8

2.3.2.2 Results . . . . . . . . . . . . . . . . . . . . 9

2.3.2.3 Overall Conclusions of the Two Tests . . . . . . . . . . . 10

3. A CRITICAL ANALYSIS OF THE TEST METHOD . . . . . . . . . . . . . . . 10

3.1 Preliminary Remarks . . . . . . . . . . . . . . . . . . . . . . 10

3.2 A Limftation of the Test Method . . . . . . . . . . . . . . . . . . . . . 11

3.2.1 The Distribution of Pressure . . . . . . . . . . . . . . . . . . 11

3.2.2 Capability of the Test Method to Simulate Effects

of a High-Rise Building Fire Scenario . . . . . . . . . . . . . . . . 11

3.2.3 The Limited Utility of the Concept of a (Constant) Orifice Coefficient . . . . . . . . . . . . . . . . . 12

3.2.4 Desirable Attributes of a Smoke Leakage

Test Procedure . . . . . . . . . . . . . . . . . . . . . 12

3.3 Some Troublesome Theoretical Aspects of the Test

Method . . . . . . . . . . . . . . . . . . . . . . . . . 13

3.3.1 General Remarks . . . . . . . . . . . . . . . . . . . . 13

3.3.2 The Two Components of Outflow . . . . . . . . . . . . . . . . 14

3.3.3 The Nature of the Steady State and Its

Implications . . . . . . . . . . . . . . . . . . . . . 15

3.3.3.1 An Overview . . . . . . . . . . . . . . . . . . 15

3.3.3.2 Flow Conditions During Times of Cool

Door Surface Conditions . . . . . . . . . . . . . 15

3.3.3.2.1 Flow Phenomenology Following

Vent Closing . . . . . . . . . . . . 15

3.3.3.2.2 Steady-State Position of the

Enclosure-to-Ambient Neutral

Plane - A First Estimate . . . . . . . . . 17

3.3.3.2.3 A Refined Estimate for the Level of the Neutral Plane and Its Implications 


\subsubsection{Flow Conditions Resulting From the} Combined Effects of Leakage and Hot Door Surface Heat Transfer .............. 22

3.3.4 A Summary of the Test Method's Shortcomings . . . . . . . . . . . . . . . 22

4. AN AlteRnAtIVE TEST CONCEPT . . . . . . . . . . . . . . . . . . . . 23

4.1 The Alternative Test Concept and Its Overall Advantages ....... . . . . . . . . . . . . . . . . . . 23

4.2 Significant Features of the Test Concept . . . . . . . . . . . . . 23

4.2.1 Continuous Quasi-Steady Operation . . . . . . . . . . . . . 23

4.2.2 Accurate Simulation of Ambient Conditions . . . . . . . . . . . 24

4.2.3 Universal Control of the Furnace-to-Enclosure

Pressure Differential . . . . . . . . . . . . . . 25

4.2.4 Accuracy of the Leakage Measurement . . . . . . . . . . . 26

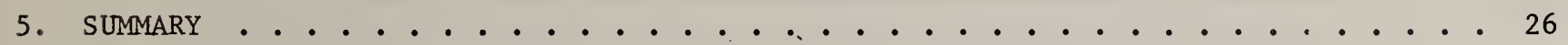

6. ACKNOWLEDGEMENTS . . . . . . . . . . . . . . . . . . . . . . 27

7. REFERENCES . . . . . . . . . . . . . . . . . . . . . . . 28

APPENDIX A. ISO/TC 92/WG 3 N 203. DP 5925 FIRE TESTS -- SMOKE CONTROL

DOOR ASSEMBLIES. PART 3. HIGH TEMPERATURE TEST

(REVISION OF DOCUMENT N 189) . . . . . . . . . . . . . . . A-1

APPENDIX B. AN ESTIMATE OF THE RATE OF GAS OUTFLOW DUE TO HEAT TRANSFER

FROM THE DOOR SURFACE . . . . . . . . . . . . . . . . . . B-1 
Figure 1. Location of thermocouples in the enclosure . . . . . . . . . . 29

Figure 2. Location of thermocouples in the enclosure outlet . . . . . . . 30

Figure 3. Location of pressure differential measurements . . . . . . . . 31

Figure 4. Various $\Delta P^{\prime}$ 's during 840-900-second closed vent interval . . . . . 32

Figure 5. Outflow velocity during 840-900-second closed vent interval . . . . 33

Figure 6. Various $\Delta \mathrm{P}^{\prime}$ s during 2400-2520-second closed vent interval . . . . . 34

Figure 7. Outflow velocity during 2400-2520-second closed vent interval . . . 35

Figure 8. Various $\Delta \mathrm{P}^{\prime}$ 's during 4020-4140-second closed vent interval . . . . . 36

Figure 9. Outflow velocity during 4020-4140-second closed vent interval . . . 37

Figure 10. Venturi throat thermocouple temperatures during 4020-4140-second closed vent interval . . . . . . . . . . . . . 38

Figure 11. Enclosure temperature as a function of elevation during the 4020-4140-second closed vent interval . . . . . . . . . . 39

Figure 12. Estimates of outflow due solely to expansion for a door of dimension $1 \mathrm{~m} \times 2 \mathrm{~m}$. . . . . . . . . . . . 40

Figure 13. Idealized model of flow within the enclosure shortly after vent

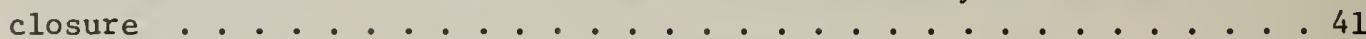

Figure 14. A sketch of a vertical distribution of enclosure temperature and plots of possible resulting distributions of enclosure pressure . . . 42

Figure 15. Plot of $\phi(\lambda)$ defined in eq. (9) . . . . . . . . . . 43

Figure 16. Plots of $\dot{\mathrm{m}}^{*}$ and $\dot{q}^{*}$ as functions of $\lambda$ with $\mathrm{K}$ as a parameter.

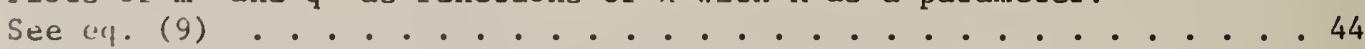

Figure 17. Plot of $\left.\dot{q} /\left[D^{2} / 2\right)(\mathrm{gD})^{1 / 2}\right]$ as a function of $\lambda$ with $K$ as a parameter. Plot of $\dot{q}$ as a function of $\lambda$ with $\Delta \mathrm{T}$ as a parameter, for $\mathrm{D}=0.3 \mathrm{~m}$

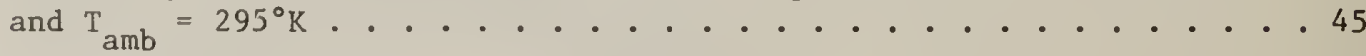

Figure 18. Plot of $V\left(z_{p}\right) / \bar{V}$ as a function of $\lambda$ with $K$ as a parameter ......46

Figure 19. A test concept for measuring leakage of door assemblies during standard fire endurance tests . . . . . . . . . . . . 47

Figure 20. Model for determining the rate of outflow, $\dot{q}$, which is associated solely with the heat transfer rate, Q . . . . . . . . . 48

Figure $1(\mathrm{~A})$ Measurement of air leakage during a high temperature test . . . A-10

F1gure $2(\mathrm{~A})$ Enclosure for leakage rate measurement . . . . . . . . . A-11

Flgure $3(\mathrm{~A})$ Enclosure and furnace surround . . . . . . . . . . . A-12

Figur 4(1) Calibration of enclosure (see clause 6) . . . . . . . . A-13 


\section{THE MEASUREMENT OF THE SMOKE LEAKAGE OF DOOR ASSEMBLIES DURING STANDARD FIRE EXPOSURES}

Leonard Y. Cooper

\section{Abstract}

A basis for relating overall intrabuilding smoke migration dynamics to high temperature, door assembly smoke leakage measurements is formulated. The results of applying the tentative, high temperature, ISO test method DP 5925 Part 3, which was developed to measure smoke leakage of door assemblies during the course of a standard fire endurance test, are reported. A critical analysis reveals that the basic objective of the method is limited in its utility in the sense that fire scenarios in high-rise buildings may not be adequately simulated. Consistent with the above-mentioned experimental results, troublesome theoretical problems with the test method and its procedures are identified. These lead to a conclusion that the test method as written is generally unreliable. An alternate test concept which removes the above-mentioned DP 5925 Part 3 limitation and all of its problems is described and its development is advocated.

Key words: Building fires; compartment fires; doors; egress; fire tests; high-rise buildings; leakage; life safety; smoke; smoke movement; stack effects; test methods.

\section{INTRODUCTION}

\subsection{The Ability of Building Occupants to Achieve Safe} Egress or Refuge

Relative to the threat of fire in occupied buildings, life safety can be measured by the ability of building occupants to achieve safe egress (or safe refuge) subsequent to a potentially hazardous ignition. The overall safe egress capability of occupants is dependent on two basic elements; namely, the time available for safe egress (i.e., the length of time subsequent to fire detection and prior to the onset of untenable conditions), and the time required for safe egress.

Safe available egress time is basically a function of the building design, including all active and passive fire protection systems, and the contained fuel loads which are characteristic of the building occupancy. Required egress time is a function of the physical nature of the egress paths, of the occupant density distribution, and of the physiological and psychological characteristics of the occupants. An excess of available 
egress time over required egress time would generally indicate a safe condition vis-a-vis life safety in fires. An excess of required over available egress time would indicate a hazardous condition.

If one follows the above approach, it is evident that estimates of the available and required egress times are required for an analysis of life safety. This work addresses itself to a specific aspect of building design which impacts most heavily on the safe available egress time part of the "equation"; namely, the smoke leakage characteristics of building partition penetrations during fully developed fire exposures. The closed door assembly is taken here as the prototype of such partition penetrations. It should, however, be stressed at the outset that the ideas developed in this work would be totally applicable to arbitrary leakage paths of interest which may be characteristic to any particular wall or floor construction practice.

\subsection{The Effect of Compartmentation on the Phenomenon of Smoke Migration}

Depending on a given fire scenario in which hazardous conditions develop and in which partial or total building evacuation is required, the actual paths of occupant egress can pass through a varlety of different building spaces. These spaces will generally become untenable at different times. Furthermore, the onset of untenabllity in a given space is likely to result from the spread of the potentially hot, toxic, and/or obscuring products of combustion (smoke). And the slgnificant physical mechanisms which govern this smoke spread can vary from one space to the next.

Compartmentation has been classically used to impede the spread of fires from one space to another. Thus by proper and proven construction practice one can anticipate contalnment of a fire within a given compartment space of fire origin for a time interval of, for example, two or more hours. Such compartmentation constructions will not necessarily abate the spread of smoke to any significant degree. Nevertheless, compartmentation remains a convenient and useful concept for the study of smoke spread phenomenology and for estimating the onset of untenable conditions. Once smoke has passed from a compartment of fire origin, through penetrations (e.g., leaks in a doorway assembly) in its barriers, and Into an adjacent compartment, new and different primary physical mechanisms of smoke spread can come into play. In short, smoke compartmentation can be the major factor in the switchover from one dominant smoke spread mechanism on one side of a barrier to a different mechanism on the other.

As a first approximation it is useful to identify two basic types of smoke migration mechanisms. One of these would be associated with a compartment of fire origin, and the other with all other parts of the bullding. Because of relatively high smoke temperatures, buoyancy effects are 1ikely to dominate the dynamics of the smoke migration in the compartment 
of fire origin. Taking account of these effects, Cooper [1] ${ }^{1}$ has begun to develop a technique for estimating available egress time within such compartments of fire origin (which can include "freely connected" multiple spaces). Assuming a limited rate of leakage into adjacent compartments and anticipating rapid mixing and cooling of the smoke upon entry therein, suggests the second, a "tracer gas" migration type of mechanism for the smoke's continued transport throughout the building. In particular, one would expect that continued migration and dilution of "cold" smoke outside of a compartment of fire origin could be studied by dynamic building infiltration and ventilation models, i.e., by assuming that continued intrabuilding smoke movement and dilution is driven by active forced ventilation systems and, if appropriate, by building stack effects.

Note that the definition of compartmentation in the present, smoke migration, context is keyed to the above words, "assuming a limited rate of leakage into adjacent compartments." The problem of quantifying such a definition so that a particular enclosure of building space can be rated as a bona fide compartment in the above sense for some length of time following ignition will not be addressed here.

\subsection{The Utility of High Temperature Smoke Leakage Measurements}

The compartment of fire origin is the source of smoke for the rest of the building. From the above discussion it is evident that a dynamic analysis of the development of untenable conditions outside of this compartment would require estimates of the rate of leakage across various paths in its bounding partitions. For example, if a door assembly provides the major leakage path, then its rate of leakage while being exposed to a characteristic threatening fire would provide the necessary input data for such an analysis. For life safety evaluation and design purposes, the leakage data of such a door assembly during the course of a standard fire endurance test would be useful in this regard. And such door assembly leakage data need not be used only for the relatively sophisticated task of estimating the actual time to untenability in the various building spaces. Indeed, it is likely that such quantitative leakage data would also be useful in a simple ranking of door assemblies relative to their smoke stopping capabilities. For example, some practical utility could be potentially extracted from the notion that: the "tighter" the door assembly, the greater the available egress time throughout the building (outside the fire compartment). A quantitative measure of door assembly "tightness" is required to invoke even this simple idea.

Presently accepted methods for measuring the response of door assemblies to fully developed fire exposure conditions are typified by ASTM E 152/NFPA 252, Fire Tests of Door Assemblies. Following that procedure, door assemblies are tested and rated for ability to stay in place when exposed to fire (and to a water hose stream) until a limiting gap size

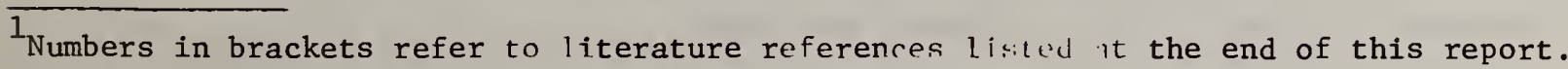


is formed. The rest does not require simulation of any particular real fire, cross-door pressure differential, and it does not measure the air (or gas or smoke) flow across the door assembly. Therefore, having received a rating by virtue of its performance during this test procedure, the leakage characteristics of a particular door assembly are still unknown. If leakage characteristics of door assemblies are to be measured then an alternate or revised test method is clearly required.

\subsection{An Overview of This Investigation}

It was the original objective of the present investigation to measure the leakage rates of various common, (ASTM E 152) rated door assemblies during the course of standard fire exposures, and, ultimately, to place the results of these measurements into the perspective of the above discussion on successful egress from buildings. The vehicle chosen to perform the high temperature leakage measurement was the proposed International Organization for Standardization (ISO) test method ISO/TC 92/WG 3 N 203 - DP 5925 Fire Tests, Smoke Control Door Assemblies Part 3, High Temperature Test. Although this test method was still under development at the time of this choice, it was the only test method available for the task at hand. The test method was implemented and was found to have both limitations and significant basic shortcomings. The investigation eventually focused in on an analysis of these shortcomings. Finally, an alternate test concept which removes the limitations and shortcomings of the present high temperature DP 5925 Part 3 test method was formulated. The details of all of this are reported in the sections to follow.

\section{APPLYING THE HIGH TEMPERATURE TEST METHOD}

2.1 The Proposed ISO Test Method for Measuring the Smoke Leakage of Door Assemblies During Standard Fire Exposures

The ISO Technical Committee ISo/TC 92, Fire Tests for Buildings and Structures, is preparing three different methods for testing the leakage characteristics of door assembl1es. These are all documented under the t1tle "DP 5925 Fire Tests, Smoke Control Door Assemblies." Each of the methods 1s being designed to test leakage under a different simulated condition of bullding smoke and fire exposure. The tests are to be identified as Part 1 - Ambient Temperature Test; Part 2 - Medium Temperature Test; and Part 3 - High Temperature Test. An introductory document which discusses the relevance of these test methods is 1dentifled as "DP 5925 Part 0 - Commentary." To date, Part 0 and only two of the three test methods, Parts 1 and 3, have been formulated to the point of being documented. The tentative test method of interest here is Part 3. A copy of the most recently revised version of this is included in appendix $A$.

The basic 1dea of the high temperature test is rather simple. A sketch of the test setup is included in figure 1 of the appendix A document. 
A door assembly to be evaluated is mounted in a wall assembly. This is integrated in a wall furnace as if the door assembly were to receive a standard fire resistance rating, for example, by ISO 3008 or ASTM E 152. A large collection enclosure covers the entire unexposed portion of the door assembly. A circular opening of diameter $30 \mathrm{~cm}$ (11.8 in) penetrates the enclosure opposite the door surface. The enclosure is carefully attached to the wall which contains the door assembly in a manner to minimize the leakage of gases from the enclosure through these attachment points. During the course of a test the furnace gases pass through the door assembly leakage paths under evaluation, into the enclosure, and out through the circular duct-like opening. The leaking furnace gases simulate the smoke laden gases that would leak across the assembly during an actual threatening fire scenario. Velocity measurements of the enclosure outflow gases are made at one point on the axis of the opening. Assuming quasi-steady flow and uniform gas velocities at a section of the outflow duct, conservation of mass is invoked and the velocity measurement is used to deduce a time varying rate of door assembly leakage.

So as not to continuously subject the unexposed surface of the door assembly to an unrealistic environment due to trapped hot furnace gases, an upper and lower vent (water sealed to prevent spurious leakage) is added to the enclosure structure. These vents are left open for 4-minute intervals during the course of the test procedure. Following every one of these 4-minute intervals the vents are closed for 1 minute during which time the quasi-steady flow condition described above presumably establishes itself. At the end of each 1-minute interval the above-mentioned outflow velocity is recorded, the vents are then opened, and the next 4-minute open vent interval is initiated.

The driving force for smoke (furnace gas) leakage during the high temperature exposure simulation is the distributed pressure difference across the door assembly, i.e., from inside to outside of the furnace. This must be specified in the test method. Toward this end the procedure specifies that the furnace pressure be controlled to maintain a zero pressure differential at the door sill. Taking the door height to be $\mathrm{H}$, and the absolute temperature of the furnace at time $t$ into the test to be $T_{f}(t)$, the effective result of this specification is a positive pressure differential across the door assembly which linearly increases the elevation, with rising from $\Delta \mathrm{P}=0$ at the sill to $\Delta \mathrm{P} \simeq 11.5$ (H/meters) $\left[1-\mathrm{T}_{\mathrm{amb}} / \mathrm{T}_{\mathrm{f}}(\mathrm{t})\right]$ pascals at the top of the door.

Other than the usual data on furnace performance, the measurements called for in the test procedure are limited to the pressure difference across the door at its sill, and the velocity and temperature of the gases at the axis of the circular outflow port of the enclosure.

\subsection{The Original Objective of This Investigation}

As discussed in section 1.3 the original objective of this investigation was to subject several different door assemblies to the high temperature Iso test method described 
above. The plan was to build an enclosure and to test four different door assemblies of the types tabulated below.

\begin{tabular}{cccc}
$\begin{array}{c}\text { Tests } \\
\text { to be } \\
\text { Conducted }\end{array}$ & Door Type & $\begin{array}{c}\text { UL } \\
\text { Classi- } \\
\text { fication }\end{array}$ & $\begin{array}{c}\text { Glass } \\
\text { Size }\end{array}$ \\
\hline 2 & $\begin{array}{c}\text { UL Classified Hollow Metal Type } \\
\text { Stiffner Design }\end{array}$ & $\begin{array}{c}1-1 / 2 \mathrm{hr} \\
(\mathrm{B})\end{array}$ & No Glass \\
1 & $\begin{array}{c}\text { UL Classified Hollow Metal Type } \\
\text { Stiffner Design }\end{array}$ & $\begin{array}{c}1-1 / 2 \mathrm{hr} \\
(\mathrm{B})\end{array}$ & $\begin{array}{c}100 \mathrm{sq} \text { in } \\
\text { Vision } \\
\text { Light }\end{array}$ \\
1 & $\begin{array}{c}\text { UL Classified Hollow Metal Type } \\
\text { Stiffner Design }\end{array}$ & $3 / 4 \mathrm{hr}$ (C) $\begin{array}{c}30 \text { by } 40 \text { in } \\
\text { Vision } \\
\text { Light }\end{array}$ \\
1 & UL Classified Kalemin Type & $1 \mathrm{hr}$ (B) & No Glass
\end{tabular}

An initial "shakedown" test was alloted for the first of the door types listed in this table. Thus, a total of five different high temperature door assembly tests were planned, where the first and second of these would be done on a 1-1/2 (B) UL classified hollow metal type door assembly of Stiffner design and with no glass.

The tests were to be run at the Underwriters Laboratories (UL) in Northbrook, I1linois.

\subsection{An Overview of the Results of Applying the Test Method}

\subsubsection{The First Test}

\subsubsection{Description of the Test}

In accord with the above objectives the first test was run on the hollow metal door in accordance with the DP 5925 Part 3 test procedure. Besides the measurements called for in the procedure, data was also acquired on the temperature and horizontal displacement of the unexposed door surface, the air temperature in the enclosure near the upper vent, and the temperature at a point on the outside surface of the enclosure.

All channels of data were recorded on paper Lape every 30 seconds during the course of the test. The enclosure vents were designed to be operated by a hydraulic system which would be activated manually.

The prescribed 4-minute open; 1-minute closed vent sequence was followed initially, but later into the test the closed vent intervals were increased to $1-1 / 2$ and then 2 minutes. The test was corminated after approximately 55 minutes because of a breakdown of the hydraulic vent control. 


\subsubsection{Results}

It is sufficient for the purpose of the present report to briefly describe the significant results of the first test at UL. The results of a second, similar test will be presented in considerably more detail in section 2.3.2.

The major measured results were related to the center line outflow duct gas velocities as measured toward the end of closed vent time intervals. With regard to this it appeared that these velocities had not reached quasi-steady values as would be required if the fundamental philosophy of the test method is to be valid.

Besides the above-measured result there was also a significant visually observed result, namely, between 1 and 1-1/2 minutes following vent closure a stratified smoke layer started to flow out of the upper part of the outflow duct. (The painted surfaces of the door and frame were the likely sources of this smoke.) This continued until the end of the closed vent time interval. It was noteworthy that the above-mentioned measured values of outflow velocities approached inordinately small values (the order of tens of feet per minute-- sometimes smaller) compared to the visually observed velocities (of the order of hundreds of feet per minute) in this smoke layer.

As a point of information, toward the end of the closed vent time intervals and toward the end of the test the recorded temperatures of fire gas in the upper part of the enclosure approached $200^{\circ} \mathrm{F}\left(93^{\circ} \mathrm{C}\right)$. Also, at these later times the unexposed door surface temperature reached the order of $750^{\circ} \mathrm{F}\left(399^{\circ} \mathrm{C}\right)$.

\subsubsection{Reflecting on the Results}

The above results clearly called for some reflection regarding the likely overall nature of the transient gas flows within and through the enclosure subsequent to the initiation of the closed vent test intervals. This resulted in a conjecture that the phenomena in question were analogous to those produced by a heat source in a ventilated enclosure. In this analogy the outflow opening in the present experimental setup would correspond to the enclosure ventilation opening. The hot leakage furnace gases and the hot unexposed surface of the door, both of which must have been generating buoyant plumes near the door surface in the present experimental setup, would correspond to the enclosure heat source. Just as would occur upon switching on the heat source in the ventilated enclosure, it was therefore conjectured that upon closing the vents during the present experimental procedure these latter plumes would result in a filling of the enclosure with an upper, growing layer of hot gases. Eventually the nature of the steady state would be one where the flow of gases at the circular ventilation opening would be outward (hot gases) at the upper portion of this section, inward (cool ambient air) at the bottom portion of the section, and with a neutral plane (zero velocity) somewhere near the elevation of the outflow duct axis. 
If the above conjectured phenomenology does indeed occur while carrying out the test procedure and/or if steady-state flows do not establish themselves fairly rapidly, say, within a minute or two following vent closing, then it is evident that there would be serious questions about the basic validity of the test method.

\subsubsection{Conclusions of the First Test}

In view of all the above it was concluded that at least one further test, identical to the first but with more instrumentation and data collection, should be carried out. Note that this conclusion was compatible with the original test plan which called for two tests on the same hollow core steel door design. More important, however, it was compatible with a new and clear requirement that the above questions raised by the first test be answered.

Another conclusion of the test was that a careful analysis of the phenomena occurring during the test procedure should be carried out. After a review of the second UL door test in the remainder of this section, a presentation of the results of this analysis-basically an in-depth critique of the proposed DP 5925 high temperature test method-- will follow in section 3.

\subsubsection{The Second Test}

\subsubsection{Description of the Test}

A second test was run at UL whlch was essentially identical to the first except for greatly improved instrumentation.

Figures 1 and 2 indicate the locations of most of the thermocouples. Most of these were located within the enclosure so that the transient development of the gas temperature distribution could be studied, e.g., for the purpose of establishing the potential compatibility of data with the conjectured stratification phenomenology discussed earlier. Those few thermocouples which were located in the outflow duct were to provide an indication of the validity of the cool lower inflow - hot upper outflow velocity distribution which was conjectured to occur during latter parts of closed vent time intervals.

Figure 3 indicates the locations where pressure differentials were measured. One of the main reasons for these, i.e., $\Delta \mathrm{P}_{1}$ and $\Delta \mathrm{P}_{5}$, was to provide an indication of the variation In time and in elevation of the enclosure-to-ambient pressure differential, e.g., for the purpose of establishing the compatibility of data with the conjectured quasi-steady position (near the outlet duct axis) of the enclosure-to-amblent neutral plane.

All data channels were scanned and recorded on magnetic tape once every 5 seconds. 
For the first 40 minutes of the test the 4-minute open; 1-minute closed vent sequence was maintained. After this time the closed vent interval was increased to 2 minutes. The test was terminated after approximately 80 minutes at which time the vents became stuck in the closed position.

\subsubsection{Results}

The results of the second test generally corroborated those of the first test. Additional insight into the flow phenomena was provided, however, by the more detailed instrumentation capability.

The pressure differential data and the outflow velocity data which cover three representative closed vent time intervals, 840-900 seconds, 2400-2520 seconds, and 40204140 seconds, are presented in figures 4-5, 6-7, and 8-9, respectively. The temperature history at the three thermocouples located in the throat of the outflow venturi for the latter of these closed vent intervals is presented in figure 10. The enclosure temperature distribution at seven different, equal spaced times during this time interval is presented in figure 11. The temperature values plotted in this latter figure are an appropriate average of the temperatures measured by thermocouples located within the enclosure at identical elevations.

A11 of the above data support the general conjecture, briefly presented above in paragraph 2.3.1.3 regarding the gas flows within and through the enclosure. The analysis of these flow phenomena to be presented in the next section will place this data into proper perspective. For the present, the following brief observations will suffice:

Figures 4, 6 and 8 indicate that quasi-steady enclosure-to-ambient pressure differentials $\Delta \mathrm{P}_{1}$ (top of door) and $\Delta \mathrm{P}_{5}$ (bottom of door) were attained within 1-2 minutes following vent closure. From the fact that these quasi-steady $\Delta \mathrm{P}_{1}$ and $\Delta \mathrm{P}_{5}$ values are of different sign, it is also evident that in each of these three closed vent sequences a neutral plane (i.e., the elevation where $\Delta \mathrm{P}=0$ ) must have been formed somewhere between the top and bottom of the door. From the fact that $\Delta \mathrm{P}_{1}$ consistently approaches the approximate value $\Delta \mathrm{P}_{5}$, one also learns that the quasi-steady positions of these neutral planes were near the mid-door elevation (i.e., near the elevation of the outflow duct axis).

If the neutral plane elevation is in the vicinity of the duct axis, then the net outflow through the duct can change significantly with relatively small variations (e.g., a few tenths of a duct diameter) in this neutral plane elevation. (This fact will be substantiated below in the analysis of section 3.3.3.) Accordingly, when the neutral plane reaches the vicinity of its quasi-steady elevation, say, to within a few inches, the a.tual net flow through the duct will still deviate significantly from its quasi-steady villik. The $1 \mathrm{ag}$ between the establishment of the quasi-steady neutral plane position 
(i.e., quasi-steady $\Delta \mathbf{P}_{1}$ and $\Delta \mathrm{P}_{5}$ ) and the establishment of quasi-steady net outflow is indicated by comparisons of the velocity histories of figures 5,7 and 9 and the $\triangle P_{1}$ and $\Delta P_{5}$ histories of figures 4,6 and 8 . For example, whereas figure 4 indicates that quasi-steady $\Delta P^{\prime}$ 's are attained by 1 minute following vent closure it is not clear from the data of figure 5 that a quasi-steady duct axis velocity is at hand at this time. As another example, figure 8 indicates that near-steady $\Delta P^{\prime}$ 's are attained by 1 minute following vent closure. However, the corresponding data of figure 9 suggests that even at 2 minutes following vent closure, quasi-steady velocities in the duct cross section may not have been attained. The enclosure gas temperature histories of figure 11 also indicate that full quasi-steady conditions had not yet occurred by the end of the 4013-4132-second test interval. Finally, the duct temperature data of figure 10 strongly support the contention that, even as quasi-steady pressure conditions begin to be established, a highly transient lower inflow of cool ambient air and upper outflow of hot enclosure gases are in evidence at the venturi throat cross section.

\subsubsection{Overall Conclusions of the Two Tests}

The results of the two tests at UL indicated that the proposed high temperature test is not likely to provide the door assembly leakage measurement for which it was designed. As will be seen, the analysis to follow in section 3 strongly supports this result. Because of this 1 t was concluded that the remainder of the UL test program, as delineated In paragraph 2.2, be postponed until a satisfactory alternate door assembly leakage test was developed. Such an alternate test concept is proposed below in section 4 .

\section{A CRITICAL ANALYSIS OF THE TEST METHOD}

\subsection{Preliminary Remarks}

This section is devoted to a critical analysis of the proposed high temperature ISO test method DP 5925 (appendix A) for measuring smoke leakage past door assemblies. As noted in section 2.3.1.4 the need for this analysis became evident after reflecting on the unexpected results of the first UL test. The results of the analysis to follow, although compatible with the results of both the first and second UL tests, will be seen to stand independent of them.

As will be seen, the analysis reveals that the basic objective of the test method is limited in its utility in the sense that fire scenarios in high-rise buildings may not be adequately simulated. More significant, troublesome theoretical problems with the test method and its procedures are identifled. The presentation to follow first discusses the test Ifmitation. Following this is an analysis of the more basic theoretical problems. 


\subsection{A Limitation of the Test Method}

\subsubsection{The Distribution of Pressure}

The basic idea of the test in question is to measure the rate of gas leakage across a subject door assembly during the course of a fire exposure which simulates a fully developed flashed-over fire. At any time during the test this leakage rate will clearly depend on the distribution of pressure difference, $\Delta \mathrm{p}$, across the door assembly. As delineated in sections 3 and 7.2 of DP 5925 Part 3, the actual distribution modeled is the one where the pressure in the furnace (representing the room of fire origin) is controlled in such a manner as to result in a zero (0-1 pascals) $\Delta p$ at the bottom of the door assembly (i.e., the neutral plane is fixed at the door sill). By maintaining a zero $\Delta p$ at this level, the vertical variation in $\Delta p$ is automatically determined by the then current temperature (density) of the furnace gases.

The idea of the particular pressure distribution specified in the test is that it presumably leads to conservative results in the sense that a higher leakage rate will result in the test than would occur if, say, the neutral plane (the level of zero $\Delta p$ ) were fixed at a level above the door sill. Indeed, for one particular door gap assumption Dekker and Haffmans [2] have estimated that almost twice as much gas would flow from the room of origin, in the case of the present $\Delta p$ distribution, than in the case of a modified distribution where the neutral plane was one third of the door height up from the door sill. As it turns out, the conservative nature of this result only holds up when one considers use of the door assembly in low to moderate height buildings or in tall buildings under moderate climate conditions, and under low to moderate wind conditions.

\subsubsection{Capability of the Test Method to Simulate Effects of a High-Rise Building Fire Scenario}

In considering use of the door assembly in high-rise buildings, or, more directly, in buildings where the stack effect is significant, the singular pressure distribution specified by the test method no longer leads to conservative results. This becomes clear from the following considerations: The source of smoke which infiltrates a high-rise building is the room (smoke zone) of fire origin. The rate at which this source passes smoke into the overall building air supply is determined by 1) the geometry of partition penetrations (in our case, door assembly penetrations) and by 2) the distribution of $\Delta p$ across these penetrations. The $\Delta p$ that would exist in practice could be of the order of several tens of pascals -- several times larger than the $\Delta$ p being considered in the present test method. In short, while the test method may lead to conservative estimates of smoke leakage when the door assembly was used in low buildings, it could lead to significant underestimates of smoke leakage rate when the door assembly was used in high-rise building applications. And it is precisely the "fire in the high-rise building problem" that has drawn so much attention to the general problem of smoke movement. 
Before leaving this section, it is appropriate to briefly describe a typical fire which would result in a relatively high over-pressure $\Delta p$ of the type referred to above. Such a scenario might look as follows: Fire breaks out in a room on a low floor in a highrise building during cold winter climate conditions. The room flashes over and a ventilation or fuel controlled fire develops where ventilation is from broken windows on exterior walls. From this time on the fire room pressure is substantially maintained at the outside pressure. This room of fire origin is connected to adjacent rooms by partitions with relatively small penetrations, e.g. (closed) door assemblies. The pressure in these adjacent rooms is substantially at an inside pressure which is characteristic of the (low) floor under consideration. The $\Delta \mathrm{P}$ across all these partitions is therefore maintained at levels which are of the order of magnitude of several tens of pascals, i.e., at levels which are of the order of magnitude of inside to outside stack effect, pressure differentials.

\subsubsection{The Limited Utility of the Concept of a (Constant) Orifice Coefficient}

In addition to the observations in the last paragraph it is timely to point out that there is no good technical basis for obtaining required "high over-pressure" results by scaling up valid "low over-pressure" data (which would presumably be acquired by following the present test method). This is the case for two reasons: 1 ) The $\Delta \mathrm{P}$ distributions are qualitatively different. Thus, the leakage rate in the present test method is a result of a strongly varying vertical $\Delta \mathrm{P}$ distribution (nominally zero at the door sill, and increasing Iinearly with height to the order of 10 pascals at the top of the door), whereas the high over-pressure type of loading to be simulated would be relatively uniform over the entire assembly, e.g., several tens of pascals \pm the order of 10 pascals. The flow coefficient for the leakage cannot be characterized as an orifice coefficient in the usual sense. The (constant) orifice coefficient concept can be valid when the flows involved are mostly turbulent (i.e., are at relatively high Reynolds number, Re). However, for the present case of long gaps (cracks) which act like moderately long two-dimensional ducts, the flows w11l be of relatively small and highly varying Re. Besides that, these flows are not likely to be fully developed for much, if any, of their duct lengths. In short, flow coefficients associated with a given (narrow) door gap of interest will be strongly dependent on gap geometry and on the $\triangle \mathrm{P}$ across the gap (or on the gap Re).

It is noteworthy that the above $\Delta \mathrm{P}$ dependent flow coefficient phenomenon, which would be exhlbited in cold gas flows as well as in hot gas flows, has been observed in the present context by Keough [3]. The added problem in the high temperature test is, of course, the fact that gap geometry 1 s changing during the course of the test due to expansion, warpage, etc. of the door assembly.

3.2.4 Desirable Attributes of a Smoke Leakage Test Procedure

The remarks in the above paragraphs lead to the following conclusions: 
Flexibility in achievable $\triangle \mathrm{P}$ distributions would be an attractive feature of a test method for measuring leakage characteristics of partition assemblies. This flexibility should include a $\Delta \mathrm{P}$ distribution which is reasonably uniform and of the order of 100 pascals, as well as a $\Delta \mathrm{P}$ type of distribution characterized by a neutral plane $(\Delta \mathrm{P}=0)$ somewhere near the door sill.

The present test method does not have the former, high pressure capability, and this is a significant limitation in the evaluation of door assemblies for high-rise building usage. This limitation could be overcome by following an alternate test concept to be discussed below in section 4 .

\subsection{Some Troublesome Theoretical Aspects of the Test Method}

\subsubsection{General Remarks}

There are two basic theoretical aspects of the test method which lead to serious questions regarding its usefulness. The first of these has to do with the fact that the gas outflow from the enclosure (during the closed vent phases of the test) has two, inseparable components. One component, the one which the test sets out to measure, is the actual leakage gases. The other component, which is of no interest, and which cannot be physically separated from the first, is the result of expansion of enclosure gases due to heat transfer from the hot, unexposed surface of the door assembly under test. As will be seen, this latter expansion component can be of the same order as the former leakage component.

The second aspect has to do with the complicated nature of the steady-state flows which develop in and through the enclosure following closure of the vents. It is after this steady state is reached that the test procedure actually calls for outflow measurements.

In the remainder of the paragraphs under section 3.3, an analysis of the impact and implications of these two aspects of the test method is presented. At first it would appear that several seemingly influential factors may have to be directly taken account of during the course of such an analysis. A partial listing of such factors would include,

The actual test procedure does not directly call for measurement at the steady state, c.f., 7.3 Operating Procedure of DP 5925. Rather it is assumed that this steady state will occur by 1 minute following vent closing, and the procedure explicitly calls for measurement at this time. The actual time to reach steady state will be a strong function of the specific door assembly under test and the time into the test, and the indirect, 1-minute prescription for steady-state definition can lead to serious error. This is borne out by the test results of section 2, for example, where the velocity data of figure 7 suggest that an effective steady state may be at hand by $1-1-1 / 2$ minutes following vent closure at 2400 seconds, and where the velocity data of figure 9 suggest that even 2 minutes following vent closure at 4200 seconds steady state may not have been reached. 
for example, furnace pressure, geometry and position of the gaps in the door assembly, volume of the enclosure, and elevation and diameter of the enclosure exhaust port. As it turns out, however, there are only four factors that are, in fact, required for such an analysis, namely, the overall leakage of the door assembly (wh1ch would, of course, be a complicated and apriori unknown function of furnace pressure and gap geometry), the diameter of the exhaust port, the outer door surface temperature, and the temperature of the enclosure gases near the elevation of the exhaust port axis. At appropriate places in the discussion below, these factors will be reintroduced.

\subsubsection{The Two Components of Outflow}

As mentioned above, one component of the outflow gas flow rate is the actual leakage rate. It is, of course, the entire purpose of the test to measure this leakage rate. Unfortunately, there is another component to these outflow gases, which can be small or large compared to the first. This added component comes into play once the temperature on the unexposed surface of the door assembly starts to become significantly larger than the ambient temperature. Thus the expansion component will be small relative to the leakage component very early in the test, and may ${ }^{3}$ remain relatively small for a longer period of t1me in the case of doors with relatively higher insulating properties. Indeed, even for uninsulated doors, and late into a test, the expansion component of the outflow may (again) be eventually masked by the leakage component if door warpage and resulting increasing gap dimensions proceed far enough along.

In general it is difficult to make apriori estimates of the relative significance of the expansion component for a given door assembly system. But an order of magnitude estimate of this flow rate 1s achievable. Such an estimate was obtained, and 1t 1s presented in appendix $B$. The result of this is plotted in figure 12. As can be seen there, for a door of dimension $1 \mathrm{~m} \times 2 \mathrm{~m}$ and for $\Delta \mathrm{T}=\mathrm{T}_{\text {surface }}-\mathrm{T}_{\text {gas }}$ of the order of hundreds of ${ }^{\circ} \mathrm{C}$, the outflow due to expansion will be of the order of tens of $\mathrm{m}^{3} / \mathrm{hr}$. It is evident from leakage rate data of [3] and [4], for example, that such rates of outflow could completely mask the leakage phenomenon under study. In such circumstances (which are, apriori, not evident) the present test method may be totally inadequate.

\footnotetext{
3The qualifier "may" is 1mportant. It is used here for the following reason: Whereas the actual expansion effect w1ll be smaller at all times in the case of a better insulated door, the insulated door may deform in such a manner as to significantly decrease the rate of leakage as the test proceeds. Thus, in the case of well insulated doors, 1t may not be unusual if the ratio of expansion component to leakage component increased from zero with reasonable rapidity. Indeed it is very difficult to generalize regarding the outcome of the potentially complicated interplay of in-depth door temperature distribution, thermal deformation, and unexposed surface heat transfer which would develop during the course of a test. This interplay would be a custom feature of any specific door assembly system.
} 
In the special case of the tests described above in section 2, and toward the end of these tests, the expansion component of the outflow is estimated from figure 12 to vary from approximately $45 \mathrm{~m}^{3} / \mathrm{hr}$ to approximately $30 \mathrm{~m}^{3} / \mathrm{hr}$ during the course of a 2-minute closed vent interval.

\subsubsection{The Nature of the Steady State and Its Implications}

\subsubsection{An Overview}

Upon closing the vents at a given time during the course of the test, the procedure is to wait until a steady state is reached, and then to measure ${ }^{4}$ the outflow from the enclosure. By applying the principle of conservation of mass in its steady-state formulation, this measured rate of mass outflow is presumably equal to the rate at which mass leaks through the door assembly. As it turns out, a description of the nature of this steadystate is elusive. However, whatever the steady state temperature and flow fields within the enclosure, it is likely that at the time of steady state the original, pre-vent closure, $\triangle \mathrm{P}$ distribution (and the resulting leakage flow rate) will have been significantly altered. Besides this, an additional problem may manifest itself in that a uniform slug flow description of the outflow velocity distribution at steady state may not be adequate, i.e., a single point velocity measurement may not permit a reasonable estimate of the outflow rate.

The considerations of the previous paragraphs under section 3.3 .2 strongly influence the quantitative aspects of the phenomena under discussion here. Yet, the above qualitative remarks are independent of these considerations as will be clarified below. The situation will first be discussed in the absence of hot door surface, expansion phenomena. Following that, a hot door surface zero leakage scenario will be discussed. Finally, the phenomena of combined effects will be presented.

\subsubsection{Fiow Conditions During Times of Cool Door Surface Conditions}

\subsection{Flow Phenomenology Following Vent Closing}

For the purpose of this paragraph we assume that the unexposed door surface is effectively at ambient temperature (i.e., the outflow from the enclosure is solely due to door leakage). This assumption will always be valid early in the test. For well insulated doors it will remain valid until later into the test.

Attention is focused on the time immediately following vent closure. The enclosure is filled with cool ambient air, and it is assumed that the $\Delta p$ distribution across the

${ }^{4}$ See the footnote at the bottom of page 13 regarding the specification of the time of measurement (steady state). 
unor ussembly at this instant is substantially as it was prior to vent closing ${ }^{5}$ (i.e., the $\mathrm{P}$ is as prescribed in the test procedure). By virtue of this $\Delta \mathrm{P}$ distribution no leakage occurs at the horizontal door sill gap. There will, however, be leakage gases entering the enclosure in the form of hot, line jets through the vertical gaps and through the upper horizontal gap of the door assembly. The horizontal momentum of these jets is quickly diffused and masked by strong increases in upward momentum.

This upward momentum is a result of the relatively strong buoyancy forces which come into play. For the case of the vertical gaps, for example, a substantially vertical, buoyant, half-plume develops, where the plume axis is coincident with the gap itself. In this case, the flow field is analogous to the flow field in a plume formed from a vertical line source of heat (buoyancy).

The unsteady phenomena related to a buoyancy source in an enclosure which is initially at uniform gas temperature have been studied by Baines and Turner [5], Zukoski [6], Zukoski and Kubota [7] and others. The steady state for this problem, when there is a ventilation opening to the outside (as there is in the present case with the outflow venturi), has been studied by a host of other authors (e.g., Kawagoe [8], Prahl and Emmons [9], Quintiere [10], and Rockett [11]. These latter studies are mainly in the context of fires in enclosures. And indeed, the flow phenomenology of interest here is very much analogous to the flow phenomenology of fires in enclosures.

Applying the ideas developed in the above referenced studies, it is likely that the following scenario will unfold immediately following vent closure:

The plumes driven by the hot furnace gases rise upward in the enclosure, laterally entraining cool ambient air all along their height. The lateral velocity of these cool gases is relatively small compared to upward velocity in the plumes, and, away from these plumes, the gases in the enclosure remain essentially in a quiescent state. The total mass flow in the plumes increases with height. The increase is due mainly to the entrained alr (i.e., the ratio of entrained air to furnace gases in the plume is relatively large). Thus the average temperature in the plume decreases with height, remaining somewhere between the temperature of the hot furnace leakage gases and the temperature of the cool ambient air. Upon reaching the top of the enclosure the plume gases rapidly spread across It in a relatively thin (compared to the height of the enclosure), hot, buoyant layer.

As time goes on, the upper, hot, plume gas layer starts to increase in thickness replacing, from above, the lower cool gases which are continuously entrained into the

\footnotetext{
${ }^{5}$ Upon closing of the vents there will actually be a relatively small and uniform increase in enclosure pressure. This is due to the fact that all the enclosure outflow is now through the relatively small constriction of the outflow port.
} 
plume. A complete analysis of the phenomenon would also indicate the requirement of a net outflow from the outflow port ${ }^{6}$. The entire situation at early times is depicted in figure 13.

As time goes on the interface between the upper and lower layers continues to drop, soon reaching the general level of the enclosure outflow port. Whether or not the steady state is at hand is not immediately clear. As will be seen, the basic question in this regard is whether the effective position of the interface continues to drop to the bottom of the enclosure or settles in a steady state somewhere above the bottom, but below the axis of the outflow port. In order to address this question a result will first be deduced concerning the steady-state level of the enclosure-to-ambient neutral plane (i.e., concerning the level at which $P_{\text {enclosure }}=\mathrm{P}_{\text {ambient }}$ ).

\subsection{Steady State Position of the Enclosure-to-Ambient Neutral Plane - A First Estimate}

A general result for the steady state position of the enclosure-to-ambient neutral plane will now be obtained. As it turns out, a direct calculation for this neutral plane position is beyond the intended scope of this analysis. The following indirect approach will be seen to yield the desired result for the enclosure outflow dynamics under review.

In figure 14 is a sketch of the enclosure, and, for a relatively late time into a closed vent phase, a vertical temperature profile for the enclosure gases (away from the plume). The uniform ambient temperature is also indicated in the figure. Corresponding to these temperature profiles are plotted the vertical ambient and enclosure pressure distributions. These latter pressure profiles are the result of vertical integration of the temperature dependent density profiles. Thus

$$
\begin{aligned}
& P_{\text {amb }}(z)=P_{a m b}\left(z_{n}\right)-\int_{z_{n}}^{z} \rho\left(T_{a m b}\right) g d z \\
& P_{\text {encl }}(z)=P_{\text {enc1 }}\left(z_{n}\right)-\int_{z_{n}}^{z} \rho\left(T_{\text {enc1 }}\right) g d z
\end{aligned}
$$

where $z_{n}$ is some arbitrary reference level, and where $P_{a m b}, T_{a m b}, P_{\text {encl }}, T_{\text {encl }}$ are pressures and absolute-temperature of the ambient and within the enclosure, respectively. The different possible uniformly separated $P_{\text {encl }}$ distributions in the figure indicate the fact that with the second of eq. (1) and from the known distribution of $T_{\text {encl }}(z) P_{\text {encl }}(z)$ can be computed only to within an undetermined constant, $P_{\text {encl }}\left(Z_{n}\right)$.

6 The idea of a net outflow of the enclosure gases, uniform across a section of the outflow port for some initial time following vent closure, is compatible with the figure 10 plot of the section 2 test results. 
Now let $z_{n}$ be the unknown position of the enclosure-to-ambient neutral plane. Thus we define $z_{n}$ as the position where $P_{\text {encl }}\left(z_{n}\right)=P_{a m b}\left(z_{n}\right)$. Also define

$$
\Delta P_{e-a}(z)=P_{\text {encl }}(z)-P_{\text {amb }}(z)
$$

Thus

$$
\begin{aligned}
\Delta \mathrm{P}_{\mathrm{e}-\mathrm{a}} & =g \int_{\mathrm{z}_{\mathrm{n}}}^{z_{1}}\left[\rho\left(\mathrm{T}_{\text {amb }}\right)-\rho\left(\mathrm{T}_{\text {encl }}\right)\right] \mathrm{dz} \\
& \left.=g \rho\left(\mathrm{T}_{\mathrm{amb}}\right) \int_{z_{\mathrm{n}}}^{z_{\text {encl }}}\left[\mathrm{T}_{\text {amb }}\right) / \mathrm{T}_{\text {encl }}\right] \mathrm{dz}
\end{aligned}
$$

In this last equation and throughout this entire work all enclosure gases are taken to have the properties of air. Furthermore, a constant absolute pressure, perfect gas model for air is assumed. Thus, $\rho T$ is assumed to be a single constant at all elevations within the ambient and throughout the enclosure.

In terms of comparison between eq. (3) and the section 2 tests, recall that histories of $\triangle \mathrm{P}_{\mathrm{e}-\mathrm{a}}$ measured at the top and bottom positions of the door assembly have been plotted in figures 4,6 , and 8 . For the specific time 4132 seconds into the second test (figure 8) the theoretical value of the bottom $\Delta \mathrm{P}_{\mathrm{e}-\mathrm{a}}$ has been computed using the measured top $\Delta \mathrm{P}_{\mathrm{e}}-\mathrm{a}$ value, the measured temperature profile of figure 11, and eq. (3). The excellent agreement between the computed $\left(-0.0150 \mathrm{in}_{\mathrm{w}}\right)$ and measured $\left(-0.0160 \mathrm{in}_{\mathrm{w}}\right) \Delta \mathrm{P}_{\mathrm{e}-\mathrm{a}}$ values can be seen in figure 8.

It is noteworthy that the latter calculation also led to an estimate of the neutral plane position at the time in question. This was found to be somewhere near the outflow port axis ${ }^{7}$.

The volume rate and mass rate of flow through the outflow port, $\dot{q}$ and $\dot{m}$, respectively, can be written as

$$
\begin{aligned}
& \dot{q}=\int_{z_{p}}^{z}+D / 2 w(z) v(z) d z \\
& \dot{\mathrm{m}}=\int_{\mathrm{z}_{p}}^{\mathrm{z}}+\mathrm{D}-\mathrm{D} / 2 \rho_{t}(z) w(z) v(z) d z
\end{aligned}
$$

\footnotetext{
7 The preclse estimate for the neutral plane elevation at 4132 seconds was found to be 6 inches above the outflow port axis. Anticipated experimental error does not, however, allow precision in this regard better than the order of a foot.
} 
where $D$ and $w(z)$ are the height and width of the outflow port, respectively, $z_{p}$ is the vertical elevation of the midheight of the outflow port, $v(z)$ is the velocity of the flow measured positive in the enclosure-to-ambient direction, and $\rho_{t}(z)$ is the density of the flow-through gases. Then

$$
\mathrm{v}(\mathrm{z})=\left[2\left|\Delta \mathrm{P}_{\mathrm{e}-\mathrm{a}}\right| / \rho_{\mathrm{t}}(\mathrm{z})\right]^{1 / 2} \Delta \mathrm{P}_{\mathrm{e}-\mathrm{a}} /\left|\Delta \mathrm{P}_{\mathrm{e}-\mathrm{a}}\right|
$$

and

$$
\rho_{t}(z)=\left\{\begin{array}{l}
\rho\left(T_{e n c l}\right) \text { if } \Delta P_{e-a}>0(v>0) \\
\rho\left(T_{\text {amb }}\right) \text { if } \Delta P_{e-a}<0(v<0)
\end{array}\right.
$$

Referring to eq. (3) it is now assumed that, in the $z$ range of interest, the maximum variation of $\mathrm{T}_{\text {encl }}(\mathrm{z})$ is relatively small in magnitude compared to the minimum of $\left|T_{\text {encl }}(z)-T_{a m b}\right|$. This would clearly be the case for the sketched profiles of figure 14 provided $z_{n}$ was in the proximity of the axis of the outflow port, e.g., provided $\left|z_{n}-z_{p}\right|<D$. Under these conditions, $T_{\text {encl }}(z)$ under the integral of eq. (3) can be approximated by $T_{\text {encl } 1}\left(z_{p}\right)$, and $\Delta P_{e-a}$ itself can be approximated by

$$
\Delta \mathrm{P}_{\mathrm{e}-\mathrm{a}}=\mathrm{g \rho}\left(\mathrm{T}_{\mathrm{amb}}\right)\left(\mathrm{z}-\mathrm{z}_{\mathrm{n}}\right)\left[1-\mathrm{T}_{\mathrm{amb}} / \mathrm{T}_{\mathrm{encl}}\left(\mathrm{z}_{\mathrm{p}}\right)\right]
$$

The $\Delta \mathrm{P}_{\mathrm{e}-\mathrm{a}}$ 's that would be formed from the $\mathrm{P}_{\text {amb }}$ profile and from the $\mathrm{P}_{\text {encl }}$ and $\mathrm{P}_{\text {encl }}$ profiles sketched in figure 14 are indicative of the anticipated validity of the fact that $\Delta \mathrm{P}_{\mathrm{e}-\mathrm{a}}$ does indeed vary linearly with $\mathrm{Z}$ in a manner consistent with eq. (7) in the $\mathrm{Z}$ range of interest. The $P$ encl profile is for $z_{n}$ somewhere near the elevation of the outflow port axis, and the $P_{\text {encl }}$ profile is for $z_{n}$ slightly below the outflow port opening.

Using the result of eq. (7) in eq. (5) the following estimate for $v(z)$ is eventually obtained

$$
v(z)=\left\{\begin{array}{l}
\left\{2 g\left[T_{\text {encl }}\left(z_{p}\right) / T_{\text {amb }}-1\right]\left(z-z_{n}\right)\right\}^{1 / 2} ; z-z_{n}>0 \\
\left\{2 g\left[T_{a m b} / T_{\text {encl }}\left(z_{p}\right)-1\right]\left(z-z_{n}\right)\right\}^{1 / 2} ; z-z_{n}<0
\end{array}\right.
$$

Using this last result in eq. (4), and taking the outflow port as in figure 14 to be circular in section and of diameter $D$, the following result is obtained for the total volume flow rate and mass flow rate through the port and out of the enclosure: 


$$
\begin{aligned}
& \dot{\mathrm{q}}^{*}=\dot{\mathrm{q}} /\left[\left(\mathrm{D}^{2} / 2\right)(\mathrm{gDK})^{1 / 2}\right]=\phi(\lambda)-\phi(-\lambda)[1 /(1+\mathrm{K})]^{1 / 2} \\
& \dot{\mathrm{m}}^{*}=\dot{\mathrm{m}}(1+\mathrm{K}) /\left[\rho_{\mathrm{amb}}\left(\mathrm{D}^{2} / 2\right)(\mathrm{gKD})^{1 / 2}\right]=\phi(\lambda)-\phi(-\lambda)(1+\mathrm{K})^{1 / 2}
\end{aligned}
$$

where

$$
\begin{gathered}
K=\left[T_{\text {encl }}\left(z_{p}\right) / T_{\text {amb }}-1\right] ; \lambda=\left(z_{n}-z_{p}\right) /(D / 2) \\
\phi(\lambda)= \begin{cases}\int-1 \\
\left.-1\left(1-\zeta^{2}\right)(\zeta-\lambda)\right]^{1 / 2} d \zeta ; \lambda<-1 \\
\int_{-1}^{1}\left[\left(1-\zeta^{2}\right)(\zeta-\lambda)\right]^{1 / 2} d \zeta ;-1 \leq \lambda \leq 1 \\
0 & ; 1<\lambda\end{cases}
\end{gathered}
$$

$\phi(\lambda)$ is plotted in figure 15. $\dot{q}^{*}$ and $\dot{m}^{*}$ are plotted in figure 16 as a function of $\lambda$ with $\mathrm{K}$ as a parameter. The corresponding values for $\dot{q}^{*} \mathrm{~K}^{1 / 2}$ are plotted in figure 17 . For $D=0.3 \mathrm{~m}$ (the diameter of the outflow port prescribed by DP 5925) the dimensional values of $\dot{q}$ are also presented in figure 17 as a function of $\lambda$ with $T_{\text {encl }}\left(z_{p}\right)-T_{\text {amb }}$ as a parameter.

For the present purposes, these plots yield the significant results of this paragraph. For example:

If $\mathrm{T}_{\text {enc } 1}\left(\mathrm{z}_{\mathrm{p}}\right)-\mathrm{T}_{\text {amb }}$ is between $60^{\circ} \mathrm{C}$ and $1200^{\circ} \mathrm{C}$, and the volume rate of flow from the outflow port is less than $275 \mathrm{~m}^{3} / \mathrm{hr}$, then the level of the neutral plane, $z_{n}$, is in the relatively narrow range

$$
-2 .<\lambda<0.25 \text { or } \quad z_{p}-D<z_{n}<z_{p}+D / 8
$$

3.3.3.2.3 A Refined Estimate for the Level of the Neutral Plane and Its Implications

The results of the previous paragraph indicate the possibility of a neutral plane (somewhat) below the bottom of the outflow port (1.e., $\lambda<-1$.). Under these circumstances the velocity across the entire section of the outflow port would be outward. This is clearly not possible as a steady-state configuration for the phenomenon under consideration. Indeed, if the outflow port velocity was uniformly outward at steady state, then all of the gases within the enclosure would have had to have entered therein as hot leakage gases from the furnace. Thus, a steady state with the neutral plane anywhere below the outflow port implies a bulk enclosure gas temperature which is essentially at furnace temperature 8 .

\footnotetext{
${ }^{8}$ Steady heat transfer from enclosure gases to enclosure surfaces, and then to outside air cannot be expected to drop the temperature of these gases significantly below their original furnace levels.
} 
From figure 17, it is clear that with the present outflow port diameter, with enclosure temperatures of the order of several hundreds of ${ }^{\circ} \mathrm{C}$ or greater (say $\mathrm{K}>1$ ), and for $\lambda<-1$, outflow volume flow rates will exceed $400 \mathrm{~m}^{3} / \mathrm{hr}$. This is inconsistent with the anticipated flow rates which are not likely to exceed $100-200 \mathrm{~m}^{3} / \mathrm{hr}$.

From the latter inconsistency it is now evident that a neutral plane elevation, $z_{n}$, which satisfies $z_{n}<z_{p}-D / 2$ (with corresponding uniformly positive outflow velocities) must be discarded as a possible steady-state scenario in the present DP 5925 test method.

In view of the above, the following conclusions result:

In the steady state configuration the enclosure-to-ambient neutral plane must satisfy

$$
-1 .<\lambda<0.25 \quad \text { or } \quad z_{p}-D / 2<z_{n}<z_{p}+D / 8
$$

As a result of this neutral plane position, the steady velocity of the flow in the cross section of the outflow port will be a strong function of elevation. In the lowest portion of this section there will actually be a layer of air which flows into the enclosure. It is, in fact, this cool, ambient, inflow air which (by mixing with the plumes of the hot leakage gases) would maintain steady-state enclosure temperatures at characteristic levels significantly below furnace temperatures.

Note that the above theoretical conclusions are compatible with the experimental results of section 2 and with the observations below eq. (3).

The DP 5925 procedure for estimating the volume rate of flow out of the enclosure is to measure the velocity at the outflow port axis, $v\left(z_{p}\right)$, and to multiply this by the area of the port. Using eqs. (8) and (9), and defining the average flow velocity through the port as $\bar{v}$, where

$$
\overline{\mathrm{v}}=4 \dot{\mathrm{q}} /\left(\pi \mathrm{D}^{2}\right) \text {, }
$$

the following experimental estimate, $\dot{q}_{\text {est }}$, for $\dot{q}$ can therefore be anticipated

$$
\left|\dot{q}_{\text {est }} / \dot{q}\right|=\left|v\left(z_{p}\right) / \bar{v}\right|=(\pi / 2)|\lambda|^{1 / 2} /\left|\phi(\lambda)-\phi(-\lambda) /(1+K)^{1 / 2}\right|
$$

Using eq. (10), $\dot{q}_{\text {est }} / \dot{q}$ has been plotted in figure 18 as a function of $\lambda$ with $K$ as a parameter. It is evident from this that the experimental estimate for $\dot{q}$ can be in significant error. 
The previous paragraphs of 3.3.3.2 developed a scenario for enclosure flow dynamics that are to be anticipated solely as a result of door assembly leakage (i.e., during test times when cool door surface conditions prevail). As it turns out, a hot door surface, zero leakage scenario would follow much the same lines.

In 3.3.3.2, line plumes of hot leakage gases were considered to be the driving mechanism for the flow. In contrast to this, for the case of a zero leakage hot door surface a purely convective type (i.e., no mass injection), two dimensional plume would be formed. This would start at the bottom of the door and rise in a boundary layer flow all along the hot door surface. The net outflow from the enclosure would be the result of enclosure gases expanding from hot door surface heat transfer. All results and figures discussed in 3.3.3.2 would be entirely relevant.

The scenario anticipated in a real, DP 5925 door assembly test would, of ccurse, involve the combined effects of leakage driven outflow and expansion driven outflow. The actual flow dynamics would be the result of a complicated combination and interaction of leakage line plumes and a two dimensional, vertical surface, wall (door) plume. The results and conclusions of 3.3 .3 .2 would again be relevant.

\subsubsection{A Sumary of the Test Method's Shortcomings}

As a result of the above investigation the following shortcomings of the DP 5925 test method have been identified.

A. The net rate of outflow from the port of the enclosure is a result of two, unknown, time-varying and inseparable components, namely, actual leakage from the furnace and enclosure gas expansion due to hot door surface heat transfer. In general these two components can be of the same order of magnitude.

B. The time to approach quasi-steady-state conditions within the enclosure (subsequent to vent closing) will depend on the door surface temperature and on the door assembly leakage characteristics. In contrast to the suggestion of section 7.3 of DP 5925 , this time will not generally be less than 1 minute. For example, in the present :BS/UL tests even 2 minutes was not generally ample for the development of quasisteady conditions. In this regard, the situation would have been even worse if the door had been specifically designed for "tightness" and/or it had been insulated.

C. Atsuming that a quasi-steady-state condition is reached within the enclosure at a reasnnably short time following vent closure $(e . g$. within a time short enough so tht the unexposed side of the door assembly was not subjected to inordinate heating 
by hot enclosure gases), 1) the velocity distribution in the outflow port cross section will be highly nonuniform with zero velocity occurring somewhere in the lower half; 2) a one point velocity measurement for estimating the net (leakage plus expansion) port outflow can lead to significant errors; and, 3) the vertical distribution of furnace to enclosure pressure differential may be significantly different from that distribution maintained during the open vent portions of the test. For example, if the door sill pressure difference is maintained at zero during the open vent phase, then it will not be zero during the closed vent phase. As a result of this overall variation in pressure distribution, the total leakage flow rate across the assembly can vary significantly depending on whether an open or closed vent condition prevails.

In view of these shortcomings it appears that the DP 5925 test method will not yield reliable estimates for the desired leakage characteristics which it sets out to measure.

\section{AN ALTERNATIVE TEST CONCEPT}

\subsection{The Alternative Test Concept and Its Overall Advantages}

This section will introduce an alternate test method concept for measuring door assembly leakage characteristics. The test method has neither the limitations discussed in section 3.2, nor the shortcomings described in section 3.3. While requiring reasonably steady furnace operating conditions, it does not require furnace pressurization. The test concept represents a universal test method in the sense that a single door assembly test setup could lead to leakage data at low, moderate and high furnace (room of fire origin) temperature and under conditions ranging from small to large pressure differentials.

A sketch of the proposed test concept is presented in figure 19. Various features of this concept are noted on this figure and the most significant ones are discussed below.

\subsection{Significant Features of the Test Concept}

\subsubsection{Continuous Quasi-Steady Operation}

The most important feature of the test concept is the fact that it involves a continuously quasi-steady operating procedure. Thus, to a good approximation and at all times during the course of the test, steady-state mass balance can be correctly applied to the enclosure.

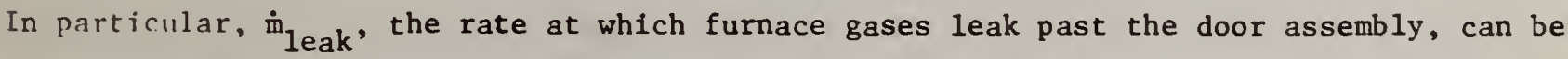
computed irom

$$
\dot{\mathrm{m}}_{\text {leak }}=\dot{\mathrm{m}}_{\text {exit }}-\dot{\mathrm{m}}_{\text {in }}
$$

where, as indicated in figure $19, \dot{\mathrm{m}}_{\text {exit }}$ and $\dot{\mathrm{m}}_{\text {in }}$ are the measured mass rates of gas flow into and out of the enclosure. 


\subsubsection{Accurate Simulation of Ambient Conditions}

In order for the test to provide a reasonably accurate simulation of the door assembly response to a real fire scenario, the temperature history of the unexposed surface of the assembly must be properly simulated. This temperature history will, of course, depend on the history of the rate of heat transfer from the assembly surface. But the rate of heat transfer is controlled by the ambient conditions. Thus, simulation of the door assembly response requires simulation, in the enclosure, of the significant features of typical adjacent room ambient conditions.

Independent of any specific door assembly of interest and independent of the pressure difference across it, the ambient condition characteristics which will lead to an appropriate simulation of the desired heat transfer are 1) maintaining the enclosure surfaces at room temperature, and 2) maintaining zero to low velocity room temperature air at positions away from the immediate vicinity of the door surface. The first of these characteristics is to ensure simulation of radiant energy exchange between the hot door surface and the cool bounding surfaces of an adjacent (to room of fire origin) space. The second of these characteristics is to ensure simulation of natural convection heat transfer from an elevated temperature door surface to a (relatively) quiescent, ambient temperature, adjacent room atmosphere.

With regard to the second of the above characteristics, low velocity is intended to mean a velocity which is, at most, characteristic of normal room draft velocities. It is also intended to mean a velocity that is small relative to characteristic velocities in the convective door surface boundary layer at times when convective heat transfer becomes significant. In general, air velocities of the order of $0.1 \mathrm{~m} / \mathrm{sec}$ or less will satisfy the low velocity criteria. Thus, for the present purposes, no significant variation in convective heat transfer is anticipated if the ambient velocities vary with this range. As will be seen, the allowable flexibility $(0-0.1 \mathrm{~m} / \mathrm{sec})$ in upward air velocity would be taken advantage of in the design of enclosure ventilation control.

As indicated in figure 19, both of the above ambient condition characteristics are a design feature of the enclosure test fixture. Enclosure surfaces are maintained near room temperature by forced cooling, either air (from fans on the outside) or water. The enclosure environment is continuously and slowly flushed from bottom to top by clean, cool, low velocity air.

Besldes perforining the prime function of door assembly heat transfer simulation, cool operating conditions for the enclosure structure would lead to its general endurance and Inng life. 
The proposed test method is conceived in a manner as to permit continuous and precise control of the furnace-to-enclosure pressure differential during the entire course of a test, and this without any adjustment or control of furnace pressure. As indicated in figure 19, this pressure control is accomplished by varying the flow resistance of the upper fan-duct system. The control would be done either manually or automatically and in a manner as to continuously maintain the enclosure pressure (i.e., the furnace-to-enclosure pressure differentia1) at any desired value.

Assume, for example, that one wished to study leakage resulting from a configuration where the elevation of the neutral plane is at the door sill (as is the objective of the DP 5925 Part 3 test method). Then, throughout the course of the test, the upper duct valve would be continuously adjusted in a manner as to maintain this pressure differential condition. (Valve adjustments would definitely be required as the door assembly leakage characteristics were altered due to continued fire exposure.) Alternatively, by a proper (large) opening of the valve, the enclosure pressure could be easily maintained at a negative pressure relative to ambient. In this manner, a relatively large furnace-toenclosure pressure differential could be imposed across the door assembly, thereby simulating the characteristic, high-rise building over-pressure phenomenology discussed in section 2 .

By proper component selection, the lower fan-duct-flowmeter system at the enclosure inlet would be designed so that the mass flow rate of air passing into the enclosure would be relatively insensitive to the above-mentioned variations of enclosure pressure. That this can be easily achieved is evident from the following observations. First notice that the enclosure pressure would always be required to stay within the bounds, say,

$$
\begin{aligned}
& -0.4 \text { in }_{\mathrm{w}}<\mathrm{P}_{\text {encl }}-\mathrm{P}_{\text {amb }}<0 \\
& -100 \mathrm{~Pa}<\mathrm{P}_{\text {encl }}-\mathrm{P}_{\text {amb }}<0
\end{aligned}
$$

Now assume that the lower flowmeter and duct is designed so that the fan delivers a desired rate of inlet air, $\dot{\mathrm{m}}_{\mathrm{in}}$, from the ambient while overcoming a pressure drop of, say, 5 to 10 in $_{\mathrm{w}}=1250$ to 2500 pascals. If $\mathrm{P}_{\text {encl }}$ is maintained within the above relatively narrow range, it is evident that with the use of such ventilation components the mass rate of air actually delivered to the enclosure would vary by a relatively small amount from the design $\dot{\mathrm{m}}_{\mathrm{in}}$ value. As noted in the previous paragraph, moderate variations in the mass rate of air flow (i.e., in the upward enclosure air velocity) do not upset the desired simulation of the door assembly response.

In view of all the above, it is evident that, with proper design the single upper valve actually provides both rapid response and universal control of the furnace-toenclosure pressure differential. The significant implication of all this is contained in 
the following sumary conclusion:

A device of this design is capable of providing a predetermined, rapid response furnace-to-enclosure pressure differential during the course of a standard, door assembly fire endurance test. With such a capability, a total evaluation of the subject door assembly leakage characteristics could be obtained.

\subsubsection{Accuracy of the Leakage Measurement}

Having described the basic test concept and some of the rationale for the design of

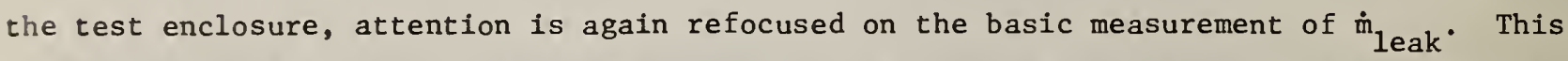
is embodied in eq. (11). Thus, the accuracy of determining $\dot{m}_{1 e a k}$ at any instant of time is dependent on the accuracy of measuring $\dot{\mathrm{m}}_{\text {exit }}-\dot{\mathrm{m}}_{\text {in }}$.

Within reasonable limits, the basic test configuration is such as to permit $\dot{m}_{\text {exit }}$ and $\dot{\mathrm{m}}_{\text {in }}$ measurements of any desired accuracy. The key to this capability lies in the fact that the pressure drop in both the upper and lower flowmeter-duct systems can be designed to be arbitrarily large. (Whatever the magnitude of the desired pressure drop, an appropriate fan would be selected to overcome it.) With the availability of a large pressure drop, an appropriate flowmeter (and associated pressure measuring instrumentation) can be selected which would provide any reasonable desired degree of accuracy in the measurement of the mass flow rates.

\section{SUMMARY}

This investigation of the measurement of door assembly smoke leakage has been presented in four major sections.

In the first section a basis for relating overall intrabuilding smoke migration dynamics to high temperature compartment partition smoke leakage measurements was formulated. The approach taken was to develop the concept of smoke compartmentation, and to identify and discuss the implications of the two different smoke migration phenomena that would be in effect on each side - the fire side and the protected side - of the leaking compartment partition.

The second section presented the results of applying the tentative, high temperature ISO test method DP 5925. This test method was designed to measure the smoke leakage of door assemblies during the course of a standard fire exposure. As was seen, these results led to unanswered questions regarding the validity of the test method. In order to answer urse questions, further testing and an in-depth analysis of the test method was carried i18. The results of the further testing were reported in section 2. 
The analysis of the DP 5925 Part 3 test method was presented in the third section. As concluded in section 3.2, the basic test method as written was found to be limited in practice. In particular, the test objective, even if attained, would not result in a clear evaluation of the performance of door assemblies during fire scenarios where standard, high-rise building, stack effects come into play.

Perhaps more significantly, serious theoretical problems with the test and its procedures were identified in section 3.3. Taken all together, these latter problems led to the following conclusion: For door assemblies where enclosure gas temperatures during quasisteady conditions do not approach the level of furnace temperatures, and where such quasisteady conditions are attained within a few minutes of vent closure, the basic DP 5925 Part 3 test method can potentially yield rough estimates for the desired smoke leakage characteristics which it sets out to measure. However, to accomplish this, significant additional data would have to be acquired. For example, once quasi-steady conditions prevail, the net enclosure outflow could be estimated from figure 17 once the elevation of the neutral plane (i.e., the position of zero velocity) within an outflow duct cross section and the temperature of the enclosure gas near the general vicinity of this elevation was determined.

An alternate test concept has been formulated which removes the limitation and theoretical problems of the DP 5925 Part 3 test method. This concept was presented in figure 19 and in section 4 wherein several of its significant features were identified and briefly discussed. The concept holds promise as a universal type of test method in the sense that a single door assembly setup would lead to reliable leakage data throughout the entire course of a fire endurance test, and under conditions ranging from small to large pressure differentials. Moreover, the test concept is not restricted only to the evaluation of door assembly leakage characteristics. Indeed, it could also be used to evaluate the leakage characteristics of overall wall and floor assemblies. In short, it is strongly recommended that the alternate test concept be developed to the point where its apparent potential promise can be evaluated in a more tangible manner.

\section{ACKNOWLEDGEMENTS}

Th:t author gratefully acknowledges Mr. Lionel A. Issen of Construction Fire Research, CFR/NBS who provided all liaison between UL and NBS during the course of the test program and who transmitted and decoded all of the data that was acquired. Also acknowledged are those members of the UL staff, notably Mr. Robert M. Berhinig, Engineering Group Leader, who carried out the tests described herein with the flexibility that was required by 11)ture of the task at hand. 


\section{REFERENCES}

[1] Cooper, L. Y., A method for estimating safe avallable egress time from a workspace, Nat. Bur. Stand. (U.S.), to be published as NBSIR.

[2] Dekker, J. and Haffmans, L., Comments on ISO DP 5925 Parts 2 and 3 Recelved from TNO, ISO/TC 92/WG 3 N 209, Sept. 1978. (unpublished committee report)

[3] Keough, J. J., Air Leakage Through Doors, Report of the Department of Works, Commonwealth Exp. Bldg. Sta., Chatswood, NSW, Australia (Nov. 1972).

[4] Dekker, J., Results of Alr Leakage and Fire Tests on Doors, ISO/TC 92/WG 3 (Finland-2) 106 (March 1973). (unpublished committee report)

[5] Baines, W. D. and Turner, J. S., Turbulent Buoyant Convection From a Source in a Confined Region, J. Fluid Mech., Vol. 37, Part I (1969).

[6] Zukoski, E. E., Development of a Stratified Ceiling Layer in the Early Stages of a Closed Room Fire, Fire and Materials, Vol. 2 (April 1978).

[7] Zukoski, E. E. and Kubota, T., A Computer Model for Fluid Dynamic Aspects of a Transient Fire in a Two Room Structure, Cal. Inst. of Tech. Jet Propulsion Center Report, NBS Grant 5-9004 (June 1978).

[8] Kawagoe, K., Fire Behavior in Rooms, (Japan) Bldg. Res. Inst., Report No. 27 (Sept. 1958).

[9] Prah1, J. and Emmons, H. W., Fire Induced Flow Through an Opening, Combustion and Flame, Vol. 25, No. 3 (Dec. 1975).

[10] Quintiere, J., Growth of Fire in Building Compartments, Fire Standards and Safety, ASTM STP 614, A. F. Robertson, ed., American Society for Testing and Materials (1977).

[11] Rockett, J. A., Fire Induced Gas Flow in an Enclosure, Combustion Science and Technology, Vo1. 12 (1976).

[12] Eckert, E. R. G. and Jackson, T. W., Analysis of Turbulent Free Convection Boundary Layer on Flat Plate, NACA Technical Note 2207 (1950). 


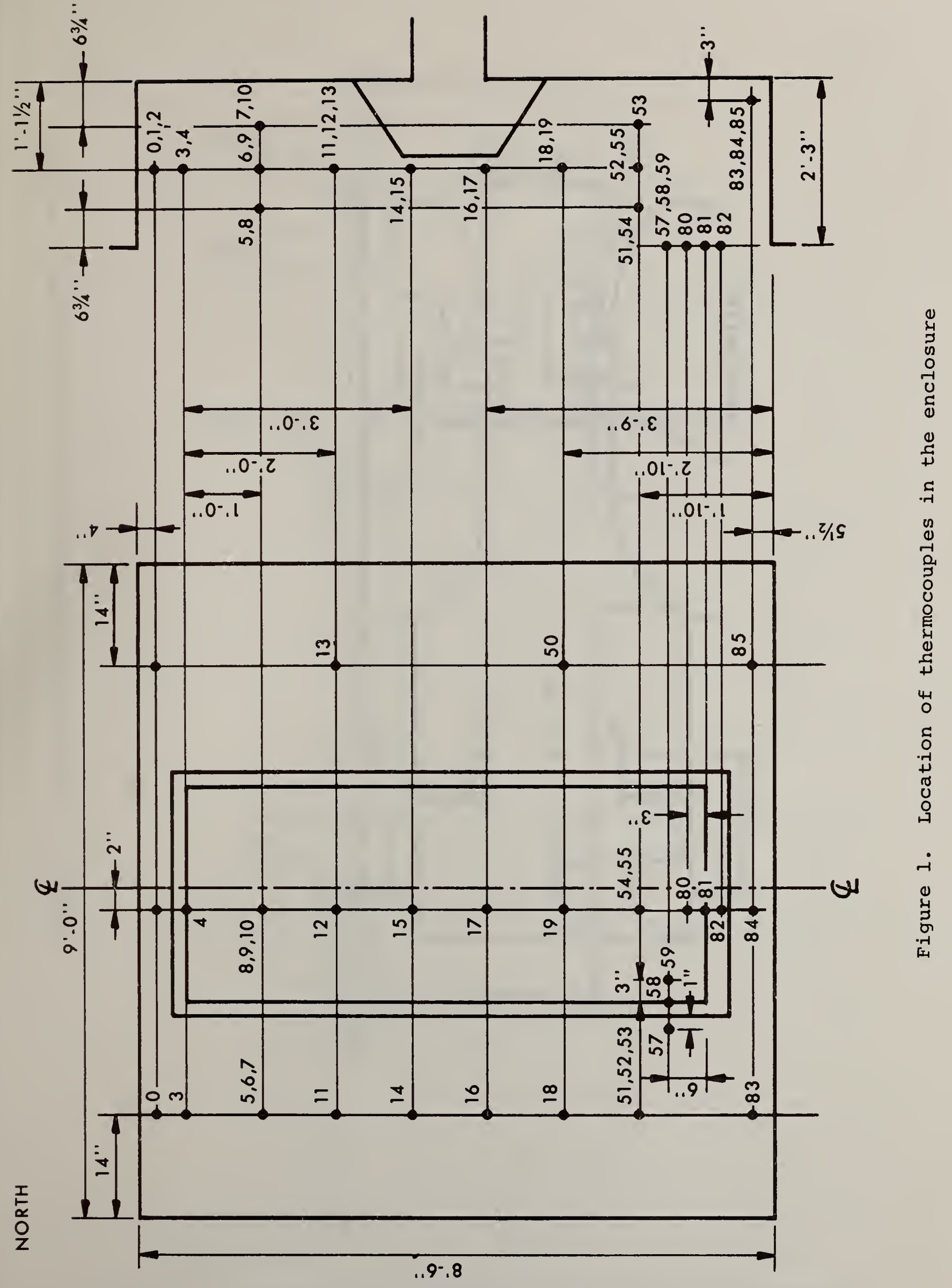




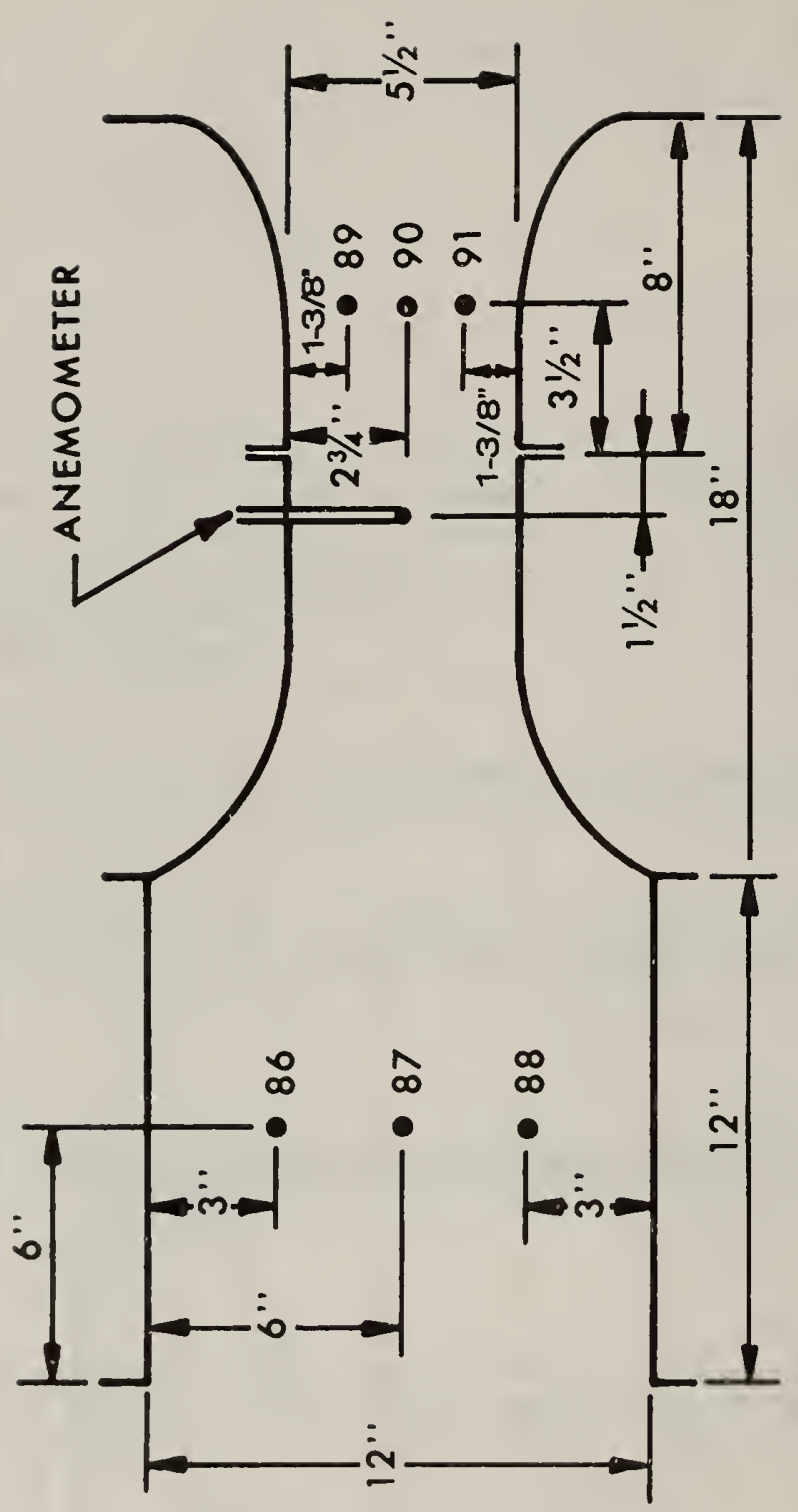

O) 


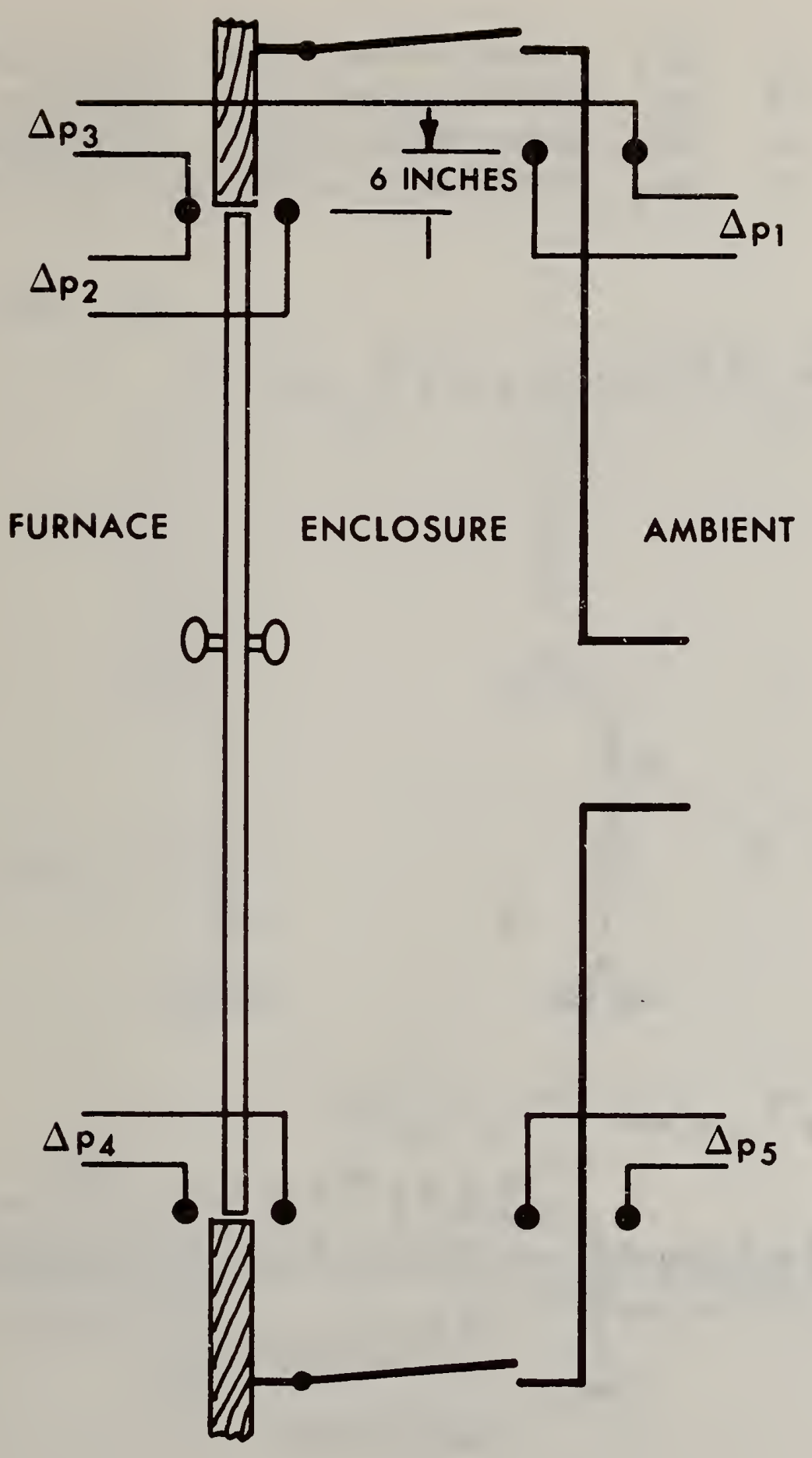

Figure 3. Location of pressure differential measurements 


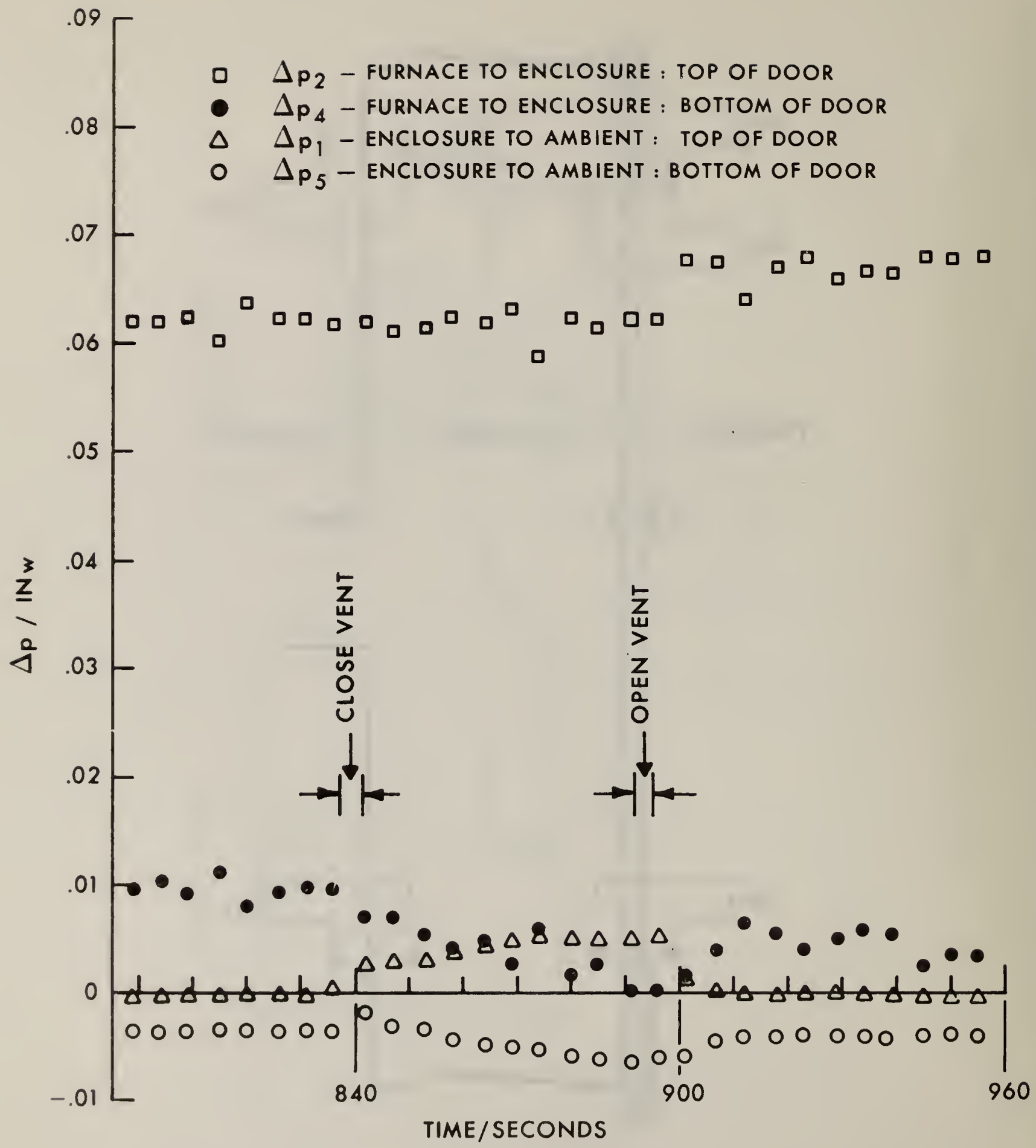

Figure 4. Various $\Delta \mathrm{P}^{\prime} \mathrm{s}$ during 840-900-second closed vent interval 


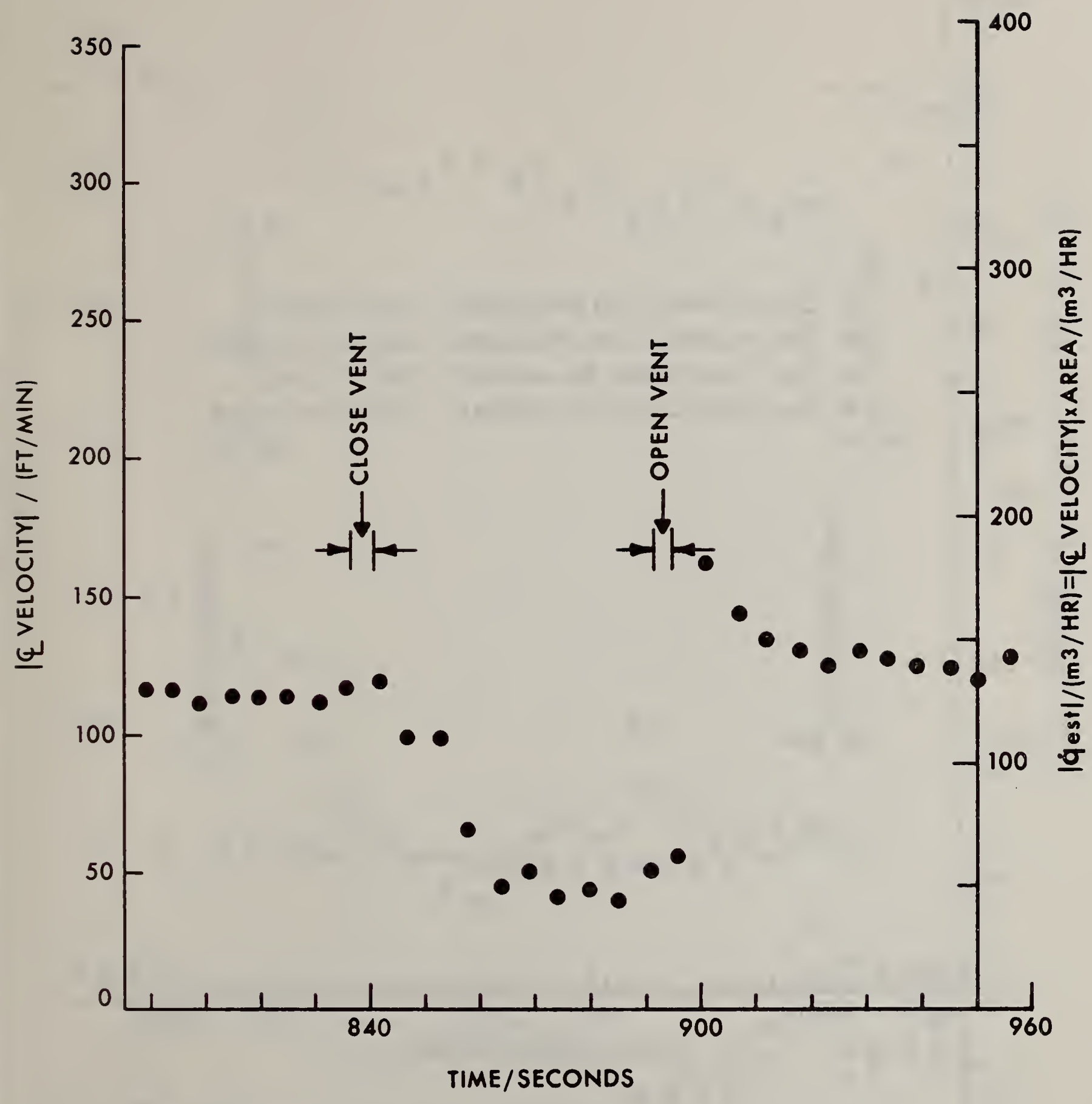

witflow velocity during 840-900-second closed vent interval 


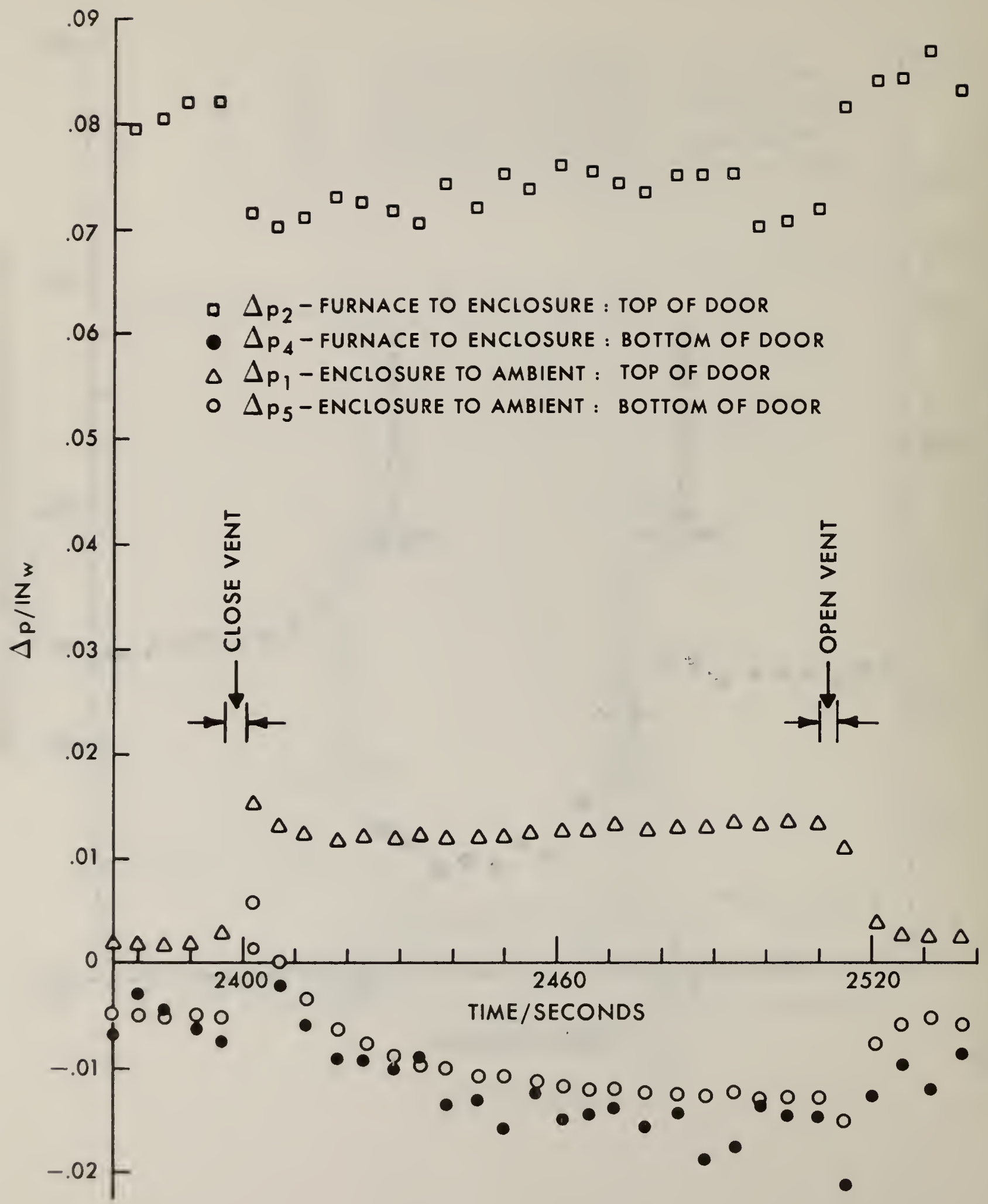

Figure 6 . Various $\Delta \mathrm{P}^{\prime} \mathrm{s}$ during 2400-2520-second closed vent interval 


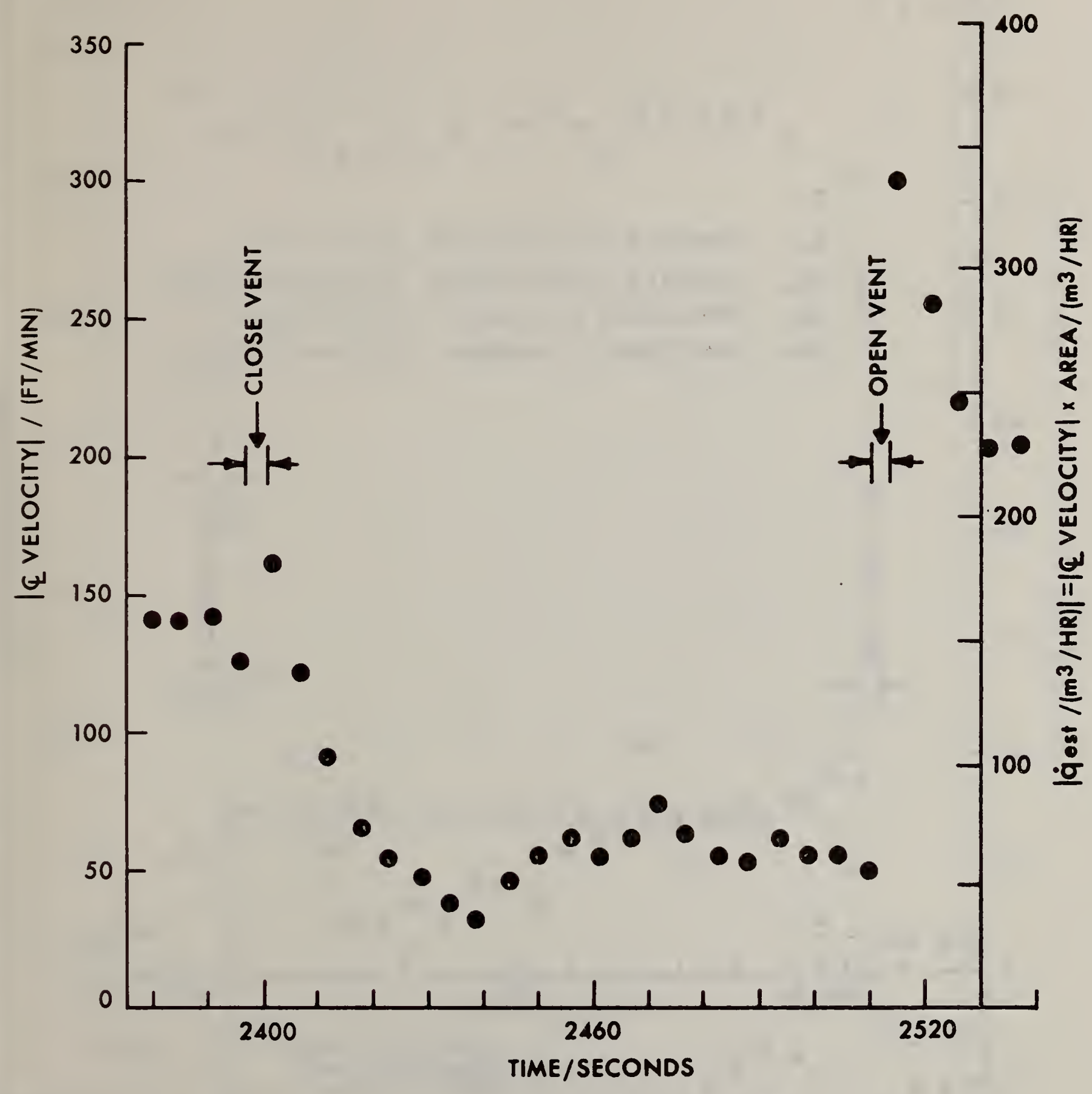

Figure 7. Outflow velocity during 2400-2520-second closed vent interval 


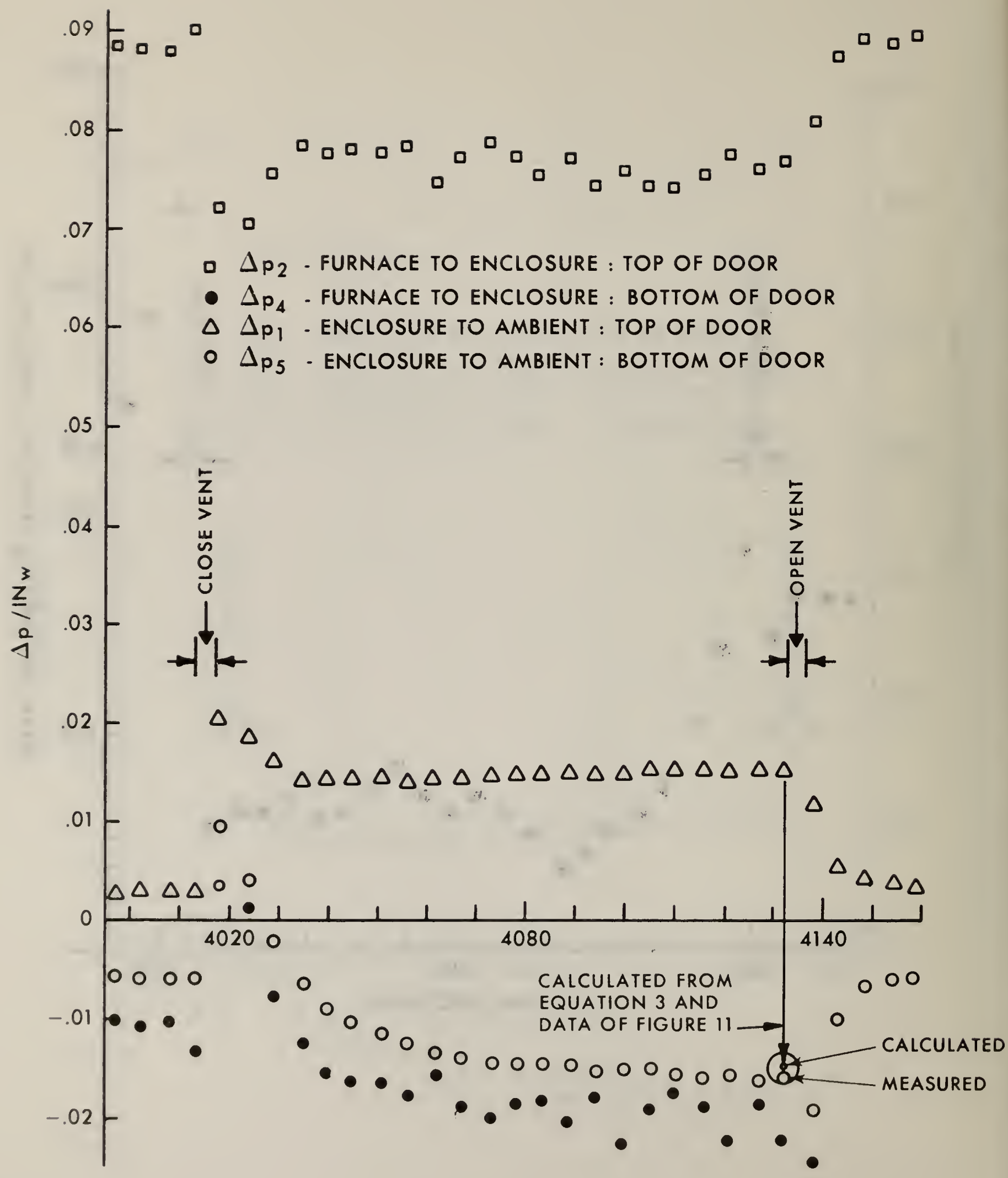

Figure 8. Various $\Delta \mathrm{P}^{\prime} \mathrm{s}$ during 4020-4140-second closed vent interval 


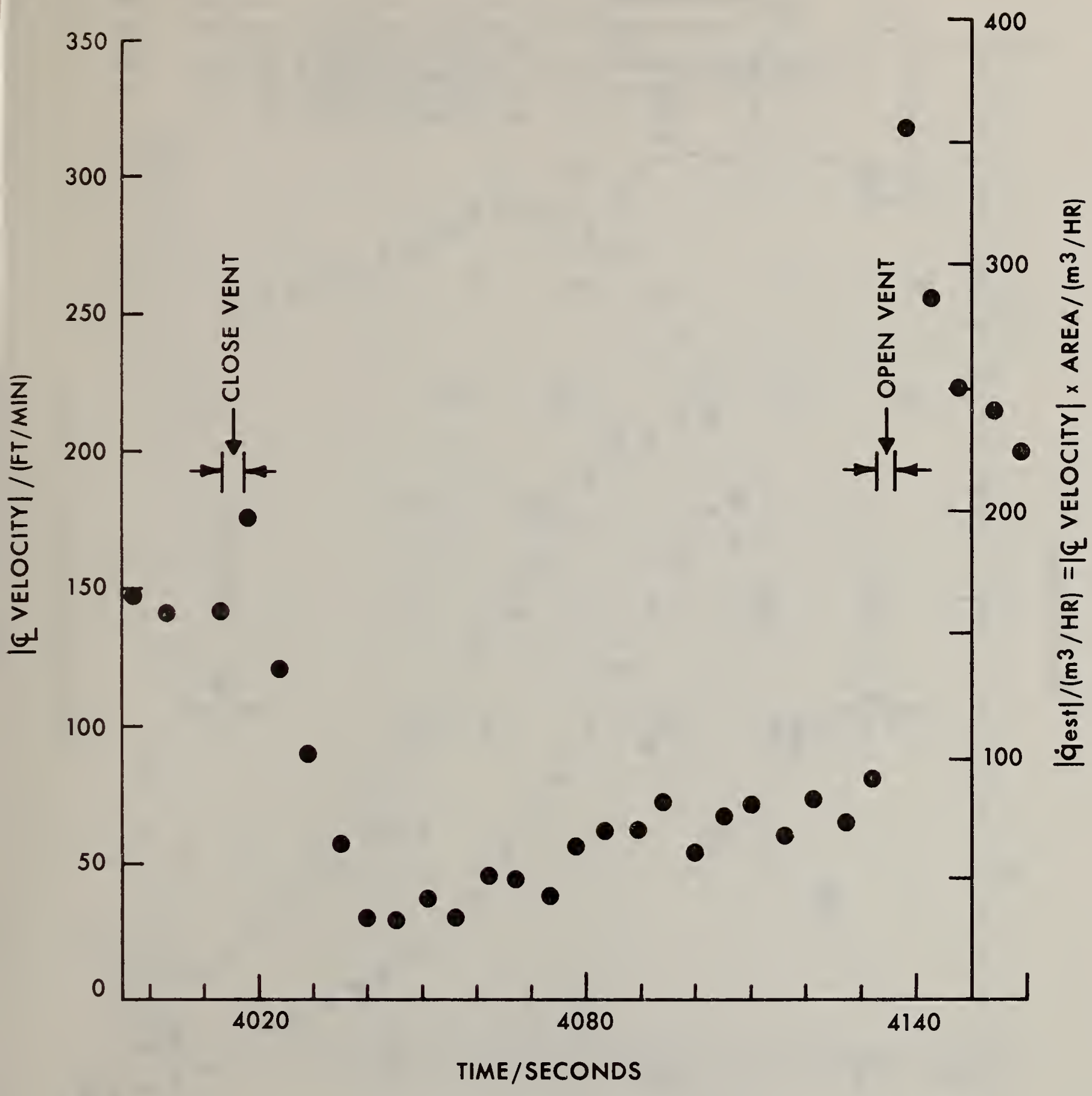

Figure 9. ()utflow velocity during 4020-4140-second closed vent interval 


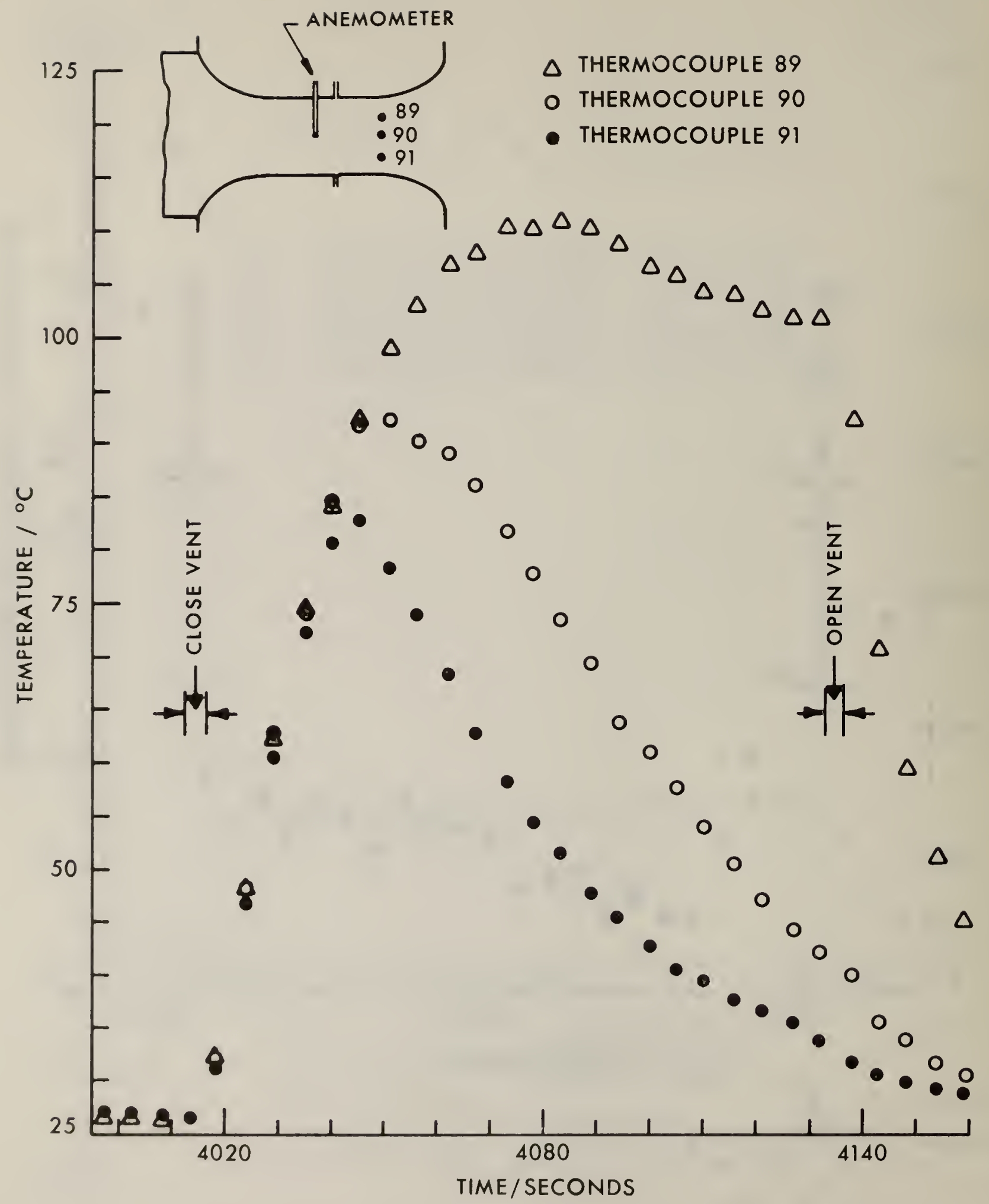

rigure 10. Venturi throat thermocouple temperatures during 4020-4140-second closed vent interval 
$\triangle 4013$ SEC. INTO TEST - IMMEDIATELY BEFORE VENT CLOSE

- 4040 SEC. INTO TEST - 27 SEC. FOLLOWING VENT CLOSE

口 4073 SEC. INTO TEST - 60 SEC. FOLLOWING VENT CLOSE

4105 SEC. INTO TEST - 92 SEC. FOLLOWING VENT CLOSE

O 4132 SEC. INTO TEST - 119 SEC. FOLLOWING VENT CLOSE

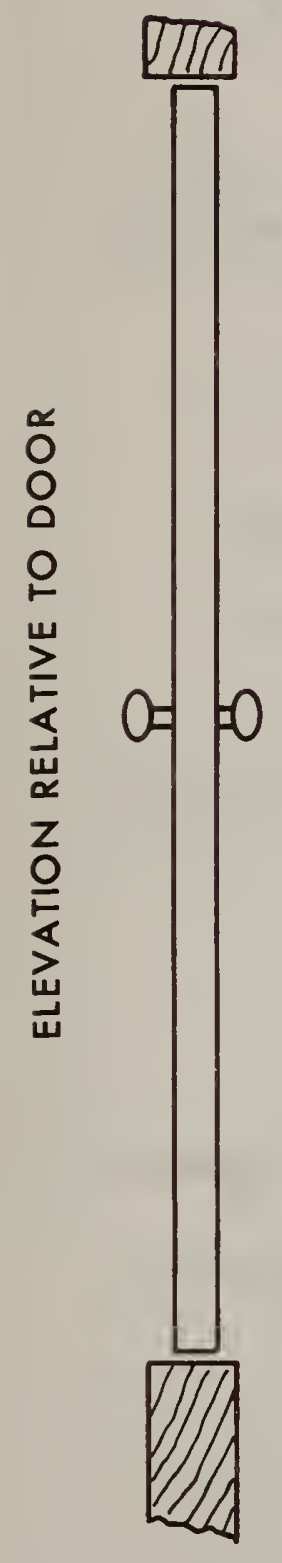

$\Delta$

$\Delta$

$\Delta$

$\Delta$

$\Delta$

$\Delta$

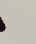

\begin{abstract}
$\Delta$
\end{abstract}
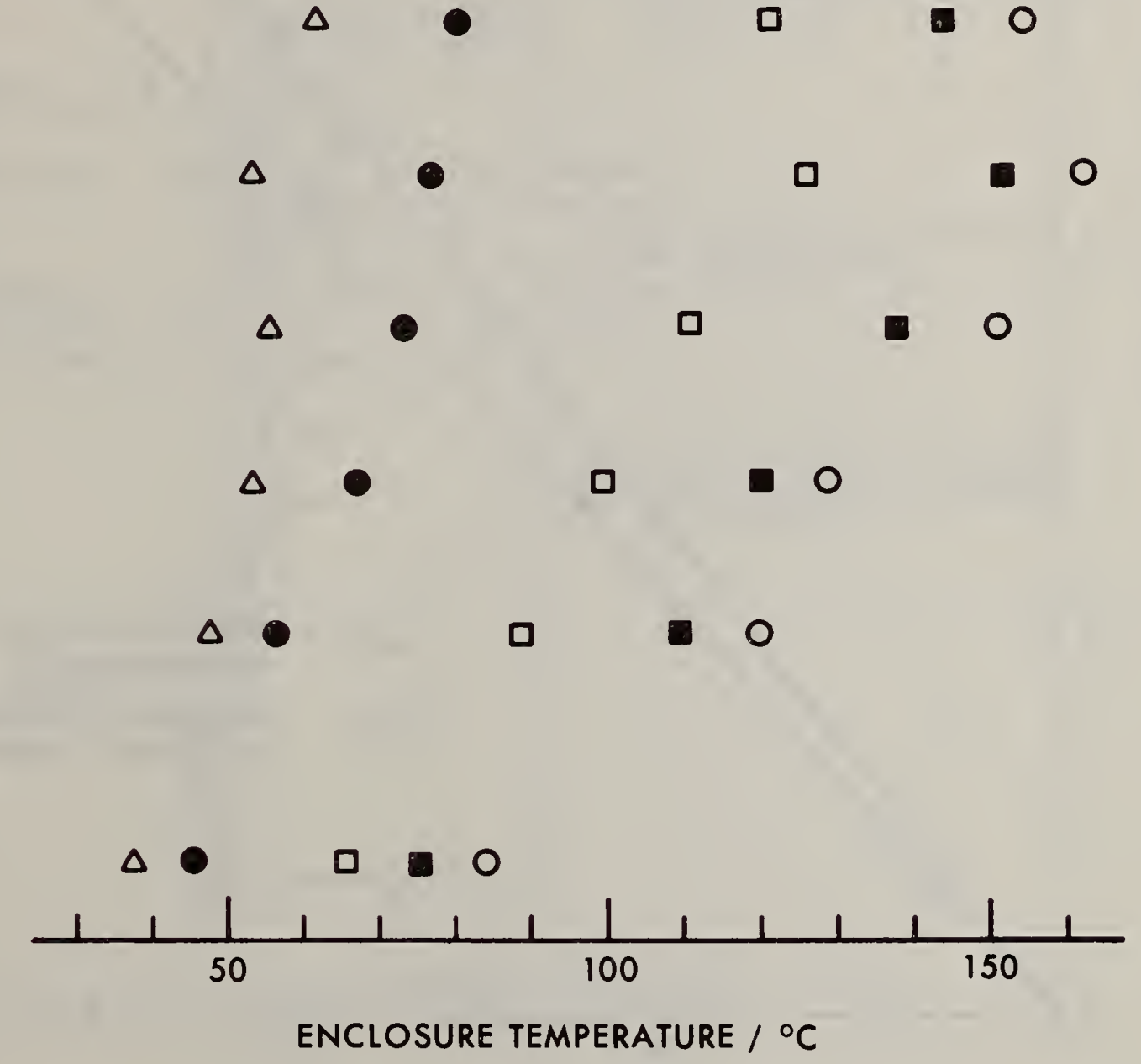

口

- 0

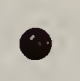

口

10

.

口

- 0

Figure 11. Enclosure temperature as a function of elevation during the 4020-4140-second closed vent interval 


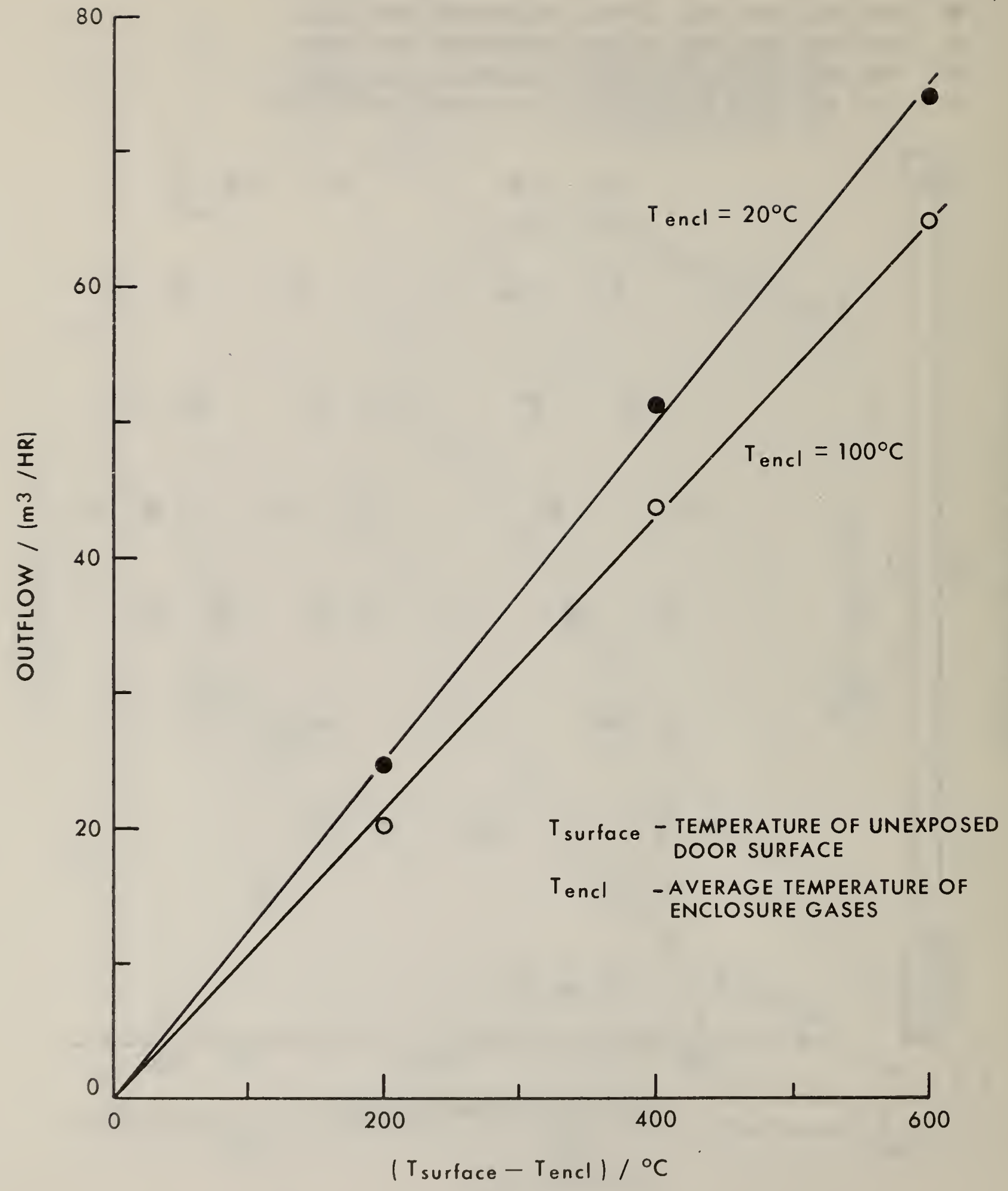

Figure 12. Estimates of outflow due solely to expansion for a door of dimension $1 \mathrm{~m} \times 2 \mathrm{~m}$ 


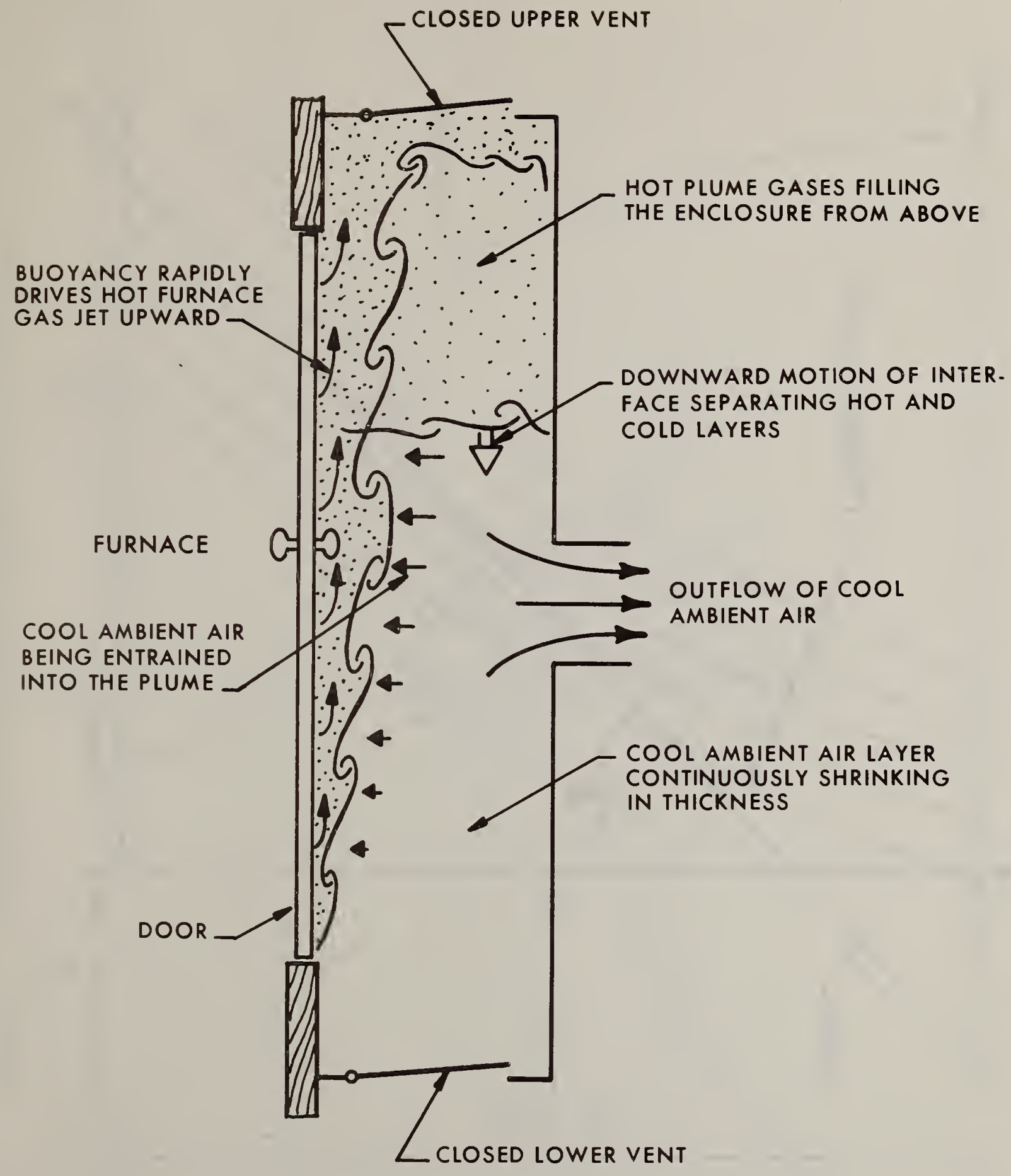

Figure 13. Idealized model of flow within the enclosure shortly after vent closure 


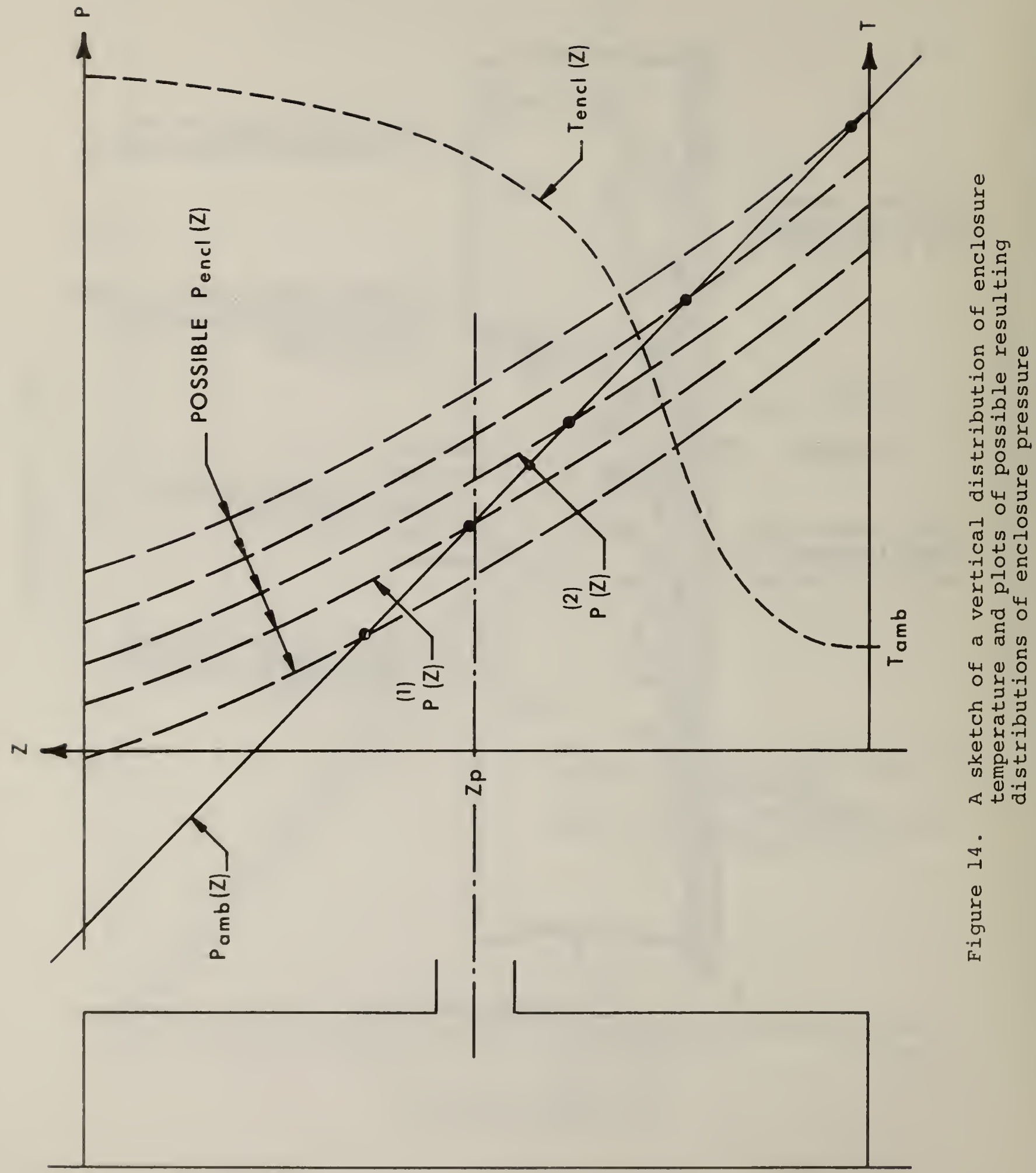




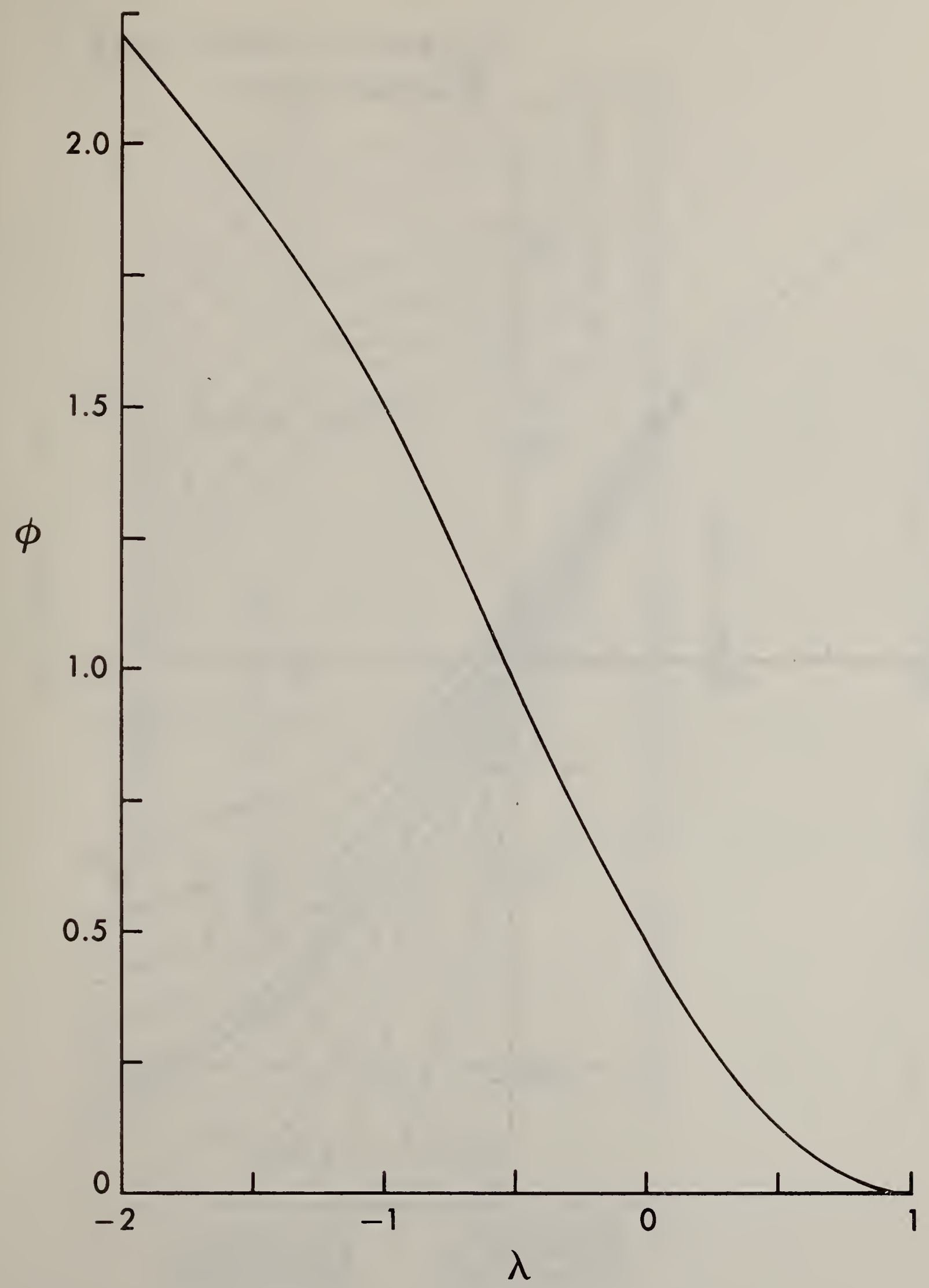

Figure 15. Plot of $\phi(\lambda)$ defined in eq. (9) 


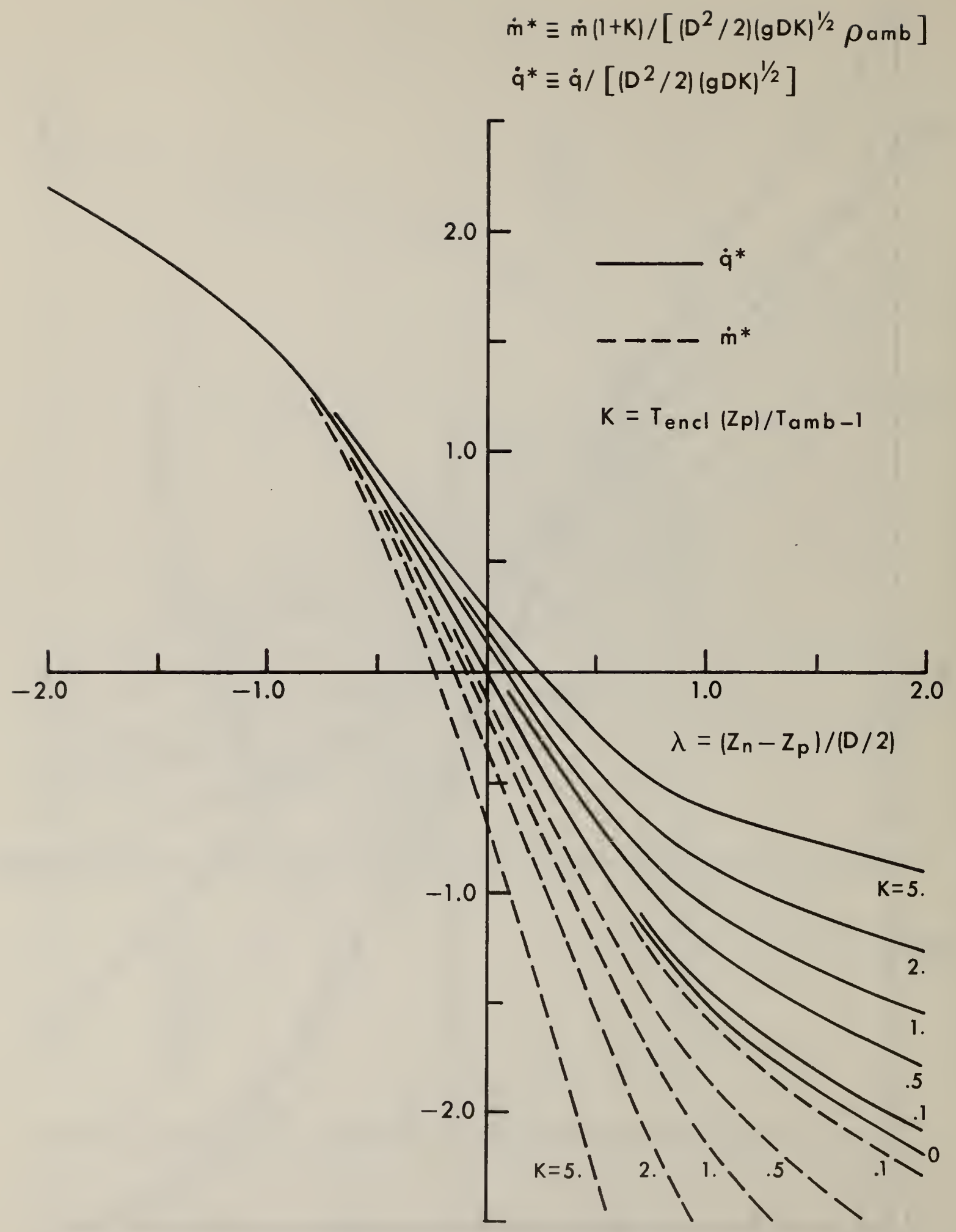

Figure 16. Plots of $\dot{\mathrm{m}}^{*}$ and $\dot{q}^{*}$ as functions of $\lambda$ with $\mathrm{K}$ as a parameter. See eq. (9). 


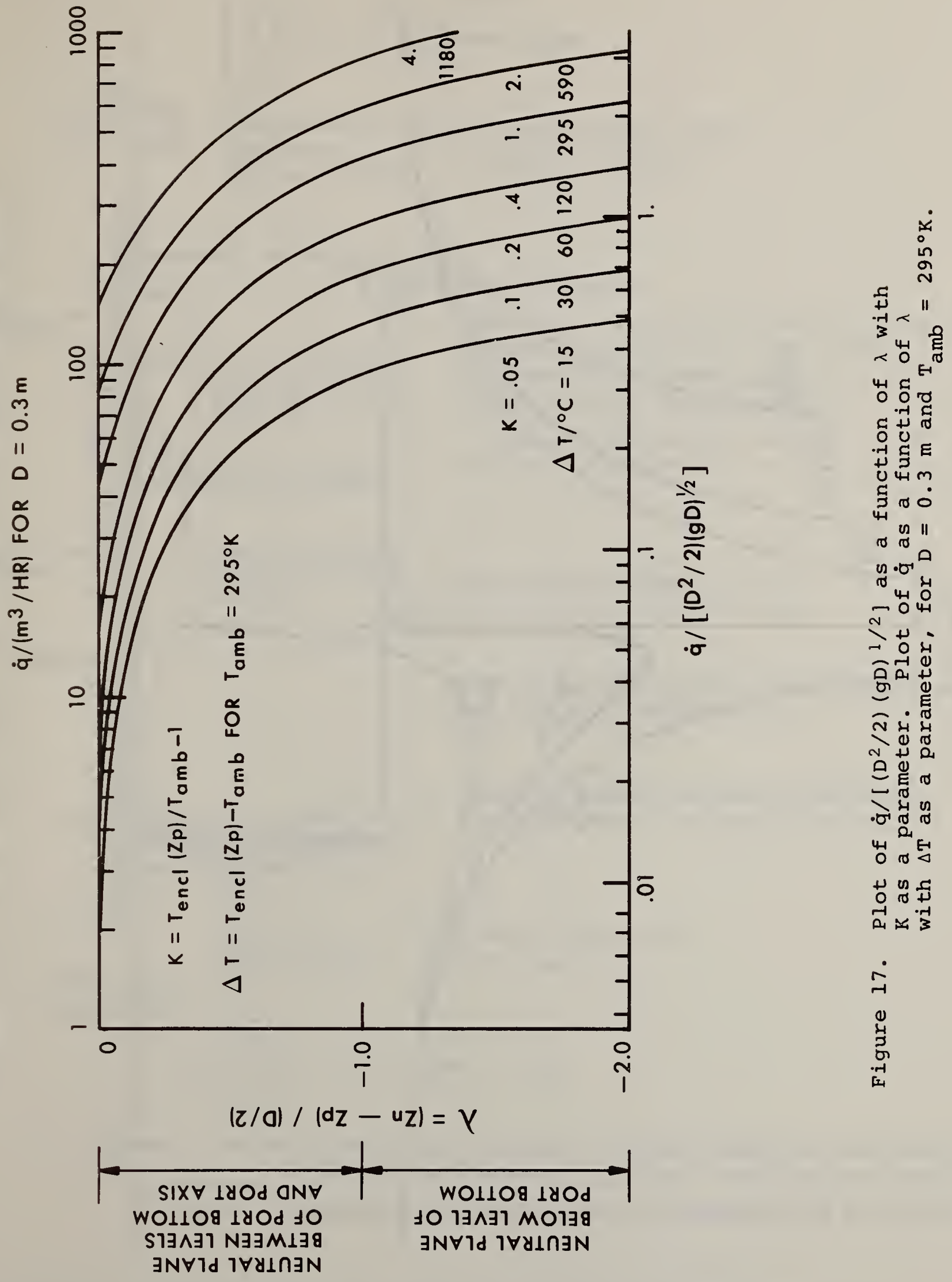




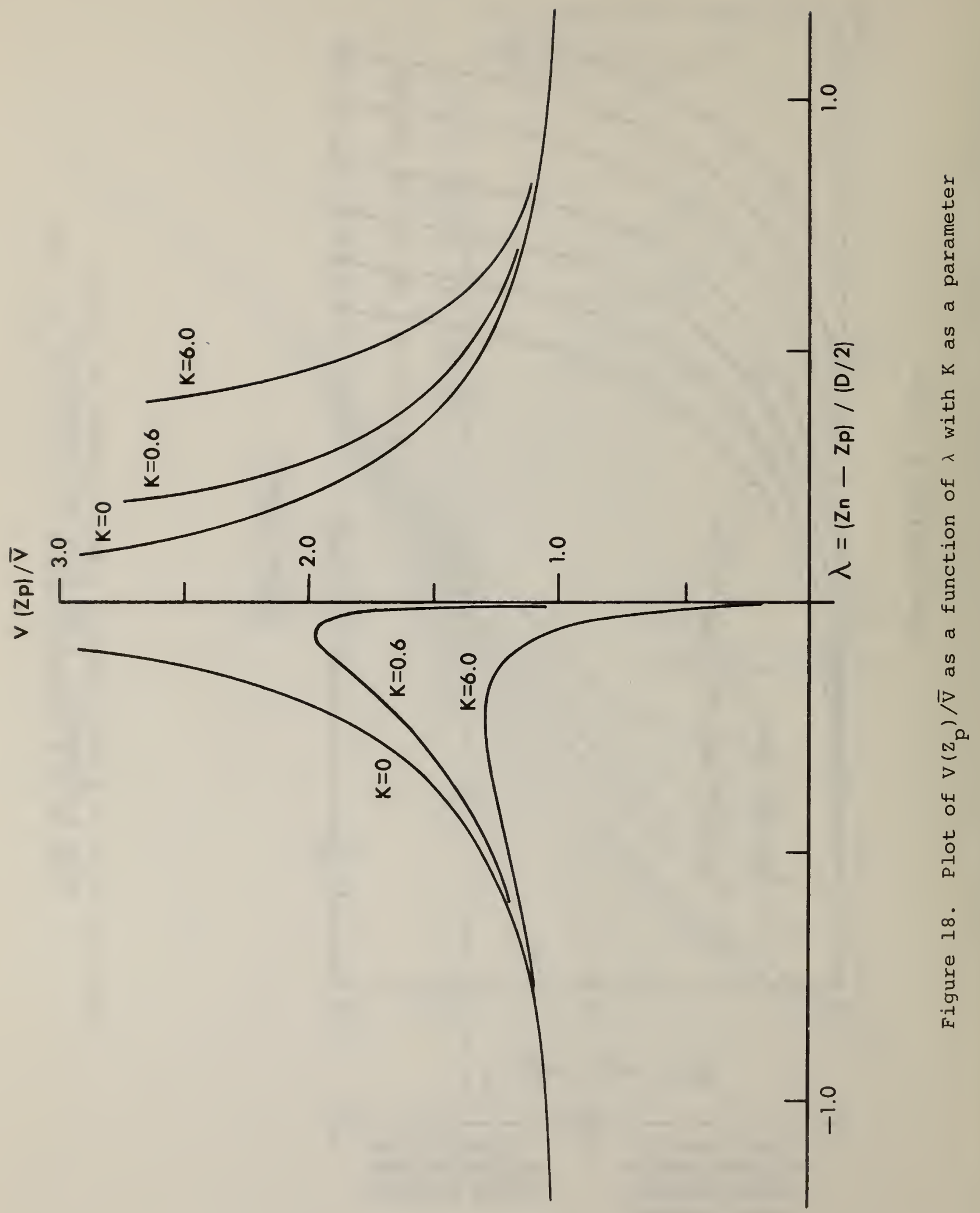




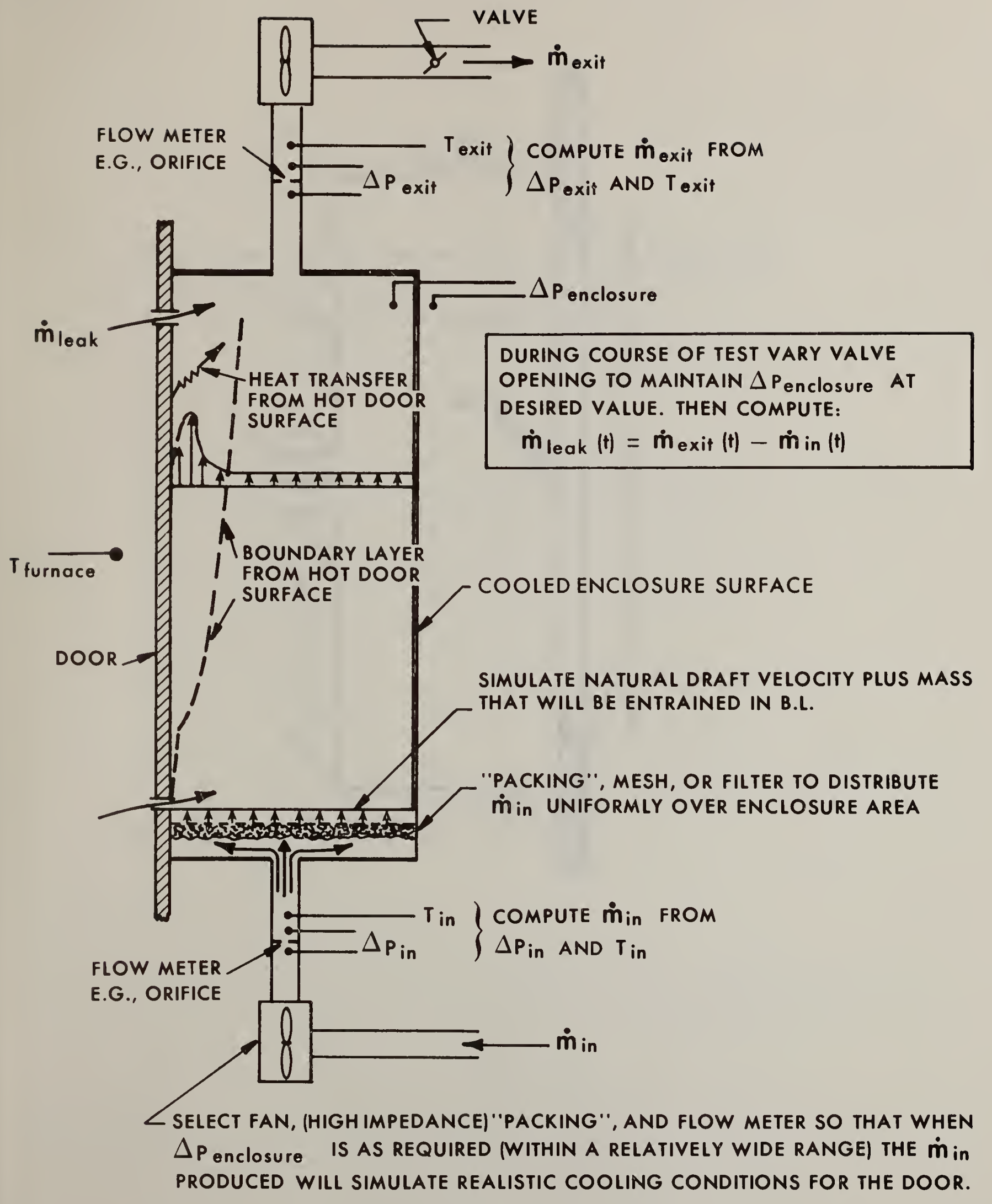

Figure 19. A test concept for measuring leakage of door assemblies during standard fire endurance tests 


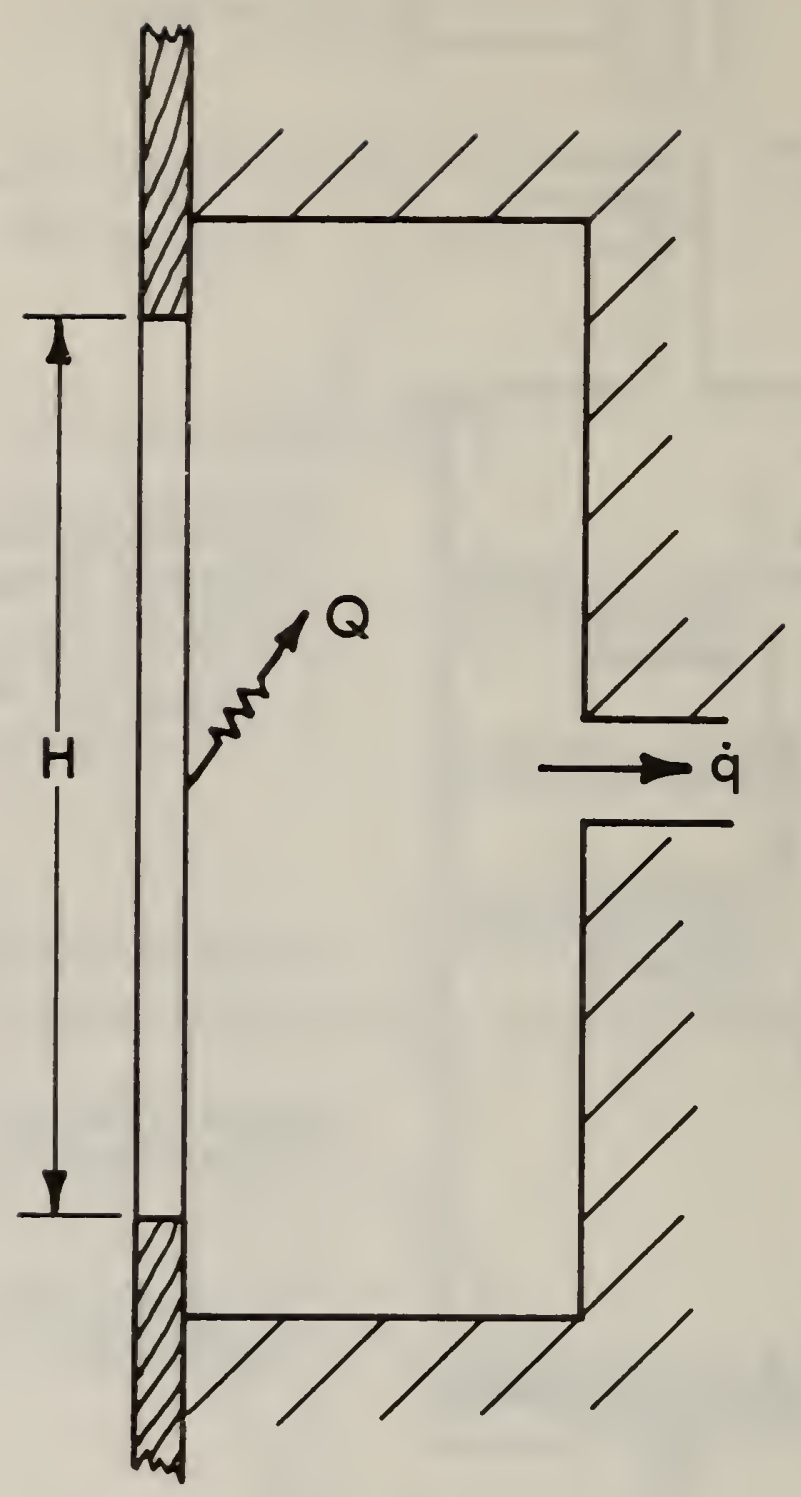

Figure 20. Model for determining the rate of outflow, $\dot{q}$, which is associated solely with the heat transfer rate, Q 


\section{APPENDIX A}

ISO/TC 92/WG $3 \mathrm{~N}$ 203. DP 5925 FIRE TESTS -- SMOKE CONTROL DOOR ASSEMBLIES. PART 3. HIGH TEMPERATURE TEST

(REVISION OF DOCUMENT N 189) 
INTERNATICNAL URGAVIZATION FOR STANDAÖDILATION ORGANISATION INTERNATIONALE DE NORMALISATION

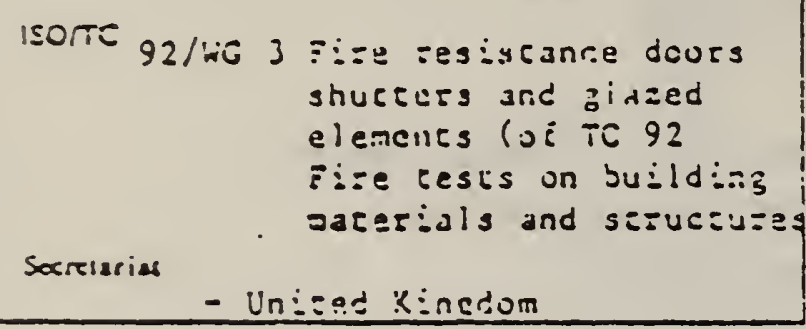

Socresarias

FRON: BRITISHSTANDARDSINST:TUTION IPAAK STREET LONOON WIA :IS

Teleptome: 01.5:99000

Felegrams: STANDARDSLONCONWI

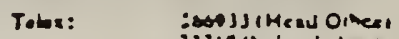

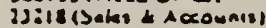

DP S925 EIRE TESTS - SYOLE CONTROL ICOR ASSEYBLIES

PART 3. HICH TEMI'LATURE TEST (ReVis:on of document Y 189)

COHTE:IS

Forevord

2. Scope and $5:$ idd of applicasion

2. Desininituns

3. Test principle

4. Apparatis

s. bicsazaciun ui iest specimens

6. Calibraciun

7. P=occlure

8. icsi tesules

9. Test repure

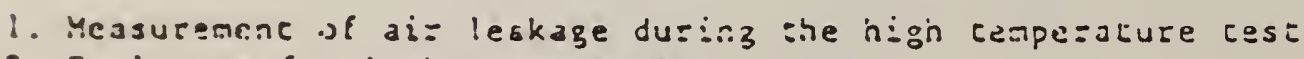

2. Enclusure ijer leakiga race meazugunent

3. Enslusurc anc iurrace surzuund

4. Calibration í enciusure 
(Tire firse yase or the roreiorj is prepared by ISO Cancral Secretariat giving decails of the merijer jodies wirich epproved the proposal.;

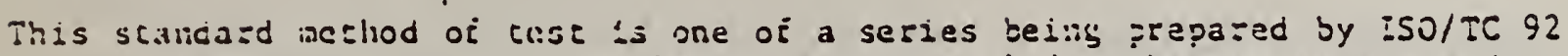

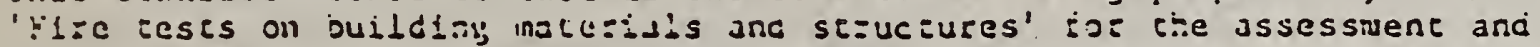
evaluation of the pejormurce or foor ussemblies intenced to act as barziezs to smoke is sisc.

The severity of the hear exposure and test condiciuns foverns the saoke sont:0i

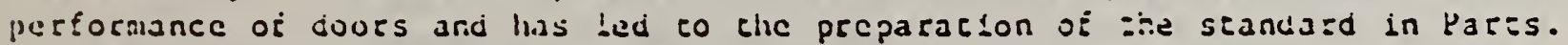
gurther expldustious and guidance on chis and other consicerasions are gi\%en i.s U2 5925: jart 0. Luboracuslas are advised ro acquain: chenselves wic! the concents of the commentary jeiore using any of the cests in this jerles.

Th!s standard spectifies a jethod of lesting and evailating the perforance of door and sintice assemblies iacended to ace as bargters to swoxe under hion

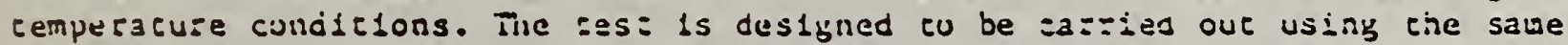
furmace and jenerally uncer the condizions of the cest specticied in ISO 30081). Il cous noc, huweve:, adope the same pressuze concitions as ISO JUU8, arad scme aspects of tie ISO j008 test (e.z. Eozion pad cese) are omicred. Furblic: ceses in the serles are being proparec es Solluws:

DP 5925 kire cescs - Snoke concrol coor asiemolies

Pare 1. Ambien: imperacure cest.

Dl 5925 Hife ceses - Sisoive concrol door assemciles

Part 2. Mediun iasperasira test.

NoTt - So that sulcable precauciors to safeguari teajin of iast person:ie: may be izken, the actention of ali concerned it:e lases is drawn to the

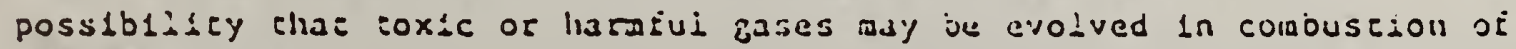
cesc elemencs.

\section{SCUYE AND FIELD CE AYMLICATECN}

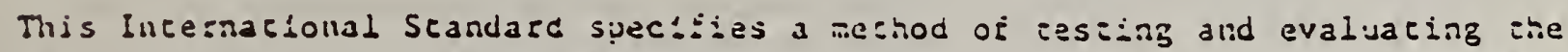

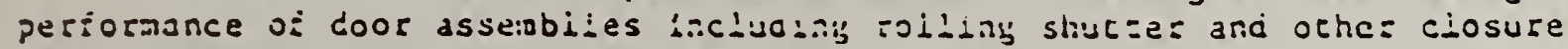

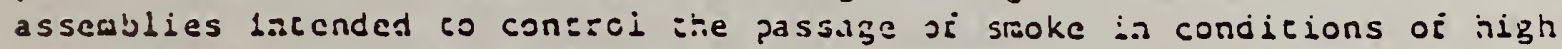

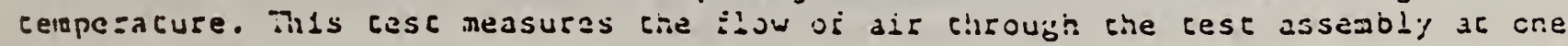
pressure level.

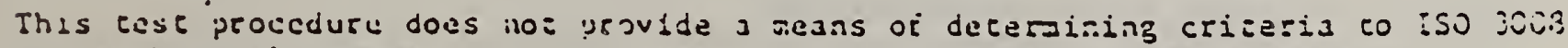

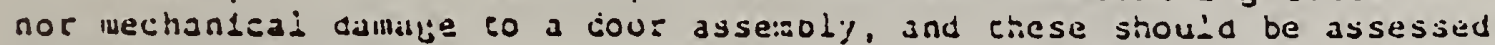

sciala 5 Let $1 \%$.

1)

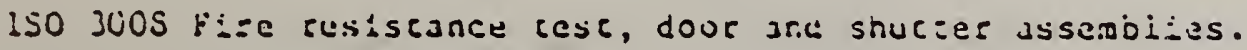




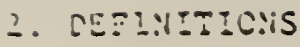

Gor the pusposic of this hicezazional standard, the definicions ofiren is.

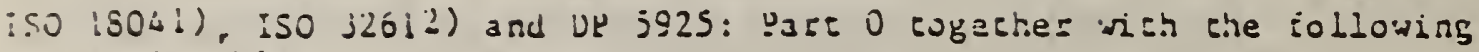

arc appliczole:

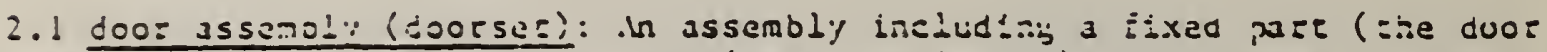

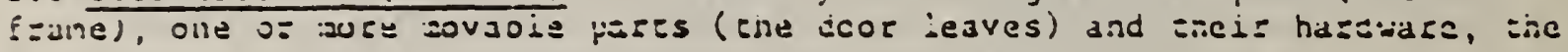
Eurction of binici is to allow or to preveric acess.

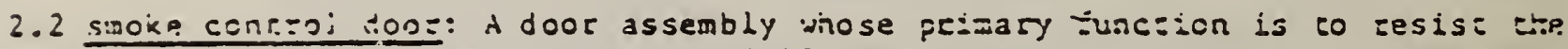
passagc of s.zoke as ceserained by Dr 5925 .

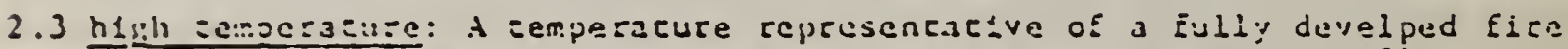
accordlug to sile seandaro se:operacure cine as specified in iso 6343).

\section{TESI PRI.TCISLE}

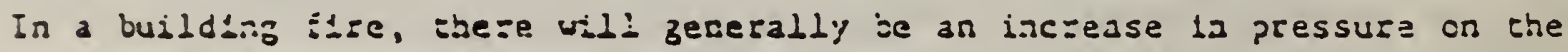

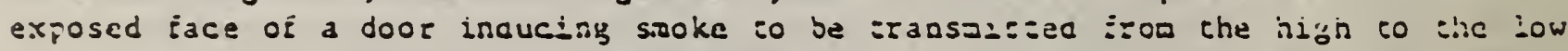
pressice stide of the coor. Al high temperzeuzes, not oniy will there je an

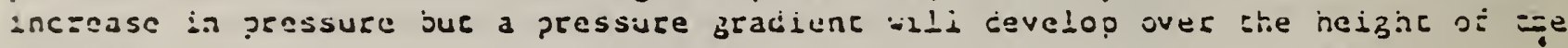

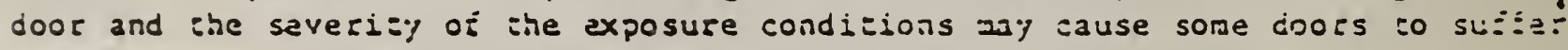
damage and oistortion inceeaslr.g the slze of japs tirough inich saoke can jass.

The test procedure exjoses a door to the heatiag condistons specijied la the

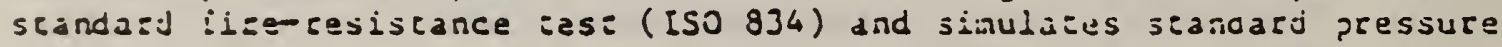

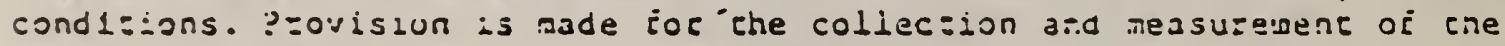

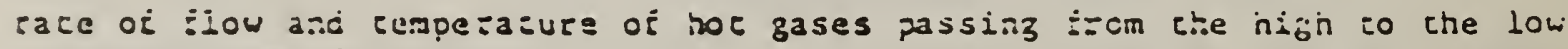
pressurc sice of else door.

4. NRAKITJS

4 . Eurrace

Il:c Eurades snall be ezpabie of subjecting one slde of the speciren co che

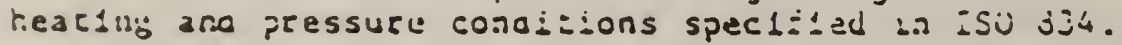

Means shall se provided sor increasing and natacaiaing the pressura condiciurs wenln the iuzace to those sequlred by 7.3 .2 .

i)

ISO 1806 Joors rerninoloy\%.

2 i

ISO 3251 :1:t icses, yocabulary.

3)

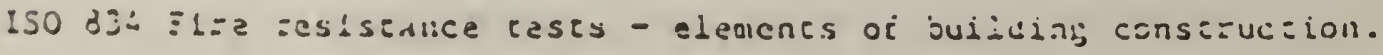




\subsection{Enciosura}

The enclosure (see ijoures 1 and 2 ) shall comprise the joljowingi):

a) A llant isecal faume shall be clad with this metal. sineet (for example approxialacej; 1.5 in in ick).

b) Ul faces of che enclosure siall have a non-reilertive black tinisin.

c) Clazed Luspectiun zanels srial: be provided as recessary.

d) Closable yeats shall be proviced in the cop and joctod, having an dica as large as is possible. If requized, addicional venes aly be provitzd. äte deslyn of the vent shatl not ailow leakage under case condicions.

c) Handles sinall be provided on the vent shucters togecher with a recitarisa to enable simuleancous closing.

f) The overail dinensions shill je appropisate to allow te to te iszij flxed to the ijl: in which the coor assembly is instulied and to cocpic: $=1 \%$ cover the exposed iace. The depth shall be beriecn ovo nan and icu sa.

8) A clrculaz openlng, of dianecer $300 \pm 5 \mathrm{~mm}$, shall be provided ac mid-helghe in the back face of the enclosure to which a sinatt of $300 \pm 10 \mathrm{~mm}$ la lengeh and ilrcularicross section siail be accaciad =0 accomodace the thermocouple and aremometer.

h) A shcet retai radiacton sibie ilch reflective surfaces for the protecilon of the anemonecer wish a ciamecer $\$ 50+10$ su sinail be atcacises co the undersice of the box ins straps at $250 \pm \overline{10}$ am irom ine jack.

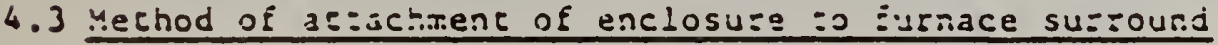

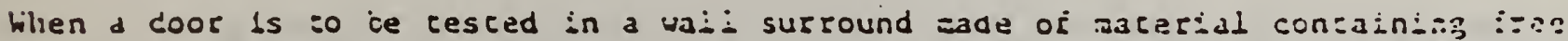

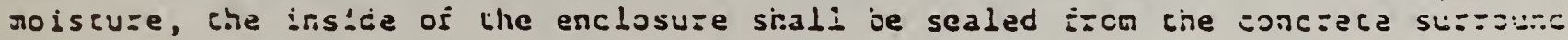

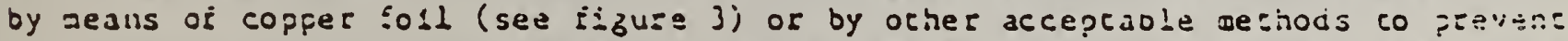

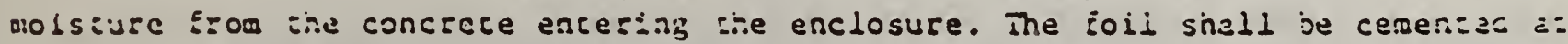
the coraes to eitidinate al $=$ leaks.

The cuclosure siali normally 2 ) be aciached to the furmace surzounc by reans of ehlek stcel angle sections as showil in ingure 3. However, chis does no: precilife elic use of ocike sulcable mesiods if desired.

1)

Working drawlings wlll be avaldable from the secretarlac or ISO/IC 92 at ine eiac of publitiation.

2) An alcernacive acthod of fixtag may be necessary for testisy double dooss. 
L.t inst:-incescion

4.4 .1 The mocouols

A themocouple shali be locazed in the axis of the peasuring shait to measure the remperature of the gases anproaching the anemometer. Addicional chermocouples 1ayy be usad at ocher joints in the enclosura..

4.4.2 Yrogsura measustur sauingene

The mexsurcmenes of pressure to un acsuracy of \pm 1 Pa shail be made ac a minir:of threc pusifions luesead alung a rerical axis on ore side of and close to :.: door assicubiy ln line di:h tile cop and bocsom edges ot the duor opening and $a=$ onc clifil of clie heiglit from the sill level (sce ISO 3008, 7.1).

\subsubsection{Allciumnere5}

A high cempensure anemonecer sholl be ilicted in a vencurt cube as show in Eigure l. Filis shall be capable of measurlag gas ilows $5=0$ a $20 \mathrm{z}^{3} / \mathrm{h}$ co $750 \mathrm{~J}^{3} / \mathrm{h}$ I $=$ imperacures up to $120^{\circ} \mathrm{C}$, and whehia a velocizy range of $0.2 \mathrm{~m} / \mathrm{s}$ co $20 \mathrm{~m} / \mathrm{s}$.

\section{S. PREPARITION OF TEST SRECIYENS}

\section{S.1 Cons:=:-0(10n 1 )}

The cese sl:a:1 be perinrmed on a complece door assembly as iritended to be usec

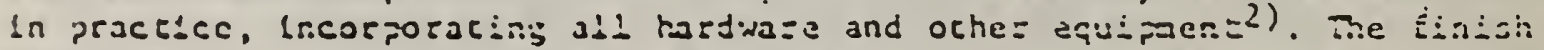
and form of the specimen shall be represencacive 0 the tinish and for of ite door as lnsialied in les lacellded posizlon of use.

The mounclins, of the icsi spacimen shall be represencatign of les use in peac::i:? so chac appeopelace clearances exise befieen door and its ízane.

When the spectien is cessed in a surgound ${ }^{3}$ ) incenced for the decernination of Elre-resisiance clie equizemencs of I5O 3003, 5.2 shall also appl\%.

1.)

See ISO jCO8, page 1., note 3.

2)

The performance of a door asscmbly is lnfluenced by the mechanical feacures: conseruction. The resules of a jlec cast ay noc aldays be vailid for a construetion iaving ovcrall dimenslons larger or auch sinaller chan those oj s.: icst spectinen ( sec i) 5225: ?arc 0).

3)

Quring etic deyelopance of the rest the specineas should be mounced in a

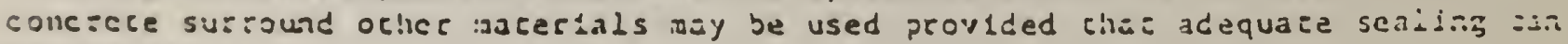
ie insisted. 


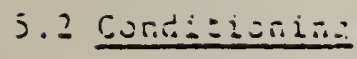

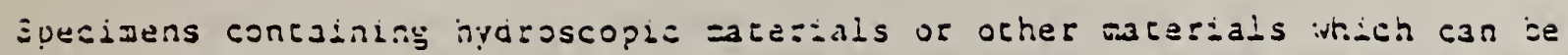

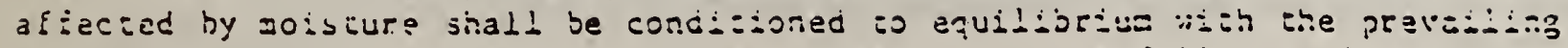

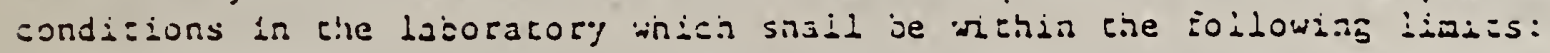

$$
\begin{array}{ll}
\text { cemperacuea (dsy buio) } & 298=15^{\circ} \mathrm{K} \\
\text { relactve hunidizy } & 40 \cong 065 \%
\end{array}
$$

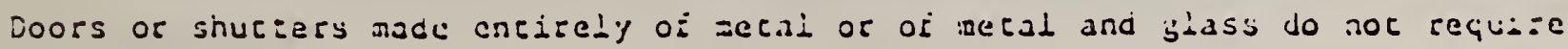
conalejuning.

\section{CALIBiLATivid}

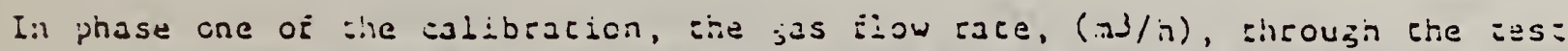

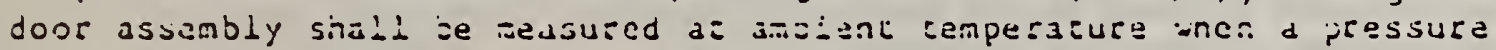

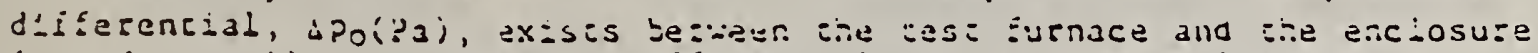

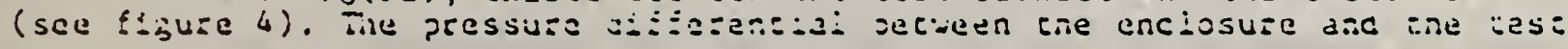

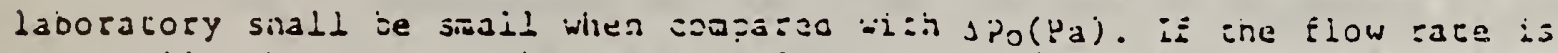

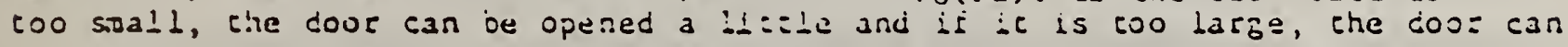
be sealed wit: cape.

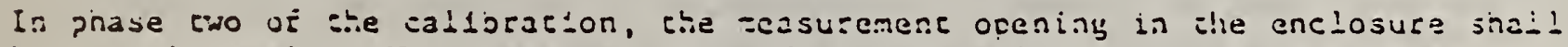

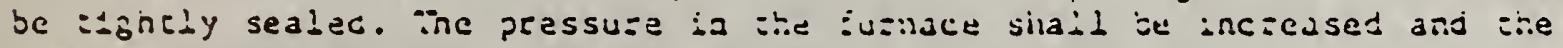

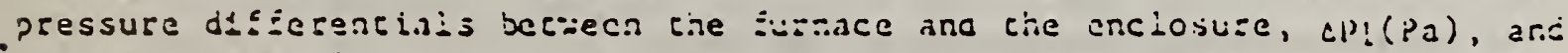

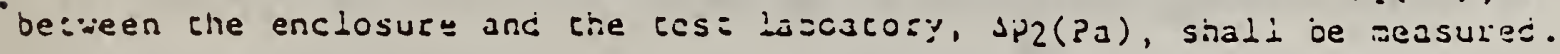
The ifglicaess of the caclosure, K, siali be ealculaced frou the sormula

$$
k=\frac{\Delta P_{1}}{\Delta P_{0} \Delta P_{2}} Q
$$

where: $Q=$ gas flow race $\left(\mathrm{m}^{3} / \mathrm{h}\right)$

and shall not exced the value of wizis.

\section{YKOCLDUR:}

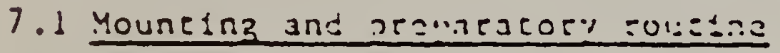

7.1.1 Bor a Eull assessmenc, icses sili:- te periormed on tio speciuens oy

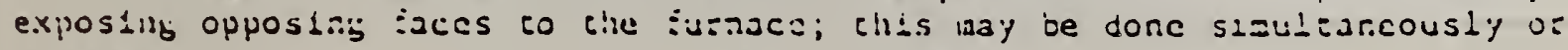
separately, dependillp on the equipaenc ivailablal).

i)

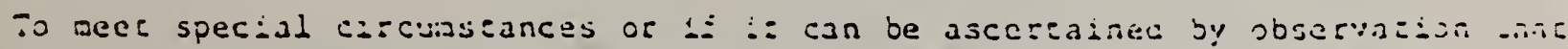

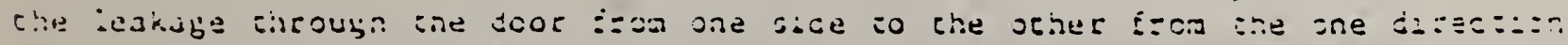

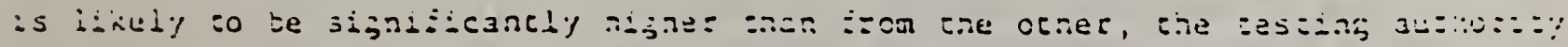

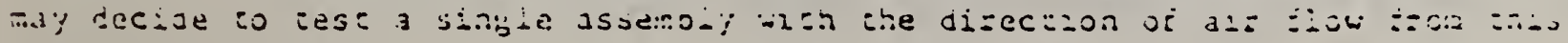
one 
i.1.2 ?-ior cu :ixing the exciosute, the dour shail be poened and alosed at

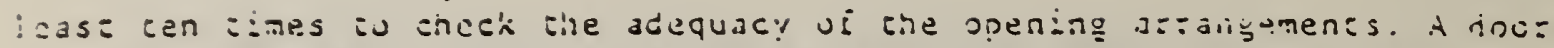

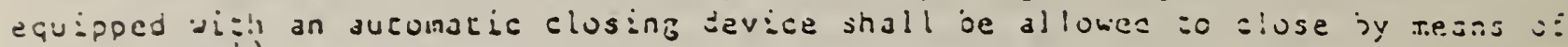
is $i s$ device ${ }^{i}$ ).

7.1.3 The enclusure shall be actached tu the Eurnact surtund in accurdance $\alpha$ : $:$ : 4.3.

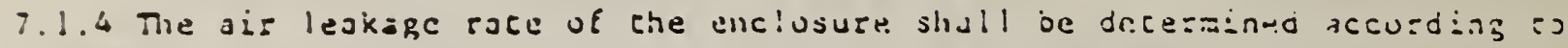
c) ause 5 .

\subsection{Tesc cundi:iuns}

7.2.1 The dour stall be subjected to the heating condisiong sequired by 1503008 .

7.2.2 a positive pressure g:adienc shail be applied in accordance wish :30 juaj, but shall be adjusted su chat the prasiuge disfegence in ine range ze:o io $-i$ ? exiscs at the botson of the cest jilecinen.

\subsection{Operacisc procedure}

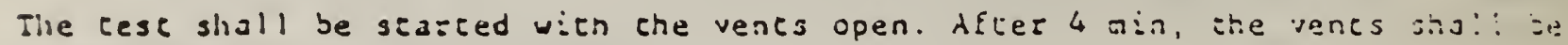

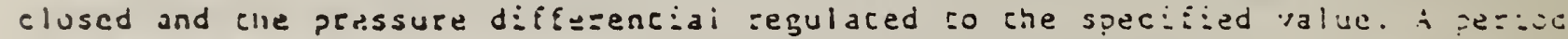

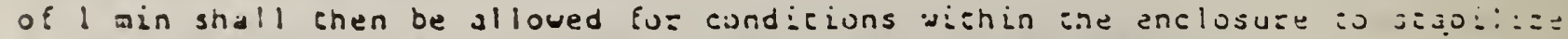
Ac the end ui shis periud, the iulluwing shail be cesorded:

a) Che prossure at cop and jutsom of the duor:

b) che comperature $\vdots .2$ tine enclusure;

c) the tempersure of the hoc zases within the messurisg shat:;

d) the flou rate of the hot bases.

The vents shail be raupended and the procedure ispared at incervals of $S$ ainutes.

i.4 Test durar inn

The cesc sinall be cerminaced

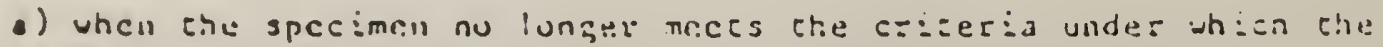
performanci: is be:ing juds:?d: ur

b) when the uperatiunal limics ise ine neasuring system are execedejai;

(1)

7his prucedura is nuc irrended to be a durabilicy rest zepresenting tic ara: and rear nurmaliy sund in use.

$: ;$

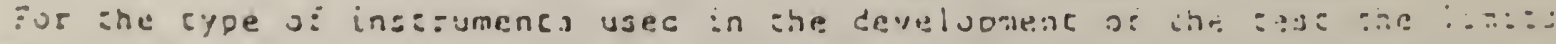

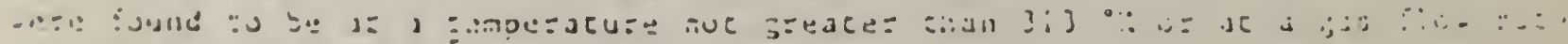

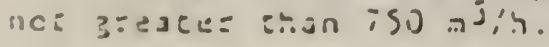


c) ac a cime mucually agreed becweun the sponsor and the resting laburacjey

\section{TEST PESURTS}

The cemperacures and iates of (low of hot asses $\left(\mathrm{a}^{3} / \mathrm{h}\right.$ ) at time incervals as specificd in 7.3 shall bo gecorded in iabuldr iorm.

\section{TF.ST KEPORT}

The cest report shall include che following information:

a) name of cescing laburacury;

b) name of spunsur:

c) date of cest;

d) name of manufacturez and crade-name (if any) of producr;

e) dctails of the constuction, pinysieal characseristics and sondisioniag of the specimen cogecher with drawinga; clearances and gaps between the door and frane shall be iully recorded;

6) description of the cest apparacus and i: applicable the dizection of ine heating sulditiuns wish reference to the door or shucter asscinoiy:

8) decails of iixings of the specimen to the juszounding wall and oi sny joints between the duor assembly and the surguunding wall;

h) Che side of clic dour which was cesced;

j) rese resules;

k) description of glazing, if any. 


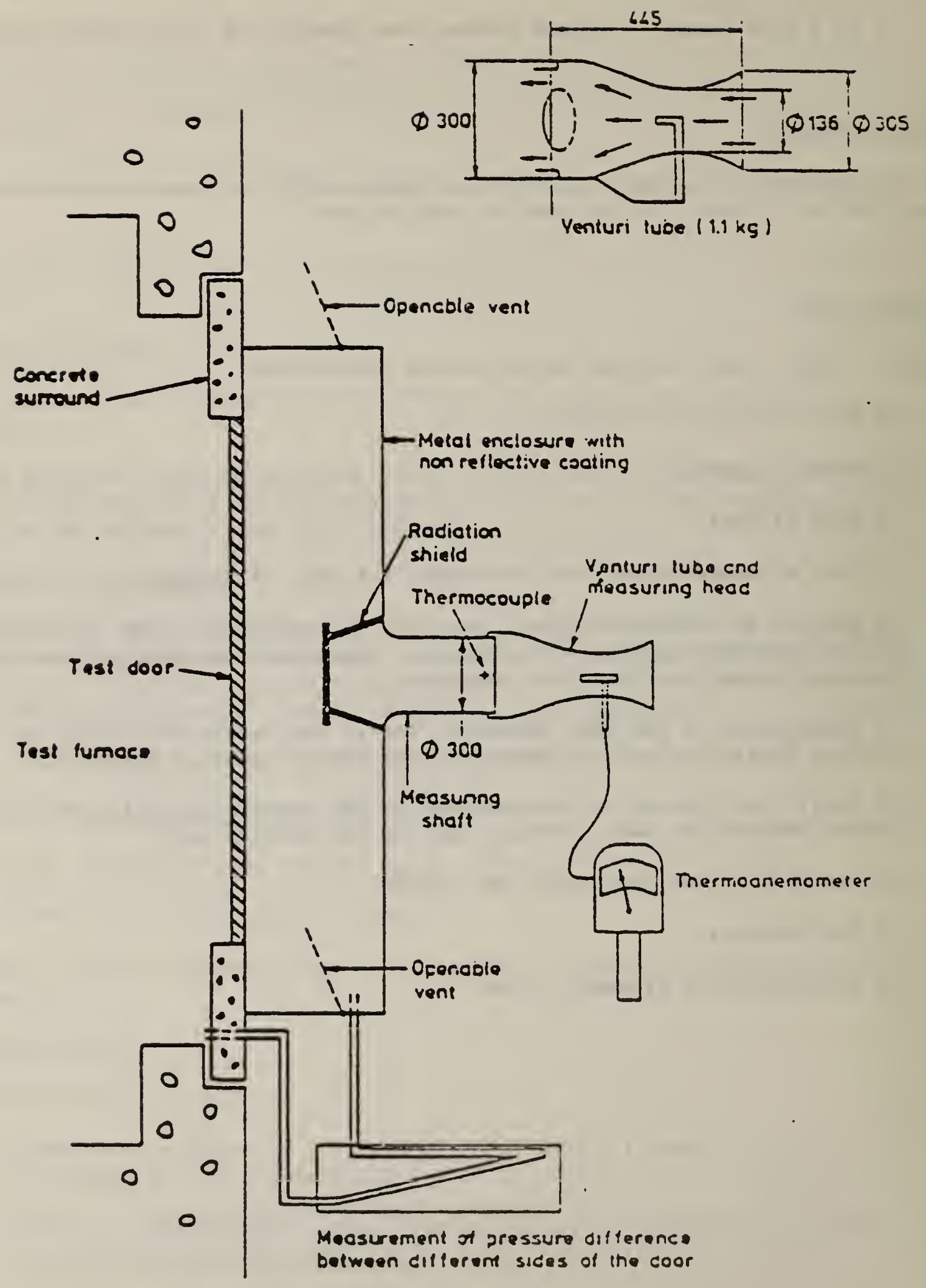

All Jimensions in miltimetres

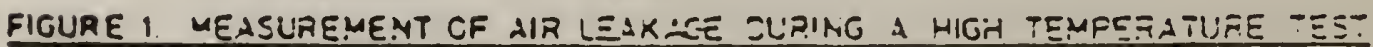

ORG. NO. $1657 \mathrm{Cl}$ ?

ISSUE 2 


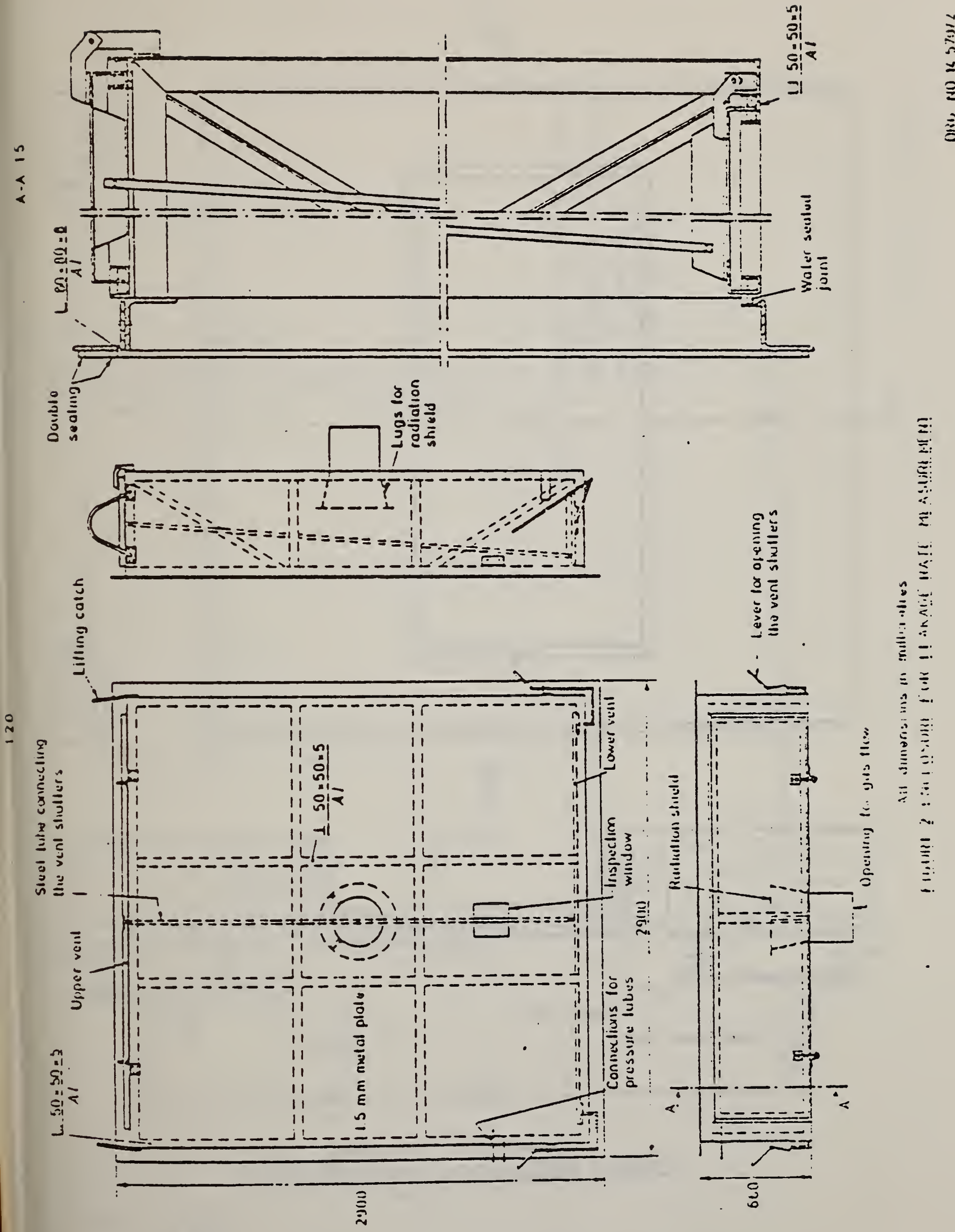



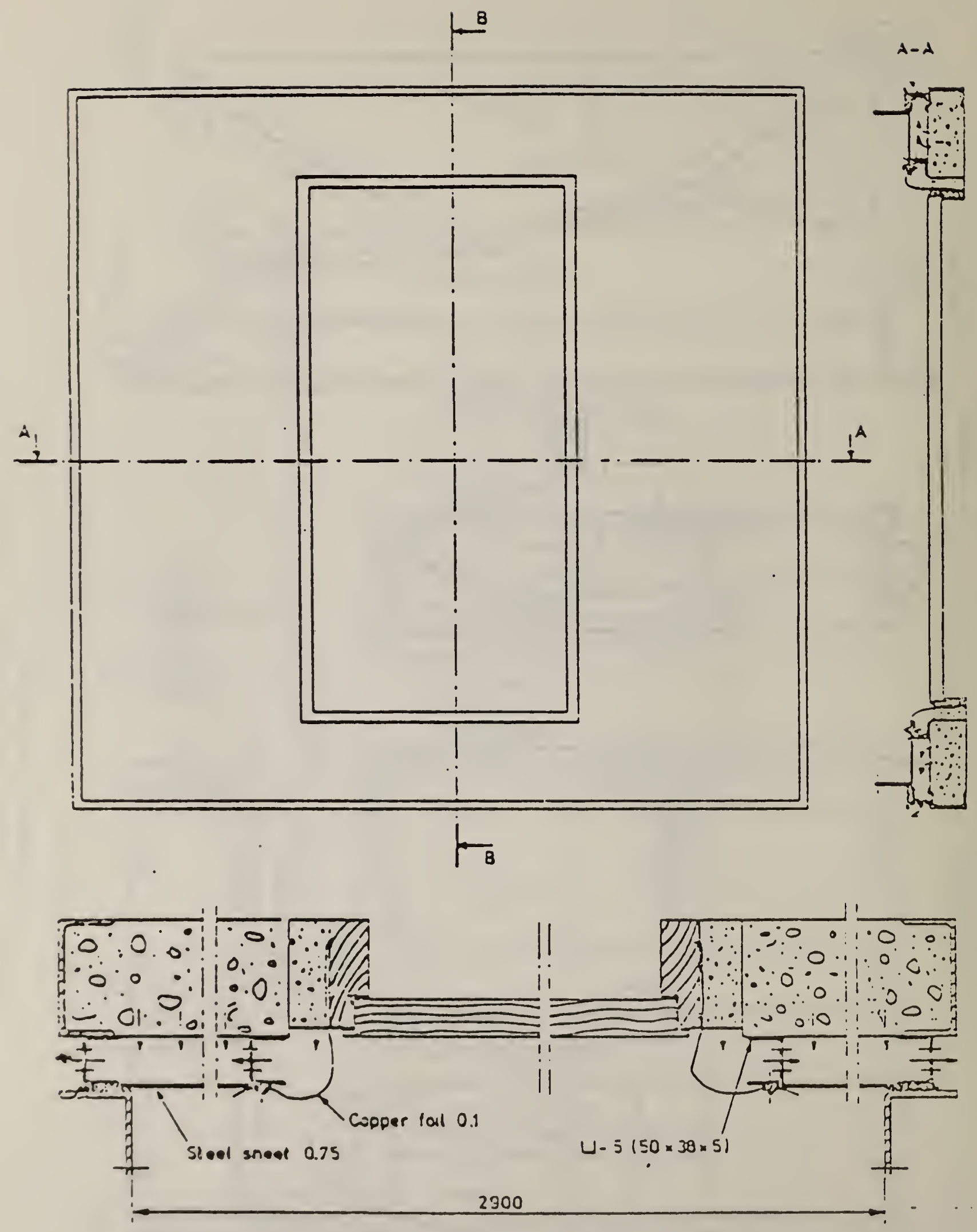

All dimensions in millimatras

FIGURE 3. EMICLCSUPE ANC FIFA:CE SIRPCUNO

ORG NO is $5 \mathrm{TI} / 3$

ISSUE 2 

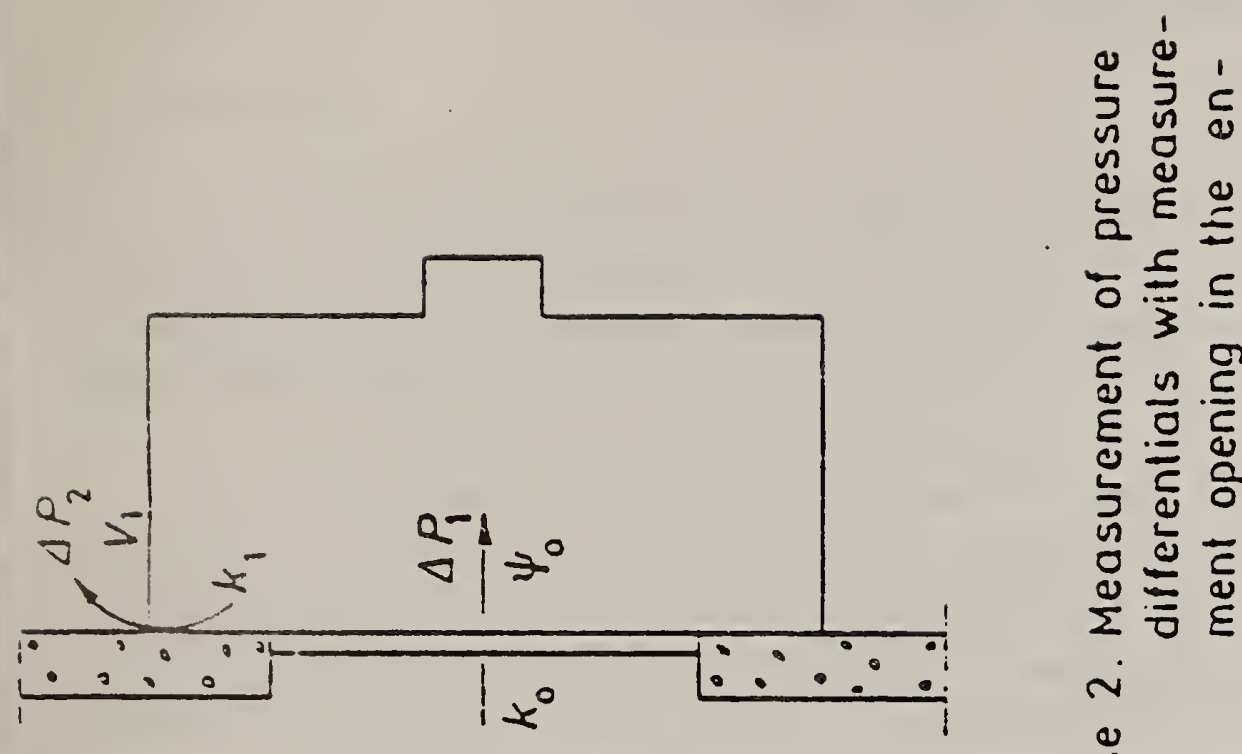

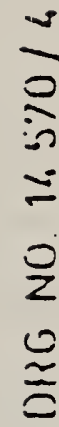
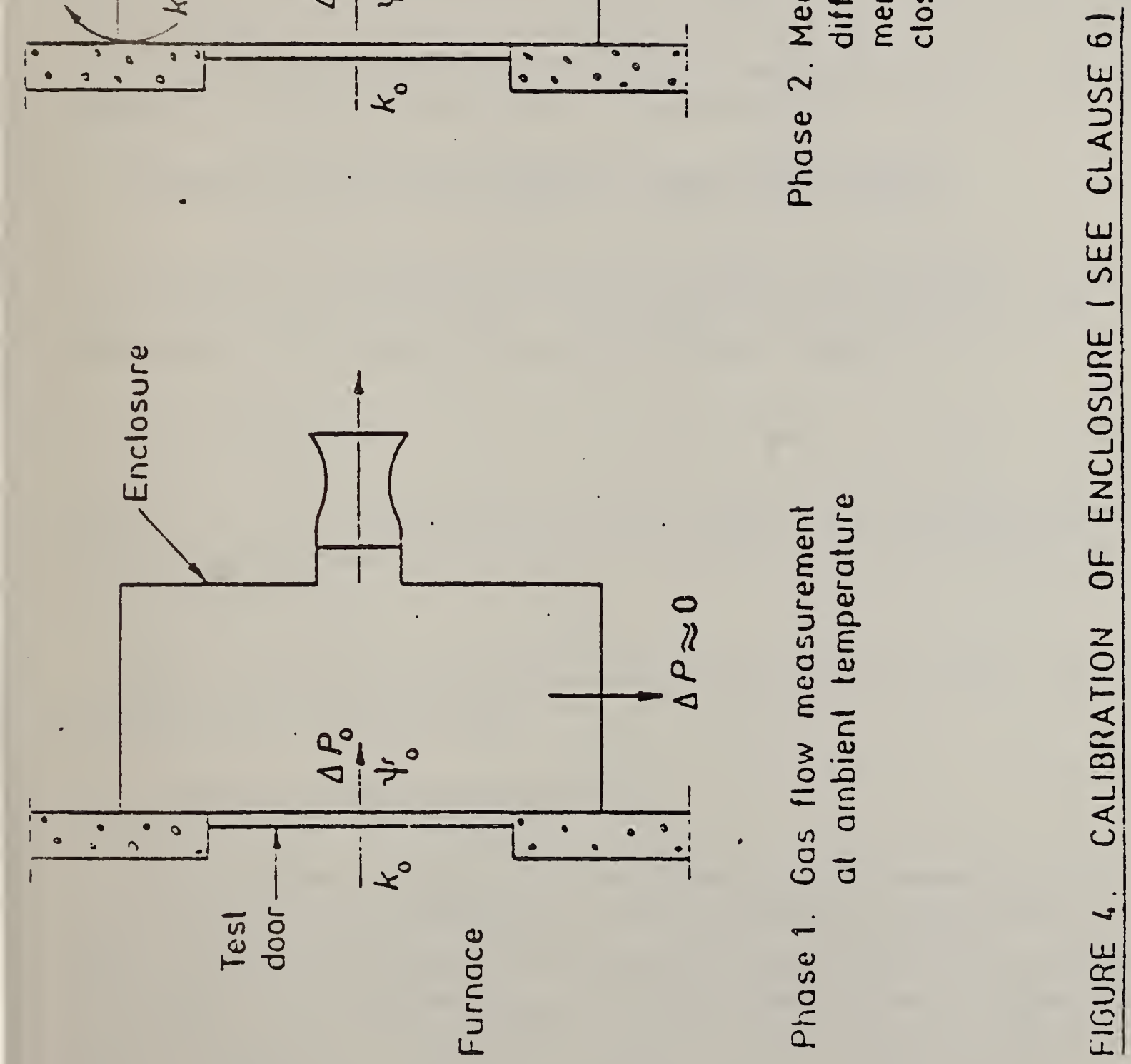

APPENDIX B

AN ESTIMATE OF THE RATE OF GAS OUTFLOW DUE TO

HEAT TRANSFER FROM THE DOOR SURFACE

B1. THE MODEL

The purpose of this appendix is to present an estimate of the order of magnitude of outflow that is to be anticipated solely as a result of heat transfer to and expansion of enclosure gases. We assume that the door assembly is without any leakage paths. We assume further that the unexposed (to the furnace) door surface is of height $H$ and width W.

The simplest possible model of the phenomenology under study is depicted in figure 20. Here we have assumed that all significant heat transfer, Q, to the enclosure gases is from the door surface. As a result of this energy input there is a net rate of expansion of gases in the enclosure, and some of the enclosure gases are pushed out of the single opening at a volumetric outflow rate, $\dot{q}$, to be determined.

\section{B2. THE RELATIONSHIP OF RATE OF OUTFLOW TO RATE OF HEAT TRANSFER}

In reference [6] Zukowski has presented a result for heat addition to gases in a fixed volume enclosure with leaks. This is directly and generally applicable to our present model. Thus, assuming uniform exit gas (air) properties,

$$
\rho_{e} \dot{q} C_{p} T_{e}=\dot{Q}
$$

where $\rho_{e}, T_{e}$, and $C_{p}$ are the density, absolute temperature and specific heat at constant pressure, respectively, of the air which is actually exiting from the enclosure opening (i.e., from the "leak").

With a determination of the heat transfer rate, the desired outflow rate is immediately at hand by using the above result.

\section{B3. AN ESTIMATE FOR THE HEAT TRANSFER RATE}

For the purpose of estimating the heat transfer rate we assume that the door surface is at a uniform surface temperature, $T_{s}$, which is reasonably constant during a given closed vent phase of the test. We also assume that away from the door surface the temperature of the gases in the enclosure, T encl, at a given instant of time is substantially uniform $\left(\mathrm{e} \cdot \mathrm{g} \cdot, \mathrm{T}_{\mathrm{e}}=\mathrm{T}_{\text {encl }}\right)$.

The above assumptions and the outflow estimates to follow are very good all through the test at early times following vent closure. In fact, at such times $\mathrm{T}_{\text {encl }}=\mathrm{T}_{\text {amb }}$, 
winere $\mathrm{T}_{\mathrm{amb}}$ is the ambient (1aboratory) temperature. At later times following vent closure (e.g.. at the approach of steady state), the uniform $\mathrm{T}_{\text {encl }}$ assumption may not be a particularly good one. However, even then the results below will provide a reasonable estimate of the order of magnitude of $\dot{q}$.

With the above in mind we consider convective cooling of the door surface by means of a buoyant, two dimensional, boundary layer which grows from zero thickness at the bottom of door*. This boundary layer will be entirely laminar, (mostly) turbulent, or in a transitional state, along the height of the door depending on whether [12]

$$
\begin{aligned}
& \text { Gr } \operatorname{Pr}<10^{8}-\text { laminar } \\
& 10^{8}<\text { Gr } \operatorname{Pr}<10^{10} \text { - transitional } \\
& 10^{10}<\text { Gr Pr - mostly turbulent }
\end{aligned}
$$

where

$$
\begin{aligned}
& \mathrm{Gr}=\text { Grashoft number }=\mathrm{g} B\left(\mathrm{~T}_{\mathrm{s}}{ }^{\left.-\mathrm{T}_{\mathrm{g}}\right) \mathrm{H}^{3} / \mathrm{v}^{2}}\right. \\
& \mathrm{Pr}=\operatorname{Prandt} 1 \text { number }=\mathrm{C}_{\mathrm{p}} \mu / \mathrm{k}(=.72 \text { for air })
\end{aligned}
$$

In these definitions for $\mathrm{Gr}$ and $\mathrm{Pr}, \mathrm{T}_{g}$ is the temperature of the fluid outside the boundary layer and $\beta, v, \mu$, and $k$ are characteristic values for the coefficient of thermal expansion, dynamic viscosity, viscosity, and thermal conductivity, respectively, of the fluid in the boundary layer.

For air, the average Nusselt number for the entire range of $\mathrm{Gr}$ can be computed from [12]

$$
\mathrm{Nu}_{\text {ave }}=h_{\text {ave }}{ }^{H / k}= \begin{cases}0.511 \mathrm{Gr}^{1 / 4} ; & \mathrm{Gr}<4.2\left(10^{9}\right) \\ 0.0184 \mathrm{Gr}^{2 / 5} ; & 4.2\left(10^{9}\right)<\mathrm{Gr}\end{cases}
$$

" there $h_{\text {ave }}$ is the average heat transfer coefficient. In the above we will evaluate all the air properties, $B, v, \mu, k$, and $C_{p}$ at the average boundary layer temperature $\left(\mathrm{T}_{\mathrm{s}}+\mathrm{T}_{\text {encl }}\right) / 2$.

\footnotetext{
\#lote that the effects of radiant heat transfer are not taken account of here. Radiant transfer from the hot door surface to the facing vertical enclosure surface would tend to maintaln that latter surface at an elevated temperature. During the closed vent phases under consideration this hot surface would transfer additional energy to the " Insure gases thus ylelding a net $\dot{q}$ which was larger than that to be computed.
} 
Using the above results we can now compute the total heat transfer rate from

$$
\dot{Q}=H W h \text { ave }\left(T_{s}-T_{\text {encl }}\right)=W k\left(T_{s}-T_{\text {encl }}\right) N u_{\text {ave }}
$$

where $\mathrm{Nu}_{\text {ave }}$ is computed from eq. (B-3).

\section{B4. THE RATE OF OUTFLOW}

Using eqs. $(B-1)$ and $(B-4)$ we obtain our desired result

$$
\begin{aligned}
\dot{q} & =W k\left(T_{s}-T_{\text {enc1 }}\right) /\left(\rho_{\text {enc1 }} T_{\text {encl }} C_{p}\right) \\
& =W \vee B\left(T_{s}-T_{\text {encl }}\right) N u_{\text {ave }} / .72
\end{aligned}
$$

In order to get actual estimates on $\dot{q}$ for our problem we have used this equation to estimate $\dot{q}$ as a function of $T_{s}{ }^{-T}$ encl for a door of dimension $\mathrm{H} \mathrm{x} \mathrm{W}=2$ meters $x 1$ meter and for the two $\mathrm{T}$ encl values $20^{\circ} \mathrm{C}$, and $100^{\circ} \mathrm{C}$. These results are presented in figure 12 . 
NBS. I IA (REV. 0-78)

\begin{tabular}{|c|c|c|}
\hline $\begin{array}{l}\text { U.S. OEPT. OF COMM. } \\
\text { BIBLIOGRAPHIC DATA } \\
\text { SHEET }\end{array}$ & $\begin{array}{l}\text { 1. PUBLICATION OR REPORT NO. } \\
\text { NBSIR } 80-2004\end{array}$ & 1. Recifjent's Ackesslon No. \\
\hline \multirow{2}{*}{\multicolumn{2}{|c|}{$\begin{array}{c}\text { THE MEASUREMENT OF THE SMOKE LEAKAGE OF DOOR } \\
\text { ASSEMBLIES DURING STANDARD FIRE EXPOSURES }\end{array}$}} & $\begin{array}{l}\text { 5. Publication Date } \\
\text { June } 1980\end{array}$ \\
\hline & & C. Pertorming Organization Code \\
\hline \multicolumn{2}{|r|}{ Leonard Y. Cooper } & 8. Performing Organ. Report No. \\
\hline \multicolumn{2}{|c|}{ 9. PERFORMING ORGANIZATISN NAME AND ADDRESS } & 14. Projoot/TaskNork Unill No \\
\hline \multicolumn{2}{|c|}{$\begin{array}{l}\text { NATIUNAL BUREAU OF STANDARDS } \\
\text { D: PARTMENT OF COMMERCE } \\
\text { WASHINGTON, DC } 20234\end{array}$} & 11. Contract/Grant No. \\
\hline \multirow{2}{*}{\multicolumn{2}{|c|}{$\begin{array}{l}\text { 12. SPONSORING ORGANIZATION NAME AND COMPLETE ADORESS (streot, cliy, stato, } z \text { IP) } \\
\text { Prepared for: } \\
\text { The Occupational Safety and Health Administration (OSHA) } \\
\text { U.S. Department of Labor } \\
\text { Washington, D.C. } 20210\end{array}$}} & $\begin{array}{l}\text { 13. Type of Report \& Period Covered } \\
\text { Final }\end{array}$ \\
\hline & & 1. Sponsoring Agency Code \\
\hline
\end{tabular}

15. SUPPLEMENTARY NOTES

Document describes a computer program; SF-185, FIPS Software Summary, is attached.

16. ABSTRACT (A 200-word or lese factual eummary of most ignificant Information. If document includes a significant blbliography or literature survoy, montion it hero.)

A basls for relating overall intrabullding smoke migration dynamics to high temperature, door assembly smoke leakage measurements is formulated. The results of applying the tentative, high temperature, ISO test method DP 5925 Part 3, which was developed to measure smoke leakage of door assemblles during the course of a standard fire endurance test, are reported. A critical analysis reveals that the basic objective of the method is limited in its utility in the sense that fire scenarios in high-rise buildings may not be adequately simulated. Consistent with the above-mentloned experimental results, troublesome theoretical problems with the test method and 1 ts procedures are 1dentifled. These lead to a conclusion that the test method as written is generally unreliable. An alternate test concept which removes the above-mentioned DP 5925 Part 3 iimitation and all of its problems is described and its development is advocated.

17. KEY WORDS (olx to welve entries; alphabetical order; capltallze only the firat lotter of the firat key word unleas a proper name; - eparated by emicolone)

Building fires; compartment fires; doors; egress; fire tests; high-rlse buildings; leakage; life safety; smoke; smoke movement; stack effects; test wethods.

18. AVAILABILITY

For Official Distribution. Do flot Release to NTIS

Order From Sup. of Doc. U.S. Government Printing Office, Washington, DC 20402, SD Stock No. SNO03-003-

x... From National Technical Information Service (NTIS), Springfield, 1. 22161

\begin{tabular}{|l|c|}
\hline $\begin{array}{l}\text { 19. SECURITY CLASS } \\
\text { (THIS REPORT) }\end{array}$ & $\begin{array}{c}\text { 21. NO. OF } \\
\text { PRINTED PAGES } \\
\text { UNCLASSIFIED }\end{array}$ \\
\hline $\begin{array}{l}\text { 20. SECURITY CLASS } \\
\text { (THIS PAGE) }\end{array}$ & 70 \\
UNCLASSIFIED & $\$ 7.00$ \\
\hline
\end{tabular}




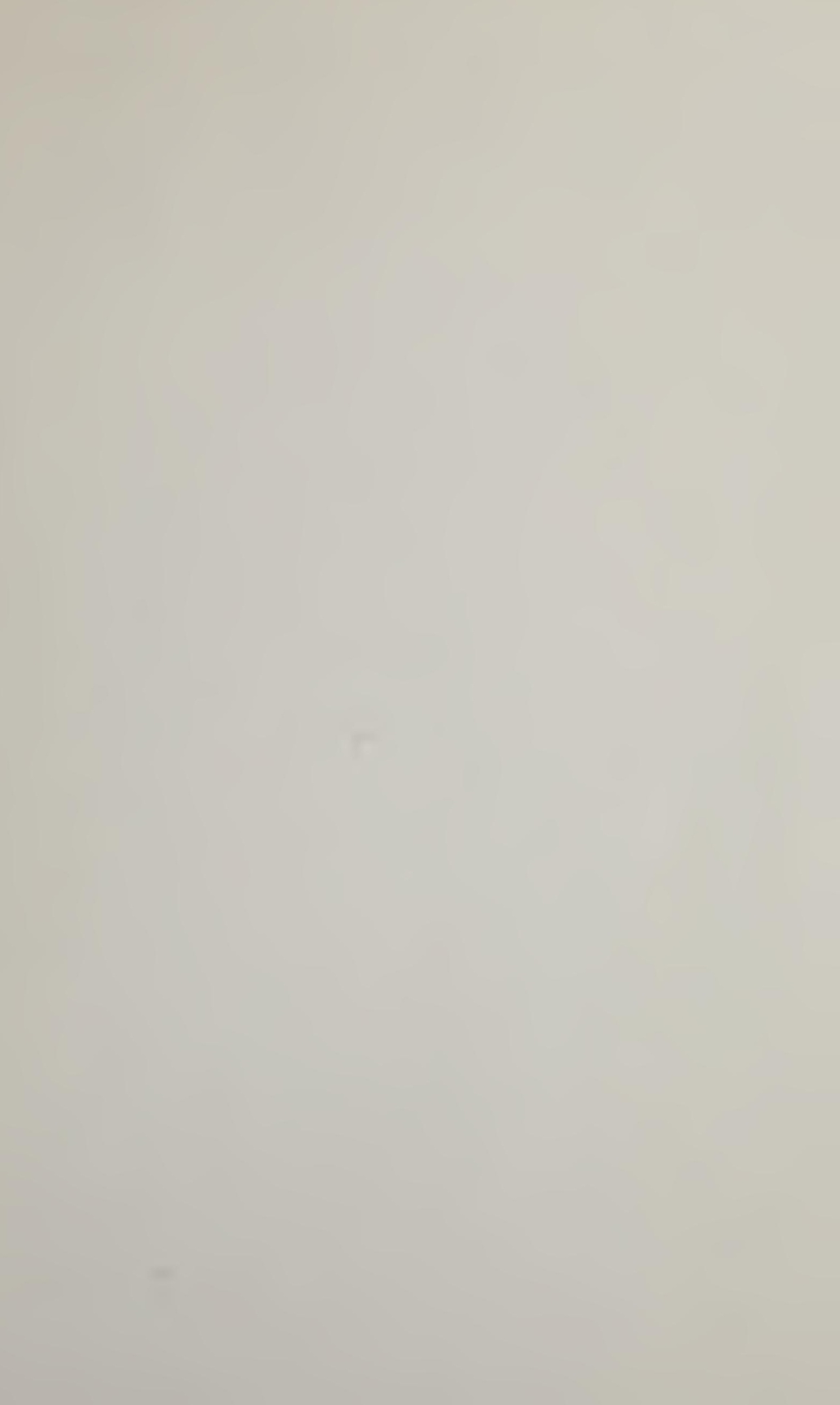


